\title{
Labour and Labour-Related Laws in Micro and Small Enterprises: Innovative Regulatory Approaches
}

Prepared by Colin Fenwick, John Howe, Shelley Marshall and Ingrid Landau Centre for Employment and Labour Relations Law

The University of Melbourne, Australia 
Copyright (C) International Labour Organization 2007 First published 2007

Publications of the International Labour Office enjoy copyright under Protocol 2 of the Universal Copyright Convention. Nevertheless, short excerpts from them may be reproduced without authorization, on condition that the source is indicated. For rights of reproduction or translation, application should be made to ILO Publications (Rights and Permissions), International Labour Office, CH-1211 Geneva 22, Switzerland, or by email: pubdroit@ilo.org. The International Labour Office welcomes such applications.

Libraries, institutions and other users registered in the United Kingdom with the Copyright Licensing Agency, 90 Tottenham Court Road, London W1T 4LP [Fax: (+44) (0)20 7631 5500; email: cla@cla.co.uk], in the United States with the Copyright Clearance Center, 222 Rosewood Drive, Danvers, MA 01923 [Fax: (+1) (978) 750 4470; email: info@copyright.com] or in other countries with associated Reproduction Rights Organizations, may make photocopies in accordance with the licences issued to them for this purpose.

ILO Cataloguing in Publication Data

Fenwick, Colin; Howe, John; Marshall, Shelly; Landau, Ingrid

Labour and labour-related laws in micro and small enterprises : innovative regulatory approaches SEED working paper

Series on conducive policy environment for small enterprise employment / prepared by Colin Fenwick John Howe, Shelley Marshall and Ingrid Landau ; International Labour Office, Small Enterprise Programme, Job Creation and Enterprise Department. - Geneva: ILO, 2007 61 p. (SEED working paper

Series on conducive policy environment for small enterprise employment ; no.81)

ISBN: 9789221204091;9789221204107 (web pdf)

International Labour Office

small enterprise / microenterprise / labour relations / workers rights / working conditions / labour law / labour legislation / comment / application / developed countries / developing countries

03.04 .5

The designations employed in ILO publications, which are in conformity with United Nations practice, and the presentation of material therein do not imply the expression of any opinion whatsoever on the part of the International Labour Office concerning the legal status of any country, area or territory or of its authorities, or concerning the delimitation of its frontiers.

The responsibility for opinions expressed in signed articles, studies and other contributions rests solely with their authors, and publication does not constitute an endorsement by the International Labour Office of the opinions expressed in them.

Reference to names of firms and commercial products and processes does not imply their endorsement by the International Labour Office, and any failure to mention a particular firm, commercial product or process is not a sign of disapproval.

ILO publications can be obtained through major booksellers or ILO local offices in many countries, or direct from ILO Publications, International Labour Office, CH-1211 Geneva 22, Switzerland. Catalogues or lists of new publications are available free of charge from the above address, or by email: pubvente@ilo.org

Visit our website: www.ilo.org/publns 


\section{FOREWORD}

Creating a conducive policy and regulatory environment, as a part of an overall business environment for enhancing the employment potential of small enterprises, has increasingly gained attention of the ILO's member States, social partners and donors. How policy and regulatory environment could be made suitable for the increased creation of quality jobs by small enterprises is being much debated. The World Bank's annual publication of the Cost of Doing Business reports, which includes labour law elements, has heightened the debate on the issues relating to business environment. The ILO, as chair of the Donor Committee on Enterprise Development's Business Environment Working Group, has collaborated with a wide range of multilateral and bilateral development agencies to organize global and regional conferences on the subject of enabling business environment.

The ILO's Small Enterprise Programme (SEED) of the Job Creation and Enterprise Development Department carried out during 2001-03 reviews of policy and regulatory environment in ten member States with an objective of ascertaining the role of enabling business environment in creation of quality of jobs by the micro and small enterprises (MSEs). The reviews noted the existence of complex rules contributing to ineffective or non-application of the labour legislations, partly as a result of inadequate state capacity and partly due to lack of awareness among MSEs. The conclusion led to further examination exclusively of the labour law in selected countries and discussions leading to preparation of this paper on the subject in 2006.

The preparation of the paper was preceded in 2004-05 by several inter-sectoral discussions on the subject as well as selected country reviews in South Asia on the role of labour law on growth and improvements among MSEs. Inter-sectoral discussions (with the participation of ACTRAV, ACT/EMP, INTEGRATION, DIALOGUE, TRAVAIL and NORMES), were instrumental in providing direction for this paper. The draft paper was presented and discussed in Geneva in late 2005. Appreciation is extended to ILO colleagues who participated from their respective departments in the above discussions and contributions to the conceptualization of the paper, including preparation of the terms of reference by Gerhard Reinecke, Employment Specialist at the ILO Subregional Office in Santiago.

This report was prepared by a team led by Colin Fenwick, consisting of John Howe, Shelley Marshall and Ingrid Landau from the Centre for Employment and Labour Relations Law at the University of Melbourne with the assistance of the researchers Ingrid Landau, Lucy Adams, Fritz Ntoko Ewang, Piers Gillespie, Marc Trabsky, and Sara Summerbell. The preparation of the paper was supervised by Gopal Joshi of SEED with research assistance provided by Sarah Field.

Since the preparation of this paper, the Committee on Employment and Social Policy of the ILO Governing Body had a discussion on the topic of 'Business environment, labour law and MSEs' in November 2006. The Committee instructed the Office to map the 'Win-Win Territory' as a basis for determining which labour legislation domains can be addressed to facilitate enterprise growth and workers' protection in MSEs. In this regard, the Office will be seeking to compile and share with the constituents, country examples of innovative practices of application of the labour law on MSEs. This paper provides numerous examples of innovative strategies adopted by the member States in widening the application of labour law, and the country examples will contribute to the policy guidelines.

Martin Clemensson

Programme Manager

Small Enterprise Programme

Job Creation and Enterprise Development Department 


\section{CONTENTS}

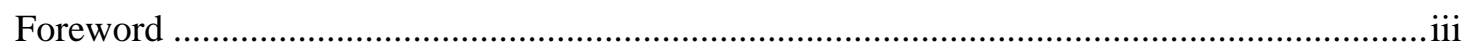

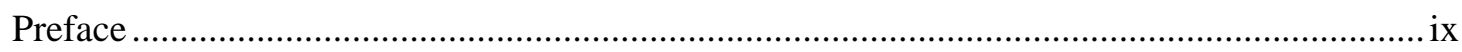

Executive summary …………………………................................................................

CHAPTER 1: LABOUR REGULATION AND MSEs:

THE POLICY CHALLENGES ............................................................... 1

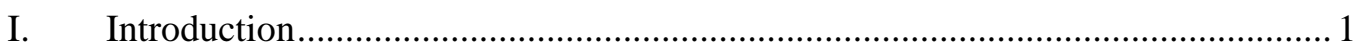

II. The promise and the challenge of MSEs ........................................................ 2

The proliferation of MSEs: An important source of employment .......................... 2

Job quality in MSEs is often low .................................................................... 3

Many MSEs are not fully formalized............................................................. 4

III. State regulation of MSEs and labour markets.................................................... 4

Approaches to State regulation .......................................................................... 4

Labour market deregulation and the influence of the Bretton Woods

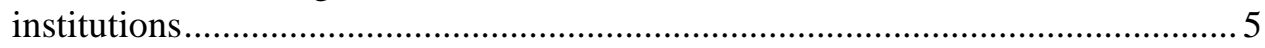

Another perspective on the role of the State and regulation ................................ 7

Labour law and MSEs: Different approaches ....................................................... 8

IV. Promoting decent work through innovative labour regulation ........................... 10

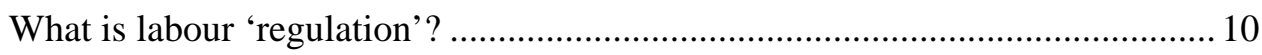

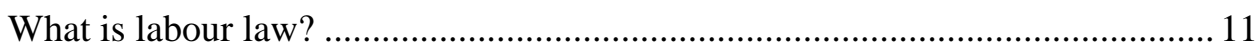

A rights-based approach to labour regulation: Decent work and international labour standards ........................................................................... 13

The aims and goals of this study .................................................................... 14

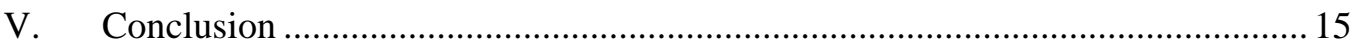

CHAPTER 2: STATE PRACTICES IN THE APPLICATION OF LABOUR AND LABOUR-RELATED LAWS TO MSEs ........................................................ 17

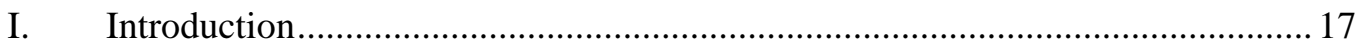

II. The scope of the employment relationship ……................................................ 17

The structure of labour markets ............................................................................ 18

Identifying an 'employee' and an 'employer'....................................................... 19

The weakness of the contract of employment in unstable enterprises ................. 20

III. The scope and coverage of labour laws and MSEs.............................................. 21

IV. Pitfalls in excluding MSEs from labour laws ........................................................ 33

Pitfall 1: Excluding MSEs from the application of certain fundamental labour rights..................................................................... 33

Pitfall 2: Over-complex and conflictive labour laws........................................ 34

Pitfall 3: Failure to communicate applicable laws to MSEs................................ 34 
Pitfall 4: Perverse incentives, and long-term costs............................................ 35

V. The application of labour laws to MSEs in practice ............................................... 36

Obstacles to application of labour law to MSEs in practice .................................. 37

Special approaches to enforcement and application of labour

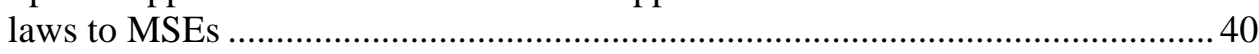

Institutions and strategies to enforce the law .................................................. 41

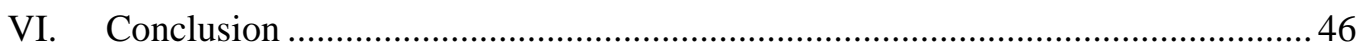

CHAPTER 3: LABOUR LAW, JOB QUALITY AND FORMALIZATION

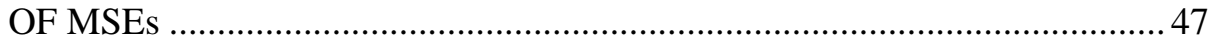

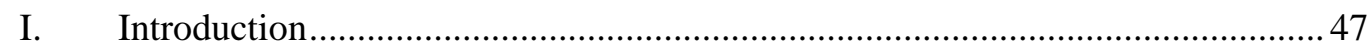

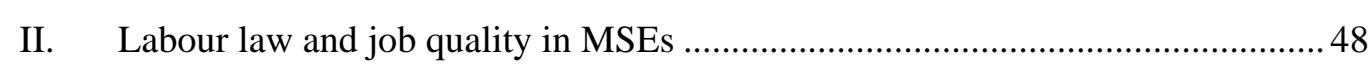

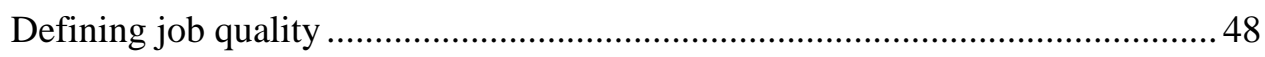

Fundamental rights: Freedom of association ...................................................... 48

Fundamental rights: The right to collective bargaining .................................... 50

Fundamental rights: The elimination of forced labour ....................................... 53

Fundamental rights: The abolition of child labour.............................................. 55

Fundamental rights: Freedom from discrimination in the workplace ...................56

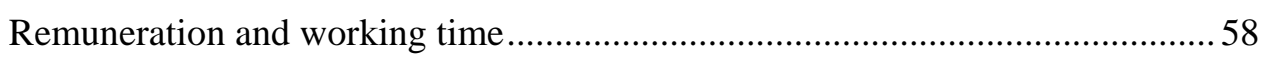

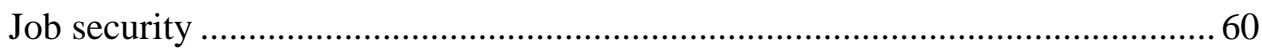

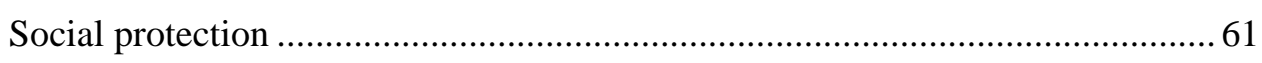

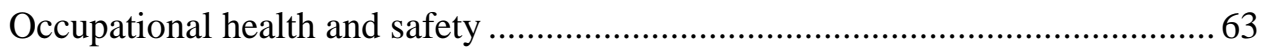

Human resource development........................................................................... 63

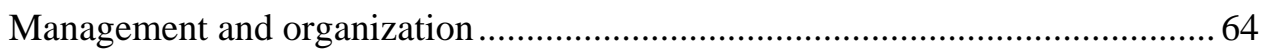

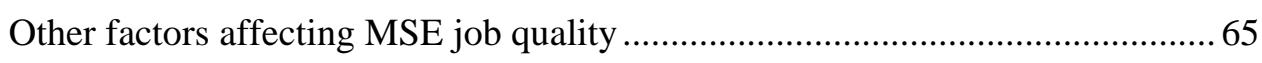

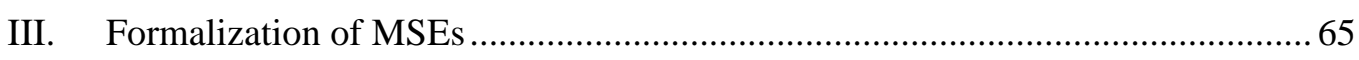

Numbers of formalized enterprises: An indicator of successful outreach

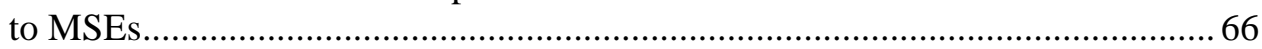

Costs and benefits of compliance with labour and labour-related laws ................ 67

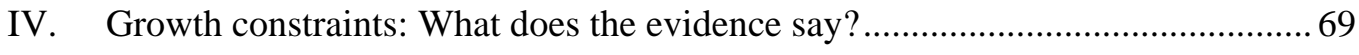

V. Labour law, gender and geography ……......................................................... 72

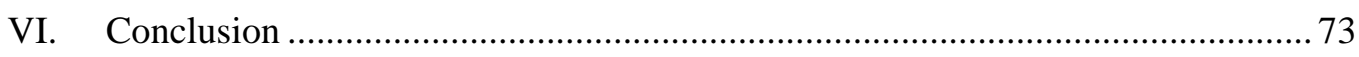

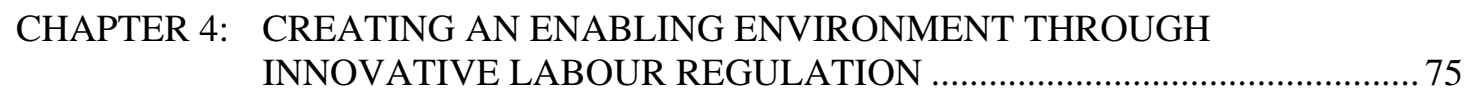

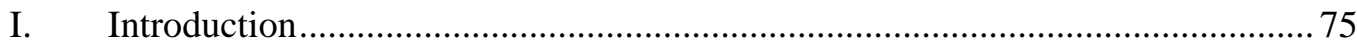

II. A theoretical framework for developing and assessing innovative

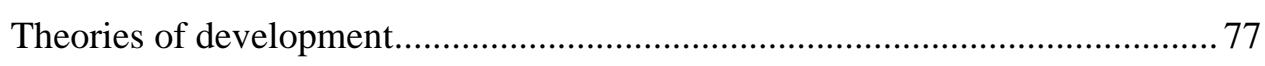

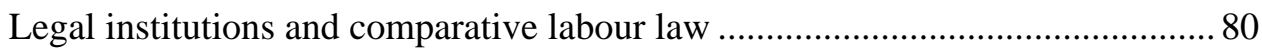

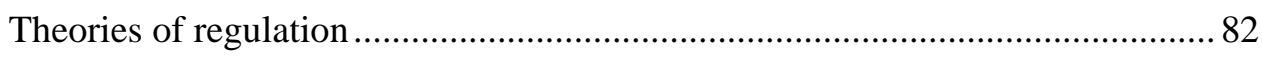

A principled approach to innovative labour regulation.......................................... 87 
III. Innovative approaches to labour regulation for MSEs......................................... 88

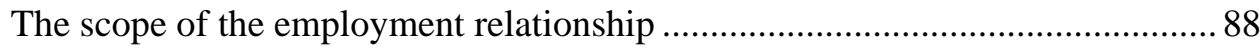

Innovative approaches to the scope and coverage of labour laws ........................ 91

Innovation in the application of labour law ...................................................... 93

Formalization as a prerequisite for access to specific benefits or policies

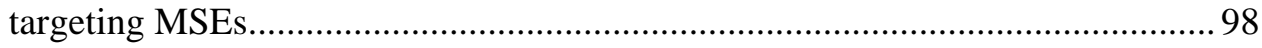

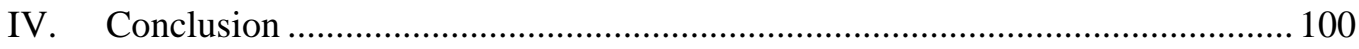

CHAPTER 5: RECOMMENDATIONS FOR IMPROVED DESIGN AND APPLICATION OF LABOUR LAWS FOR MSEs ..................................... 103

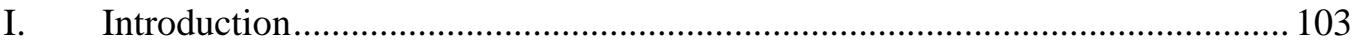

II. The objectives of labour regulation for MSEs ................................................... 104

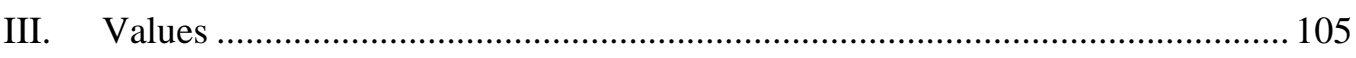

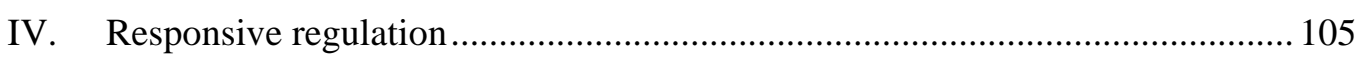

Designing for enforcement and compliance .................................................... 105

Information, education and incentives for formalization.................................. 108

Monitoring compliance and coordination between state and private actors ...... 108

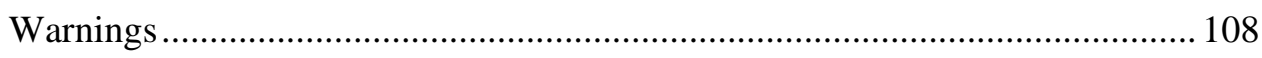

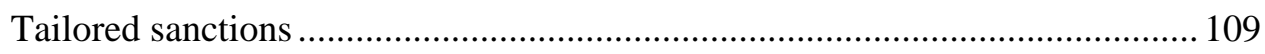

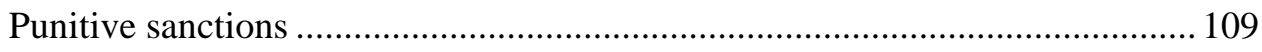

Design and implementation must be participatory ............................................ 109

The design and implementation of the regulation should be specifically targeted at improving job quality in MSEs ......................................................... 112

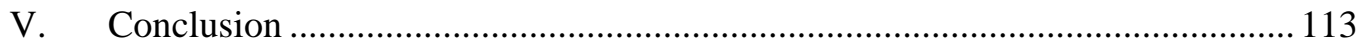

APPENDIX 1: FORMAL SCOPE AND COVERAGE OF LABOUR LAW

TO MSEs ................................................................................... 115

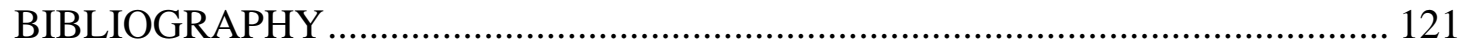

\section{List of figures:}

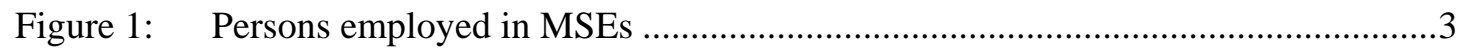

Figure 2a: Collective bargaining by enterprise size, South Africa, 1999..............................51

Figure 2b: Collective bargaining by enterprise size, Chile 1998..........................................51

Figure 3: MSEs providing social security coverage, 2001 ................................................62

Figure 4: Ranking of factors influencing decisions related to working

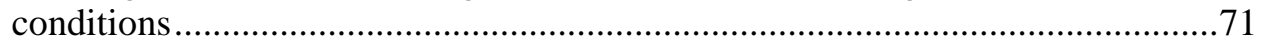

Figure 5: Pyramid of labour regulation strategies for MSEs..........................................107

\section{List of tables:}

Table 1: Formal application of occupational health and safety laws and regulations to MSEs

Table 2: $\quad$ Formal application of laws relating to collective (large-sacle) dismissals to MSEs ...........................................................................................24

Table 3: $\quad$ Formal application of freedom of association and collective bargaining laws to MSEs 
Table 4: $\quad$ Formal application of social security laws and regulation to

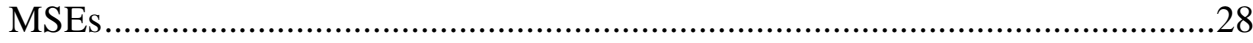

Table 5: $\quad$ Formal application of employee consultation laws and

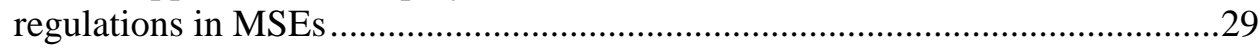

Table 6: Formal application of minimum wage laws and regulation

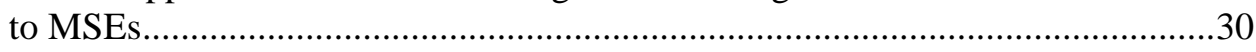

Table 7: Average earnings and hours worked per week for Chile and

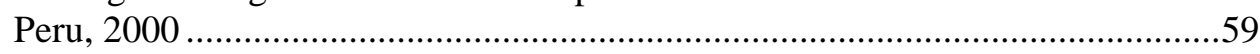




\section{PREFACE}

This paper examines the application of labour law in micro and small enterprises (MSEs) by comparing the practices in various member States of the ILO. Extending the coverage of labour law to numerous MSEs has been problematic in several countries largely due to practical reasons of the limited state capabilities and the number of enterprises involved. While the enterprises make 'strategic choices' of which legal provisions to comply with, States have the choice of 'responsive regulation' as well.

The role of the State in creating a level playing field for all enterprises is being increasingly recognized as critical for bringing about an enabling business environment. Such role of the State in formulation and application of policies and regulations has been debated in terms of their effect in business growth as well as workers' protection as enshrined in the ILO's Fundamental Principles and Rights at Work and other conventions. Although doubts have been raised about legislating the labour market without effective State wherewithal to implement such laws, the rush to deregulation in some countries has also raised the apprehension of the market anarchy in the absence of rules.

Many countries have labour law provisions applicable to all enterprises whereas many others have parallel labour law regimes or simply exemptions for the MSEs from application. Hence, a multitude of MSEs is found operating in an informal economy outside the legal purview with dim prospects of growth, poor working conditions and low productivity. During the discussion on the informal economy in 2002, the International Labour Conference concluded that the growth of the informal economy can often be traced to inappropriate, ineffective policies coupled with the lack of conducive legal and institutional frameworks and the lack of effective implementation of policies and laws. Based on the policy reviews carried out by SEED of the ILO in ten countries, labour legislation has been identified as one of the important elements of the regulatory environment affecting the performance of MSEs.

A conducive policy and regulatory environment reduces excessive administrative burdens and costs for enterprises; and at the same time, the long-term productivity gain is feasible only with workers' protection. There has been much debate about lowering the cost of doing business, including the arguments put forward in the Doing Business reports of the World Bank Group. Nonetheless, minimizing regulation to the extent of deregulation may not be the answer since the market does not operate efficiently without a legal framework; and the exploitative 'race to the bottom' under the competitive pressures in the absence of such a legal framework only damages long term survival of enterprises and jobs. Appropriate and effective regulation is necessary for reducing the burden and cost for enterprises in complying with the regulatory requirements while maintaining workers' protection.

'Responsive regulation' by the State means taking into account the attraction and incentives for the enterprises in complying with the labour regulation while the State maintains the threat of sanction as the last resort. This means an interplay of how enterprises make 'strategic choices' in complying with various regulations and how the State encourages such decisions through innovative regulatory approaches including education and awareness raising in collaboration with the ILO's social partners. This working paper provides such country examples as references for the constituents to debate their own reform processes.

Gopal Joshi

Small Enterprise Programme

Job Creation and Enterprise Development Department 


\section{EXECUTIVE SUMMARY}

Micro and small enterprises (MSEs) are increasingly a major source of employment creation, and therefore a focus of economic and development policy. Job quality in MSEs, however, is often very poor. At the same time, many MSEs are unstable or short-lived, and many operate in a state of semiformality. This has repercussions for job quality, and for broader economic development and growth. A key issue for the International Labour Organization (ILO) and for its member States is therefore how to devise a legal and regulatory environment for MSEs that promotes Decent Work, but which also facilitates economic growth.

Labour and labour-related laws can be an important means of improving job quality - and of promoting Decent Work; but they are often perceived by MSE owners and entrepreneurs (and others) as imposing unsustainable regulatory burdens and costs. This study examines States' practices in the application of labour law to MSEs, and from its findings outlines a set of principles that can guide States to develop innovative regulatory approaches to labour regulation for MSEs. These principles suggest that there is an important ongoing role for the State in labour regulation which in turn can play a key part in promoting job quality and also stabilization and growth of MSEs.

The precarious and varied nature of work in MSEs means that many workers do not have regular, full-time or 'typical' work contracts. As a result they are not 'employees' within the eyes of the law, and are automatically excluded from the operation of many labour laws, whose scope and coverage is frequently determined by this key labour law concept. In addition, many States simply exclude MSEs from the scope and coverage of some or all of their labour laws. Generally these exclusions operate by setting numerical thresholds: enterprises with fewer than a specified number of workers are excluded. In some cases States have adopted 'parallel labour law' regimes that offer a simplified labour law for MSEs. In adopting these approaches, a number of States have been influenced by the Bretton Woods institutions and others that have advocated the 'deregulation' of labour markets, on the basis that this will facilitate job creation.

Quite apart from labour law implicitly or explicitly excluding workers in MSEs, in many cases States do little to apply or to enforce labour laws to MSEs in practice. In some cases this is a result of legal design issues: administrative authorities are given too much discretion and too little guidance in its exercise; in some cases the availability of discretion lends itself to corruption. In other cases the labour administration is simply under-resourced or otherwise unable to address the challenge of applying and enforcing labour law to the very many (and very different) MSEs within their jurisdiction.

The outcomes for workers in MSEs are frequently unsatisfactory. MSE workers are often excluded from the scope of labour laws that create important rights that have a deep relationship with workers' job quality. MSE workers are often excluded from laws that require or permit the formation of trade unions at the enterprise level; consultation requirements in relation to occupational health and safety or collective dismissals; or in some cases from the operation of social security laws. Even where MSEs are officially within the scope and coverage of 
labour laws, deficiencies in their application and enforcement frequently leave workers without the benefit of their intended protection.

The specific impact is that job quality for MSE workers generally falls way short of what is necessary to promote or to achieve Decent Work. Levels of trade union membership and collective bargaining are low in MSEs. Forced labour and child labour are found in some MSEs, and are more common in MSEs that operate close to or within the informal economy. Workers in MSEs typically experience discrimination in the nature of their working conditions; women workers in particular are over-represented in MSE work, and therefore suffer both direct and indirect discrimination in the level of their working conditions. For all MSE workers, empirical evidence suggests that wages are lower and working hours longer than for workers in larger enterprises. MSE workers also commonly lack social protection, and endure worse occupational health and safety outcomes than workers in larger enterprises.

There is little evidence to suggest that excluding MSEs from labour laws, or failing to apply them in practice, has major positive effects in terms of MSE growth and economic development, or is likely to induce MSEs to become and to remain fully formalized. The basic idea that the application of labour law to MSEs imposes unsustainable costs itself overlooks the benefits that can flow from compliance with labour laws, including the development of a safer, happier, and more productive workforce. It is also a view that focuses on the short-run or operational costs of compliance, without considering the long-run benefits that may flow from labour law compliance. Enterprises that compete for workers and with each other - on the basis of job quality are more likely to provide higher remuneration and better working conditions. Evidence from studies by both the ILO and the OECD suggests that MSE owners and entrepreneurs do not regard the costs of complying with labour laws as a major constraint on MSE growth. Other studies have also found that MSE owners and entrepreneurs make strategic choices about which elements of their regulatory environment they will comply with from time to time. That they make strategic choices - in the context of their particular market climate - suggests that they will also respond to innovative regulatory approaches that are targeted specifically at MSEs.

This study identifies a number of innovative regulatory approaches that States have adopted to try to achieve the goal of applying labour and labour related laws to MSEs, without imposing significant costs upon them. Some States have adopted legislative measures to redefine the scope of the employment relationship in broader terms. Others have taken a 'staged' approach, for example gradually extending the scope of social security schemes to ensure that over time they include MSEs. A number of States have developed special agencies or units within their labour administration that have particular responsibilities for the promotion of labour law and its application to MSEs.

A key approach taken by a number of States has been to develop and to implement innovative approaches to the enforcement of labour laws for MSEs. These include developing enforcement strategies that target the particular characteristics of MSEs, including education and information campaigns, targeted inspections, and substitution of training for the imposition of fines where MSEs do not comply. Many of these strategies are built around the need to overcome the low levels of legal literacy of both MSE workers and their owner-entrepreneurs. A number of States have also been able to develop strategic mechanisms and approaches for the application of labour law, including the establishment of regional trade union representation schemes to overcome the 
fact that MSEs usually fall below relevant numerical thresholds. Another approach - facilitated by the ILO - has been to link different elements of the State administration to each other to improve outcomes in particular areas. Thus for example city council health services and community organizations can play a role in improving occupational health and safety outcomes.

The findings of this study suggest that States neither must nor should simply exclude MSEs from the application of labour laws. There is little evidence to suggest that this has positive effects for MSEs. At the same time there is much evidence to show that it has significant adverse effects for MSE workers, in the form of very poor job quality. This in turn has important flow-on effects for MSEs and for economic growth more generally. Higher job quality is positively associated with higher productivity, and so with sustainability of growth and development. The exclusion of MSEs from labour law therefore only deprives MSEs of the benefits that flow from workers experiencing better job quality. From the point of view of development theory, a State that takes this approach fails to ensure that it is developing its citizens' human capabilities: it thereby fails them as individuals, and society as a whole. A State that takes this approach is also significantly hampering the prospect of developing the critical interlinkages that are associated with the establishment of economically nutritious activity and industrial upgrading, which are hallmarks of economic development.

States face difficult policy choices in developing labour regulation for MSEs. They must balance the twin - and apparently competing - goals of improving job quality while promoting and rewarding entrepreneurship and economic growth. Moreover they face considerable pressure, particularly from the Bretton Woods institutions, to 'deregulate' their labour markets (in particular). This study suggests, however, that there is no simple choice to be made between regulation or deregulation: the removal of State regulation (in the form of legislation, for example) still leaves other forms of constraint and control (that is, of regulation) of behaviour in the labour market. In the first place it leaves the general law and the ordinary court system; indeed it gives them a greater role. Thus States must address the challenge of developing the best method of regulating, and so of moving toward achievement of their important policy goals. Moreover they must do so because the proper functioning of the markets that should produce the economic growth they seek requires regulation by the State: the market does not and cannot simply exist without regulatory action by the State. On the contrary: markets are embedded in regulatory systems.

This study shows that States can develop labour regulation policies for MSEs according to the following principles:

1. Labour regulation should pursue three inter-related and mutually reinforcing objectives: promoting human capabilities, improving job quality, and encouraging formalization of MSEs.

2. Labour regulation should be underpinned by the basic values of the Decent Work agenda: it should recognize that all those who work have rights at work.

3. Labour regulation should be innovative and responsive. That is, the scope and coverage of labour law and the methods by which it will be applied and enforced should be developed together. Secondly, labour regulation should be designed by participatory processes, both during its initial development 
and in subsequent reviews. Thirdly, the design and implementation of labour law for MSEs should be specifically targeted at them.

Taking a responsive regulatory approach does not mean that States must abandon the objectives of labour regulation. On the contrary, the basic values of the Decent Work agenda must serve as the touchstones for any regulatory framework, and must always be protected in labour laws. The challenge for States is to identify, to encourage and to develop innovative methods of labour regulation. To do so, they must draw on their own resources, their existing institutions, and their citizens (especially through their representative organizations) to establish locally designed regulatory strategies to pursue the twin goals of job quality, and formalization of MSEs. In this way, labour regulation can play a vital part in the achievement of Decent Work, and also in enterprise development and formalization. 


\section{CHAPTER 1 \\ LABOUR REGULATION AND MSES: THE POLICY CHALLENGES}

Chapter summary

- MSEs are an increasingly important source of employment creation in many States.

- Job quality in MSEs is generally very poor.

- Poor job quality is due in part to the fact that many MSEs are unstable, short-lived and operate in a state of semi-formality. This has repercussions for job quality and for broader economic growth and development.

- The formalization of MSEs is critical for the creation of Decent Work: MSEs that operate within the scope of the regulatory framework are more likely to create productive, remunerative jobs in which workers have rights at work, security, and equality.

- States must devise a policy environment that balances the need to protect workers, with acknowledgement of the extent to which MSEs genuinely require special regulatory measures in light of their ability to meet the costs of the regulatory framework.

- A key challenge for the ILO and for its member States is how to devise a legal and regulatory environment that promotes Decent Work in MSEs and facilitates economic growth.

- Labour and labour related laws can be an important means of improving job quality.

- $\quad$ This study suggests that there is significant scope for States to take regulatory action to address these challenges.

\section{Introduction}

This report is concerned with the most appropriate forms of labour regulation for micro and small enterprises (MSEs): businesses which include 'own account workers' who occasionally bring in family members or friends to work when there is too much work for one person, and businesses which employ up to five, twenty or sometimes even more people. The first chapter in this report provides background information to explain why this issue matters. It also outlines the key policy debates concerning the application of labour laws to MSEs.

This chapter of the report shows that although MSEs are increasingly a major source of employment, job quality in MSEs is often very poor. This is because employment in MSEs is frequently precarious. A related problem is that many MSEs operate 'semi-formally': their owners and operators respond to the regulatory environment in which they operate by making strategic choices about whether and when to comply with regulatory requirements. Previous studies have suggested that MSE owners and entrepreneurs may see the application of labour and labour-related laws as a particularly important element of the regulatory environment in which they operate. Despite these problems, MSEs are a key focus of both economic and development policy in many States, which see their potential for employment creation and contribution to overall economic growth. The role of the State in facilitating the creation of Decent Work in MSEs is therefore crucial: it is the State that shapes the policy and regulatory environment within which MSEs operate, including of course those parts of it represented by labour law. 
There is a significant policy debate about the best way to regulate labour standards in MSEs and to what end. It is often argued that the State can best facilitate MSE growth by limiting the impact of its regulatory regime: reduced regulatory burdens should mean that the costs of regulatory compliance will fall. This in turn should encourage the further development of MSEs; it should help promote entrepreneurship. This study draws on evidence from a range of countries to show that the majority of States do exclude MSEs from various types of labour laws. It appears that for the most these exclusions are an attempt to relieve MSEs of the costs - both direct and indirect - of compliance with labour laws. It is not clear, however, that this policy approach has positive effects either for workers, or for MSEs. Excluding them from labour laws, for example, may only serve to exacerbate the problem of low job quality. Nor is it obvious from existing data that relieving MSEs of these particular burdens has a significant positive impact in terms of MSE growth, or in terms of encouraging MSEs to formalize.

The purpose of this study is therefore to develop a better understanding of States' current practices in the application of labour and labour related laws to MSEs, and of the effects and impact of those practices.

\section{The promise and the challenge of MSEs}

\section{The proliferation of MSEs: An important source of employment}

MSEs, for many years, have been a significant feature of certain economies. In recent years, however, they have grown both in number and in importance. This has been in part a response to sustained and increasing pressure for flexible production, especially through global supply chains, ${ }^{1}$ which has affected both developing and industrialized economies. A second important cause of growth in MSEs has been the inability of labour markets to absorb the impact of structural adjustment programmes, which have been criticized for leading to greater poverty, unemployment and underemployment, and for contributing to growth in the informal economy. ${ }^{2}$ The effects of these policies were particularly acute in the former state-socialist transition economies and in Latin America where, in each case, the State had been a major employer. ${ }^{3}$

MSEs have been particularly responsive to these forces, proving to be most dynamic at creating opportunities for workers to engage in productive activity, particularly when they have been forced out of other employment. Thus, MSEs have generated more job opportunities than large enterprises, particularly in non-

\footnotetext{
$1 \quad$ ILO, 2002b, p. 2.

2 Ibid., p. 30.

3 For example, in Venezuela, the percentage of public employees increased from 17.5 per cent in 1950 to 35 per cent in 1982. An estimated 250,000 public workers were surplus labour who cost the state three billion US\$ per year in wage payments: Coker, 2001, p. 188. The total percentage of workers employed in the public sector in Latin America declined from 15.5 in 1990 to 13.4 in 2001: ILO, 2002c, p. 103.
} 
agricultural employment. ${ }^{4}$ Today MSEs often represent a majority of all enterprises and between them employ, or have the potential to employ a significant proportion of the world's workers: one ILO study across seven countries found that MSEs accounted for 97.5 to 99.7 per cent of all enterprises. ${ }^{5}$ MSEs are also especially important as the source of employment for a significant majority of women who work.

Figure 1 shows the proportion of workers employed in MSEs in nine of the countries that were examined for the purposes of this study. The proportion of workers employed in MSEs ranges between 18.9 per cent in Costa Rica, and 71.5 per cent in Peru. Thus, at the lower end of the scale, one in five workers may be employed in MSEs, while at the higher end it can be as many as seven in ten.

\section{Figure 1: Persons employed in MSEs (national definition)}

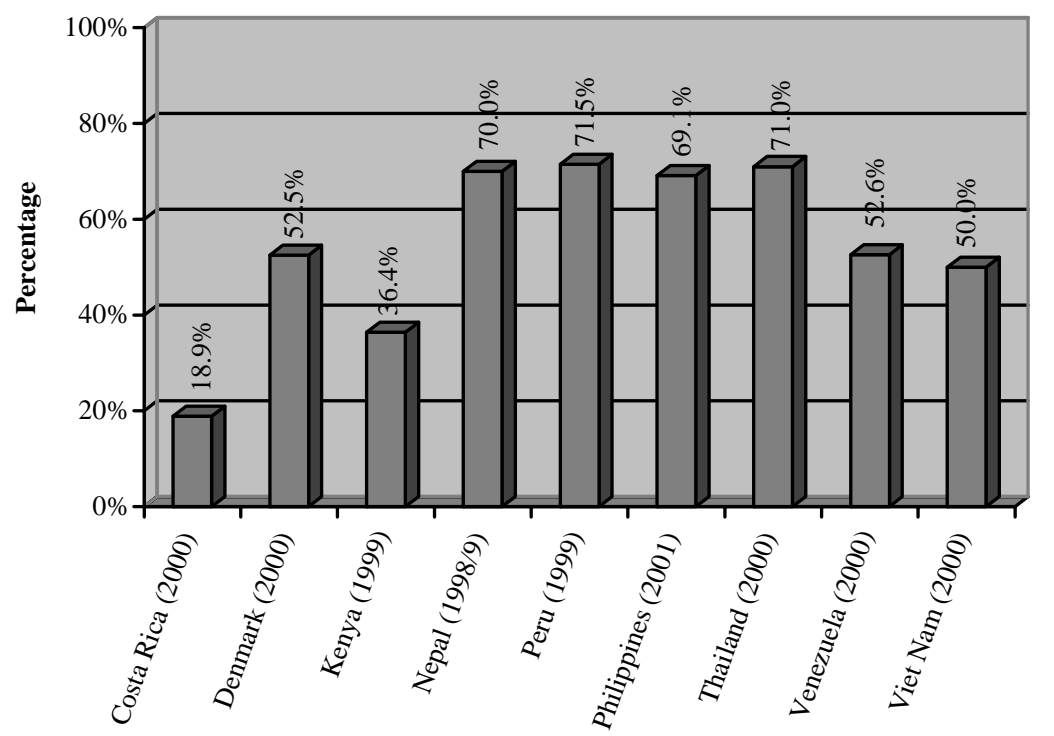

\section{Job quality in MSEs is often low}

A key question for the International Labour Organization (ILO) is whether jobs in MSEs provide workers with Decent Work. In other words, do they have employment, rights at work, and social protection, and are they able to participate in social dialogue about these issues? This is the topic of Chapter 3. The limited empirical research on the question suggests that while MSEs have the potential to be the drivers of employment generation and of economic growth, the quality of employment in MSEs is generally far worse than in other areas of the economy; a significant contributing factor is that a substantial number of MSEs operate in the informal economy. Job quality plays a critical

4 Reinecke and White report that 'policies of economic liberalization caused an increase of the MSE share in non-agricultural employment'. Reinecke and White, 2004, p. 22.

5 Ibid., p. 19. 
role in developing and assuring workers' productivity, and so contributes to enterprise success and in turn to broader economic growth. ${ }^{6}$ Low job quality in MSEs - whether formal or informal - also presents a significant obstacle to the improvement of the quality of life of people who live in poverty. Related difficulties include the possibility of worker 'churning' (workers moving through MSE employment, but without new work being created), and the limited commercial prospects for many MSEs, which are frequently founded in times of crisis. $^{7}$

\section{Many MSEs are not fully formalized}

Poor job quality in MSEs is related to the fact that a significant proportion of MSEs operate in the informal economy, where workers and enterprises are 'not recognized or protected by legal and regulatory frameworks. ${ }^{8}$ But it does not follow that all other MSEs are part of the formal economy: the concepts of the 'formal economy' and the 'informal economy' are not simple opposites. Enterprises are usually found somewhere on a continuum of compliance: they are formal in some respects, but not in others. This reflects the limited and contingent state of business development of many MSEs, which is in large measure a result of frequent and rapid fluctuations in demand in the markets in which they operate. ${ }^{9}$ However it comes about, the fragile state of many MSEs has the effect that frequently they are likely to find compliance with regulatory requirements - including labour law - to be disproportionately burdensome.

Evidence suggests that entrepreneurs make strategic choices about which laws they will and will not comply with, and thus the level of formality of the enterprise. ${ }^{10}$ The knowledge that entrepreneurs make strategic choices about regulatory benefit or cost is important. It shows that entrepreneurs do react, and will respond, to the policy choices made by governments in the design of the regulatory environment for MSEs. ${ }^{11}$ This is significant because it suggests that MSEs and the entrepreneurs that own and manage them are likely to be responsive to carefully constructed policy approaches. This study shows that States both can and should develop their regulatory approach to MSEs with this sort of responsiveness in mind.

\section{State regulation of MSEs and labour markets}

\section{Approaches to State regulation}

The hybrid and fluid character of many MSEs poses a particular policy challenge: to develop a regulatory environment that will encourage MSEs to

Deakin and Wilkinson, 2005, p. 293.

Reinecke and White, 2004, p. 6.

8 ILO, 2002b, p. 3.

9 Reinecke and White, 2004, p. 18.

$10 \quad$ Maldonado, 1995, pp. 705, 727.

11 Reinecke and White, 2004, p. 53. 
develop into strong, growing enterprises that participate fully in the formal economy, but to do so in a way that best promotes the creation and maintenance of Decent Work. The formalization of MSEs is important, as it helps to maximize the possibility of sustainable growth and economic development. The formalization of MSEs is also critical for the creation of Decent Work: MSEs that operate within the scope of the regulatory framework are more likely to create productive, remunerative jobs in which workers have rights at work, security, and equality. ${ }^{12}$ States must therefore devise a policy environment that balances the need to protect workers, with acknowledgement of the extent to which MSEs genuinely require special regulatory measures in light of their ability to meet the costs of the regulatory framework. This study suggests that there is significant scope for States to take regulatory action to address these challenges.

\section{Labour market deregulation and the influence of the Bretton Woods institutions}

Not surprisingly, there are different views on whether and how to regulate MSEs. At one end of the scale is the 'neoliberal approach' ${ }^{13}$ strongly advocated (in particular) by Hernando de Soto and, more recently, by the World Bank. ${ }^{14}$ Proponents of this approach argue that the effect of the legal environment on entrepreneurs can be one of the principal factors leading enterprises away from formality. ${ }^{15}$ According to this view, the state should reduce the regulatory burden as much as possible; no less in the area of labour laws than any other. In particular, it should focus on reducing the level and complexity of the legal framework that applies to MSEs. ${ }^{16}$ This is an argument for so-called 'deregulation'.

In recent decades countries throughout the world have embarked on programmes of labour market deregulation. In the developing world this has frequently been under the auspices of structural adjustment programmes, commonly with funding from the Bretton Woods institutions. Structural adjustment has brought labour market reform to much of Latin America ${ }^{17}$ and Africa, ${ }^{18}$ and (particularly since the economic crisis), to Asia. ${ }^{19}$ Labour market deregulation has been pursued in industrialized economies for similar reasons: in

12 ILO Governing Body's discussion of the 'rights deficit in the informal economy': ILO, 2002b, pp. 43-44.

13 As defined by Maldonado, 1995, p. 709.

14 World Bank, 2005.

15 de Soto, 1989 referred to in Maldonado, 1995, p. 709; Portes, 1994, p. 126; and World Bank, 2005.

16 Maldonado, 1995, pp. 705, 709.

17 Bronstein identifies Bolivia, Costa Rica, Mexico, Colombia, Argentina, Peru and Brazil: Bronstein, 1997, p. 136, pp. 10, 134, 163. More recently Vega Ruiz has analysed how reforms in Latin Amerioca to laws regulating MSEs have to a large degree been reforms of labour laws, Vega Ruiz, Libertad de asociación, libertad syndical y el reconocimiento effective del derecho de negociación colectiva en América Latina, 2004.

18 Mogalakwe and Siphambe, 2000; Sachikonye, 2000; Kani, 2000; Mthinidi, 2000; Hansohm et al., 1999; and Van Der Geest and Wignaraja (eds.), 1996.

19 Cooney et al., 2002. 
the belief that increased labour market flexibility will be conducive to higher productivity and therefore to greater competitiveness in the globalizing economy.

While each country has approached labour market deregulation in the course of responding to its own individual circumstances, the influence of the Bretton Woods institutions has been significant. They have strongly promoted labour market reforms aimed at facilitating enterprise efficiency, in terms of both labour market flexibility and labour productivity. Standard elements of the policy prescription have been decentralized wage determination; cost containment by marginalization of the activities of trade unions; and the establishment of export processing zones. In some cases firms operating in export processing zones have been excluded from the operation of labour law; in others they have been allowed to operate within a special (reduced) regulatory regime. ${ }^{20}$ While the Bretton Woods institutions now appear to accept the need for regulation to promote and protect core labour standards, ${ }^{21}$ they generally consider that high levels of employment protection will inhibit 'wage flexibility' and 'labour mobility’, and discourage employment growth.

The World Bank, for example, has suggested that higher labour standards in the formal sector may lead to an increase in informal employment. A 1995 report entitled Labour and Economic Reforms in Latin America and the Caribbean argued that the large proportion of workers in the informal economy in Latin America was attributable to 'labour policies that overlooked the role of wages and working conditions as incentives and market signals, reducing the number of formal jobs and encouraging the development of the informal sector' ${ }^{22}$ This view, however, is criticized by many commentators as lacking a basis in empirical evidence. $^{23}$

The uncertainty about whether the World Bank's insistence on labour market deregulation is effective in practice only adds weight to a separate, but equally significant difficulty with its policy prescription: the Bank's increasing insistence on the importance of labour market reform does not give any consideration to how important this is relative to other challenges that States may face. The World Bank's approach does not provide any means to judge the weight or significance that ought to be given to its preferred modes of labour market deregulation in any given case. It may well be true that in some developing economies - as well as in some industrialized economies - there is regulation in the labour market (or elsewhere) that should be revised and streamlined in the interests of greater efficiency and productivity. It is equally true, however, that labour market reform is not always or everywhere the number one development challenge that States are facing. In the many developing economies that also face social and political upheaval - including to the extent of civil unrest and war - it seems unlikely that, when viewed objectively, labour market deregulation is the most important area of policy reform. In short, it is

20 Frenkel and Kuruvilla, 2002. pp. 387, 390.

21 In Doing Business for 2004, p. 29, the World Bank acknowledges that regulation of labour markets to protect and respect the rights protected in the ILO's Declaration on Fundamental Principles and Rights at Work represents the minimum necessary level of regulation.

22 World Bank, 1995, p. 6.

23 Galli and Kucera, 2004, p. 20. 
necessary for States to have more scope to choose their own policy priorities than the World Bank's prescriptions would appear to allow.

Quite apart from the influence of the Bretton Woods institutions, the new emphasis on promoting MSE development also poses dangers for levels of protection for workers, which can in turn have a negative effect on economic performance. It is one of the findings of this report that policies aimed at fostering MSE development often focus on increasing productivity exclusively, and neglect the issue of increasing job quality. In Chapter 4, we explain how such approaches are inconsistent with evidence which suggests that job quality is a critical factor contributing to economic growth.

\section{Another perspective on the role of the State and regulation}

Given the uncertainties and possible dangers of labour market deregulation, other State approaches to economic development must be considered. The policy challenge for States posed by MSEs can be viewed from a different perspective, placing greater emphasis on the impact of 'the decentralization and reorganization of the production and work processes at the global level. ${ }^{24}$ This approach may leave greater room for regulatory action by the State: ongoing State regulation is necessary, both to assure basic labour standards for workers, and also to control the harmful effects of competition that is based on low wages because of non-compliance with relevant legal requirements and which is therefore illegitimate. $^{25}$

This study suggests that regulation by the State - or coordinated by it - is both necessary and desirable to ensure basic standards for workers. In particular, it is necessary to assure job quality. But this is necessary in turn for the longer term viability of MSEs: job quality is closely linked to productivity, and so to economic growth.

A key consideration is whether the 'deregulation' approach is likely to lead to greater flexibility in modes of work organization and industrial structures. In other words, can a reduction of the regulatory burden of labour law help entrepreneurs to flourish in ways - and in business forms - that may not previously have been possible? To date there is little evidence to support the practice of deregulation in this respect: studies in Latin America (in particular) have failed to identify any positive examples of the sort of 'flexible specialization' that deregulation should have helped to produce. Indeed, the role of the State in developing a suitable regulatory environment remains paramount, because entrepreneurs lack many of the skills and resources needed to pursue anything other than 'sweatshop or homework production'. ${ }^{26}$

More fundamentally, there is no simple dichotomy between regulation and deregulation. The State (or other parties) may regulate more or less directly, but there are always modes of regulation. Take the simple example of 'deregulation' of labour markets. If this were to occur, the theory is that it would be in favour of 
allowing the market to determine outcomes: in essence, the law of contract would regulate labour market exchanges. But what this means is that the ordinary legal system and courts, together with the 'market' would be substituted as the regulatory mechanism, instead of State-based law. It is immediately clear that this is not an absence of regulation, but a shift in types of regulation. A further crucial factor here is that markets themselves require regulation. Indeed, they do not exist without it: the most important elements of market regulation are the laws and legal institutions that establish and protect property and transactional rights.

Before turning to the nature of debates about labour market regulation in particular, and then considering examples of States' practices, it bears emphasising that there are many policy areas in which States must make key decisions if they are to provide a supportive regulatory environment for MSE growth. They include specific small enterprise policies, registration and reporting requirements, and access to finance and credit, as well as policies, laws and regulations relating to taxation and labour standards. ${ }^{27}$

While no doubt MSEs - like any profit-making enterprise - respond principally to the market, it must be recalled that the market does not exist in a vacuum. The market is not just 'out there', pre-existing the State's policy environment: 'well-functioning markets do not come about spontaneously but rather depend on various institutional arrangements and policy interventions. ${ }^{, 28}$ States must take positive steps to create and to implement a positive policy and regulatory environment, bearing in mind that policies shape legal and regulatory environments, which in turn shape the institutional environment within which enterprises function. The ILO, through its members, has acknowledged and supported the need for positive action by the State in this area in, for example, its Job Creation in Small and Medium-Sized Enterprises Recommendation, 1998 (No. 189) (article 5).

Adopting the position that the State must retain a key role in developing and implementing the regulatory framework for MSEs does not mean, however, that any or all forms of regulation can or should be supported. This study supports elements of the argument for 'deregulation', for example, its insistence on simplification of legal procedures. In the end, however, the question is really one of identifying the most appropriate regulatory technique for achieving a desired policy goal.

\section{Labour law and MSEs: Different approaches}

While this study suggests that the State can and should play a positive role in shaping the regulatory environment, it must be acknowledged that States face significant policy challenges. They must seek to design and to implement a policy and regulatory environment that promotes the multiple goals of (1) fostering enterprise and employment growth, (2) ensuring job quality, and (3) encouraging the growth and formalization of MSEs, in particular by taking due account of their ability to sustain regulatory burdens. In this respect, labour law is only one of a wide range of relevant areas of social and economic regulation.

27 White, 2005, p. 26.

28 Reinecke and White, 2004, p. 18; Polanyi, 1957; and Burk, 1988. 
Where the application of labour law to MSEs is concerned, governments must consider two separate but related aspects. The first is the scope and coverage of labour laws themselves: do they apply, officially, to MSEs? The second is the application of labour laws to MSEs in practice: how does administrative policy promote and enforce those labour laws that apply to MSEs?

1. The scope and coverage of labour laws. States generally take one of four different approaches. Some countries make no exception in the scope of their labour laws for MSEs. China, for example, purports to apply all labour laws regardless of enterprise size or formality. A diametrically opposite approach is to completely exclude all enterprises below a threshold number of employees from the application of labour law (as in Pakistan). ${ }^{29} \mathrm{~A}$ third approach is to promulgate a 'parallel labour law regime': that is, a labour law specifically designed to apply to MSEs. The most common approach, however, is to exclude MSEs from some particular requirements of the labour law, for example relating to consultation in the workplace. ${ }^{30}$ In Chapter 2 of this report, we present empirical evidence concerning country approaches to this question, and conclude that simply excluding MSEs from the scope or coverage of some or all labour laws may lead to several potentially harmful side-effects.

2. The application of labour laws to MSEs in practice. The application of labour laws to MSEs in practice is at least as important as their formal scope. After all, it doesn't very much matter what the law says on paper if those laws are not being applied or enforced. The findings presented in this report confirm that states also take a variety of approaches to the application of labour laws to MSEs in practice. Some States, whether by design or default, appear disinclined to attempt to administer labour law among MSEs, while in others they do so only selectively. This is due to a number of different factors which are discussed in detail in Chapter 2, Part V.

The application of labour law to MSEs poses a dual challenge for labour administration. Decent Work deficits can be seen as a failure of governance. Labour laws can play a key role in providing for social protection, which in turn can help lead to Decent Work. But traditional State-based methods of applying and enforcing labour laws cannot be left to work on their own. Instead, we conclude that the State must develop 'new ways to increase economic capabilities and strengthen voices, defend rights, generate and transfer resources and change incentives.' In short, the State must take an imaginative approach to regulation when it comes to the application and enforcement of labour law to MSEs (and also to the informal economy more broadly). ${ }^{31}$

29 This approach does not reflect a recent trend. Rather it is a continuation of aspects of Factories legislation that applied in former British colonies.

30 For different typologies, see Von Potobsky, 1992, p. 131; and Daza, 2005.

31 For recent consideration of the potential for alternative regulatory approaches to improve enforcement and application of a 'command and control' model of labour regulation, see Cooney, 'Making Chinese Labour Law Work'. Copy held on file by authors. 


\section{Promoting decent work through innovative labour regulation}

In this section, we provide an introduction to some of the key concepts underpinning our study of 'innovative labour regulation' in this report.

\section{What is labour 'regulation'?}

This study uses a concept and definition of labour 'regulation' that avoids the simplistic debate about regulation versus deregulation. ${ }^{32}$ For the purposes of this study, the term 'regulation' includes, but is not limited to, the use of legal rules and sanctions as a mechanism for setting and enforcing behavioural norms. In other words, while setting rules remains essential, 'regulation' covers much more than this. When this study uses the term 'regulation' it covers both legal rules, and other means of inducing changes in behaviour to better comply with particular policy goals. While this includes inducing changes to comply with legal rules such as labour laws, it also encompasses other means of achieving the policy goals of those laws.

Turning to labour standards in particular, a typical definition adopts a conventional view of labour regulation as:

Any governmentally established procedure, term or condition of employment, or employer requirement that has as its purpose the protection of employees from treatment at the workplace that society considers unfair or unjust. The common element across all standards is that they are mandatory - they are governmentally imposed and enforced. Employer failure to comply with standards brings legal sanctions on the employer. ${ }^{33}$ (Emphasis added).

Most labour regulation is based on this sort of approach, which is a mandatory model of regulation. Under this approach, legal instruments (laws) establish mandatory standards, and make a government agency responsible for monitoring and enforcing the standards. They usually also set out a range of sanctions that the State agency can impose if the rule is breached. Studies of regulation in action accept that law is a key means of regulation to achieve better labour standards, however, they also show that the 'command and control' model of regulation can be an ineffective and often counterproductive mechanism for achieving compliance with desired policy goals. ${ }^{34}$ One of the reasons for this is such mandatory regulation is frequently associated with high levels of prescription in regulation: that is, with levels of detail and obligation that detract from enterprise performance far more than they contribute. This is consistent with the problems that States experience in seeking to apply labour laws to MSEs in practice.

Of course it is frequently argued that the solution to such problems is to abandon legal regulation of markets altogether - to adopt the 'deregulation' approach. There are at least two key responses to this. Firstly, as noted, it is not possible simply to 'deregulate' markets: it is more accurate to think of different

\footnotetext{
32 Howe, 2005,

33 Block and Roberts, 2000, p. 55.

34 Ayres and Braithwaite, 1992.
} 
modes of regulation. Markets are not naturally arising, self-ordering, mechanisms created 'simply through the interaction of innate human characteristics. ${ }^{35}$ Secondly, many studies have emphasized the diverse regulatory techniques and responses that States may adopt. These techniques can be used together with ‘command and control' regulation, to achieve desired policy objectives.

It has also been recognized in many contexts that if regulation is to be effective, then it must be more inclusive of, or 'responsive' to interested actors, other than the State and its agencies. In other words, it should not simply be devised and directed by the State. One key response to the problem of ineffectiveness faced by many legal systems is to incorporate alternative institutional structures and procedures to facilitate participation of interested parties in regulatory regimes. ${ }^{36}$ Labour regulation, for example, should be responsive to actors such as trade unions and business. These arguments are directly relevant to both the scope and coverage of labour law, and to its application in practice, where MSEs are concerned.

Criticizing direct legal regulation as ineffective does not mean that the State should abandon the policy goals that it has pursued through law, including labour laws. Responsive regulation requires institutional structures that regulate substantive ends, as well as sanctions for enforcing those ends. Chapter 5 takes this argument further, using the concept of a 'labour regulation pyramid' to show that direct legal regulation, supported by sanctions, remains necessary to ensure that other regulatory techniques are effective. What the pyramid approach also shows, however, is that a diverse array of regulatory approaches, techniques or instruments may be used to achieve change. ${ }^{37}$

This study shows two key things about responsive labour regulation. Firstly, the State can draw on a wide range of regulatory techniques in its regulatory design, meaning the whole range of approaches to the achievement of its policy goals. Secondly, regulatory approaches that involve a range of regulatory actors as part of a strategy to achieve better compliance with, or observance of, desired labour standards are likely to be more effective in balancing labour law compliance and accountability with economic development. Chapter 5 spells out these principles in more detail, with reference to specific examples of innovative labour regulation practices.

\section{What is labour law?}

MSEs operate in policy environments that involve many areas of law, including of course labour law. Other important policy areas include access to finance, tax, and ownership of property. But the focus of this study is labour law, so it is essential to make clear what it means by the concepts 'labour law', and

\footnotetext{
35 Shearing, 1993, p. 68.

36 Ayres and Braithwaite, 1992, p. 6; Black, 2000, pp. 597, 597-598. Decentred or responsive regulation is thought to improve the effectiveness of regulatory regimes by making them more inclusive of interested actors, and encouraging dialogue and debate between those actors - a form of deliberative democracy.

37 Black, 2000. A more detailed discussion of the different regulatory instruments or techniques available to the state can be found in Daintith, 1988; and Baldwin and Cave, 1999.
} 
'labour and labour-related law'. It is necessary, in particular, to accompany the broad conception of labour regulation outlined above. A clear definition of 'labour law' is also necessary because it is important to be precise about which labour laws impose what sorts of costs, or otherwise impose regulatory burdens on MSEs.

As noted earlier, MSEs are responsive to the policy and regulatory environment in which they operate, making choices about the extent to which they comply with particular regulatory burdens. Thus, MSEs are likely to respond differently to different labour laws. Obviously, these distinctions can have important implications for regulatory design, and for the emphasis that is placed on different labour laws and regulatory techniques when considering their application to MSEs.

Maldonado's overview of the findings of ILO studies in a number of Latin American countries emphasized that while priority ought to be given to those labour laws that protect vulnerable workers and proscribe hazardous working conditions, other matters such as wages, working time and overtime 'are sensitive issues', and that social security raises yet another discrete range of issues. In other words, Maldonado has shown that it is necessary to determine the priority to be given to the application of some labour laws, taking into account the extent to which they will impose particular burdens on MSEs. Likewise, his synthesis of findings from a number of studies in Africa suggests that wages issues should be treated separately from social security issues: they may impose different costs and, in the case of social security, the State also has a role to play. ${ }^{38}$ In this respect Maldonado's findings reflect States' practices in excluding MSEs from various elements of labour law: as we noted above, States appears to have used this strategy as a means to acknowledge the constraints that these costs can impose on MSEs.

The research on which this study is based (presented in Chapters 2 and 3) was developed using the following definition of 'labour law', and the analysis of labour law policies for MSEs reflects it. This study conceives of 'labour law' or 'labour-related laws' as any State recognized labour rights and standards that reflect the general goal of improving the quality of working life, and the relative bargaining power of people who are dependent upon their labour for a living, whether they are working or without work. ${ }^{39}$ For this study, we have identified a number of different labour rights and standards which are recognized as having the potential to improve and to maintain job quality and poverty reduction. These rights and standards are enumerated below. 
Labour rights and standards

- Collective bargaining and freedom of association

- Anti-discrimination/equal employment opportunity

- Prohibitions on forced labour/child labour

- Minimum wage

- Overtime/working time limits

- Paid time off

- Unemployment insurance

- Workers' compensation

- Protection against unjust dismissal

- Occupational health and safety standards

- $\quad$ Advance notice and consultation (for large scale layoffs)

- Parental/family leave

- Employee consultation

- Protection of rights and entitlements on transfer of undertaking.

In one sense this definition, and the various rights and standards it encapsulates, is merely quantitative: in the preparation of this study it simply helped as a way of identifying exactly which labour rights and standards are recognized by national labour law systems. In another sense, however, the definition is qualitative: when viewed collectively, these standards and rights embody a definition of the ideal of 'Decent Work'. At the same time, however the various elements of this range of 'labour laws' do not represent a unified or compulsory whole. As we noted above, different labour laws may have different cost implications for MSEs. So too, they may have different effects and be of differing levels of importance for quality of work and life.

\section{A rights-based approach to labour regulation: Decent work and international labour standards}

The study's definition of labour law is consistent with (and conducive to) the pursuit of Decent Work. It is important also to note that ILO members have already expressed their support for many of the types of State regulation of MSEs for which this study argues: that support can be presumed from the fact that so many ILO standards provide for precisely such intervention in the labour market. Moreover in 2002 the International Labour Conference expressed its support for the application of international labour standards in the particular context of the pursuit of Decent Work in the Informal Economy. Together with the ILO's articulation of a Decent Work agenda, international labour standards may therefore serve as a source of guidance in devising innovative regulatory approaches to labour regulation for MSEs.

All of the core standards may - and should - be applied to MSEs. Beyond the core conventions there is a number that may have particular importance, 
including instruments relating to labour administration and labour inspection, ${ }^{40}$ and employment policy. A key instrument is the Job Creation in Small and Medium-Sized Enterprises Recommendation, 1998 (No. 189). Some instruments directed to particular groups of workers might be significant where the workers to whom they are addressed are more commonly engaged in MSEs. These might include the conventions dealing with home work, ${ }^{41}$ and indigenous and tribal peoples. ${ }^{42}$ It should be noted that few ILO Conventions specifically exclude MSEs from their operation. ${ }^{43}$

The concept of Decent Work involves four interlocking elements: employment, rights at work, social protection and social dialogue. Although not all MSEs are found in the informal economy, the ILO's previous consideration of how to promote decent work in the informal economy captures some of the important goals promoted by this study:

The goal is to promote decent work along the entire continuum from the informal to the formal end of the economy, and in development-oriented, poverty reductionfocused and gender-equitable ways.

The key point is that the concept of Decent Work is fundamentally about the recognition that 'all those who work have rights at work'. Thus, an examination of how to achieve Decent Work necessitates a rights-based approach: in this case to the question of how best to apply labour laws to MSEs.

\section{The aims and goals of this study}

The study has three major aims. The first is to identify States' practices in the application of labour law in MSEs. It explores the extent to which States exclude MSEs from the scope and coverage of labour laws, and whether and how those laws are applied in practice. This is the subject of Chapter 2. The second aim is to consider the impact of the various practices that States have adopted on job quality for MSE workers, and on MSEs themselves. This is the subject of Chapter 3. The third aim is to try to identify solutions that strike the right balance between promoting MSE growth and profitability, while ensuring appropriate protection for workers engaged in the sector. This is the subject of Chapters 4 and 5.

The goal of the study was to explore whether it is possible to develop, apply and enforce labour law that promotes Decent Work in MSEs, while also promoting the increased formalization of MSEs. The findings show that States neither must nor should simply exclude MSEs from labour and labour-related laws in the hope of stimulating growth. Excluding MSEs from the scope and coverage of labour law, or from its application in practice, appears to have had little positive economic impact. This suggests that 'deregulation' of the labour market is not the best way forward: if it has not led to significant positive outcomes, then the role of the State remains more significant than a deregulatory

\footnotetext{
40 Labour Administration Convention, 1978 (No. 150), Labour Inspection Convention, 1947 (No. 81); Social Policy Convention, 1962 (No. 117).

41 Home Work Convention, 1996 (No. 177).

42 Indigenous and Tribal Peoples Convention, 1989 (No. 169).

43 Von Potobsky, 1992, pp. 605-606.
} 
approach might contemplate. In any event, State regulation remains important for the establishment and proper functioning of the markets in which MSEs operate. This includes State regulation of labour conditions.

A key finding is that States can and do adopt innovative regulatory approaches to the application and enforcement of labour laws, that are responsive to the needs of MSEs. This can in fact enhance the process of economic development rather than impede it, because innovative regulation can promote job quality in a way that is adapted (responsive) to the circumstances of MSEs. At the same time, however, innovative approaches to regulation do not require the State to abandon traditional methods of labour regulation in the form of legally binding standards that are enforced: legally binding standards must remain the touchstone of any regulatory system.

A further finding is that the application of labour law to MSEs is not inconsistent with economic growth and development. On the contrary: innovative labour regulation can play a major role as part of a positive regulatory environment for ensuring Decent Work, while helping to promote MSE growth and formalization.

\section{Conclusion}

MSEs offer great promise for economic growth and employment creation. Many jobs in MSEs are however of low quality, in part because many MSEs operate only semi-formally, which in turn limits their ability to improve workers' job quality. MSEs therefore pose significant challenges for State regulation. Many States are or have been under pressure, particularly from the Bretton Woods institutions, to adopt 'deregulatory' approaches to their labour markets, and in particular to the application of labour law to MSEs. Regardless of the Bretton Woods institutions, however, States have adopted approaches to the application of labour regulation to MSEs that reflect their own priorities from time to time; many have acknowledged the cost implications of compliance with labour law by excluding MSEs from some or all labour laws. Some of the approaches that States have taken to the application and enforcement of labour law to MSEs suggest however that they are not likely to be effective at ensuring job quality, higher productivity and growth, or at encouraging MSEs to formalize, which could in turn contribute to higher job quality.

It is both useful and necessary to adopt a broad understanding of what is meant by regulation: there is no simple dichotomy between regulation and deregulation. Rather, States must be prepared to adopt innovative regulatory approaches. Where labour law and labour regulation are concerned, States must also adopt a broad understanding of what constitutes labour law, and might usefully draw inspiration from the rights of workers that are promoted by international labour standards, and the Decent Work agenda. 


\section{CHAPTER 2}

\section{LABOUR AND LABOUR-RELATED LAWS TO MSES}

Chapter summary

- It is important to draw the distinction between the formal scope and coverage of labour law, and the application of labour law in practice.

- Most States have acknowledged the cost implications of complying with some labour laws by formally excluding most MSEs from at least some elements of their labour law framework.

- An important preliminary consideration when examining the formal application of labour law to workers is the scope of the employment relationship. Many workers do not have regular, fulltime work contracts and may, as a result, be automatically excluded from the operation of many labour laws.

- States generally take one of four broad approaches to the scope and coverage of labour and labourrelated laws in relation to MSEs, ranging from full application of labour laws to complete exclusion of MSEs.

- Excluding MSEs from the application of certain labour laws can leave MSE workers with little or no protection for many of their fundamental rights at work.

- A major challenge facing States is the application of labour laws to MSEs in practice.

- Some states have adopted innovative and targeted approaches to the application and enforcement of labour laws to MSEs.

- Innovative approaches to labour regulation in MSEs can contribute significantly to the achievement of a Decent Work agenda for MSEs, while also contributing to their economic growth.

\section{Introduction}

This chapter presents the findings of research into States practices in the application of labour and labour-related laws to MSEs. It deals with two related aspects of the issue: first, the scope and coverage of labour law - whether it applies officially to MSEs - and secondly, the application of labour law to MSEs in practice - whether labour law is enforced and obeyed. Both areas are relevant to 'legal design' or 'regulatory design'. The findings are principally drawn from research into the labour laws of 14 countries, which is presented in detail in a matrix style in Appendix 1.

States have adopted a variety of approaches to the scope and coverage of labour law. Generally, however, States have acknowledged the operational cost implications of complying with some labour laws, by excluding most MSEs from at least some elements of their labour law framework. The findings about the application of labour law in practice are more uniform: it is evident that States face significant challenges in this area. In response, however, a number of States have developed innovative regulatory approaches to achieve the policy goal of the application of labour law.

\section{The scope of the employment relationship}

The nature and scope of the employment relationship is critical to the application of labour law for all workers, whether or not they work for MSEs. It 
is a legal notion that is widely used both to describe, and to regulate, the link between a person called an 'employee' (frequently referred to as a 'worker') and an 'employer' for whom the 'employee' performs work under certain conditions in return for remuneration. It is through the employment relationship, however defined, that reciprocal rights and obligations are created between the employee and the employer. A survey of the relevant laws in more than 60 ILO member States confirmed that labour legislation often only protects those workers who are working within a clearly defined employer-employee relationship. The universal significance and importance of the employment relationship will be discussed at the ILO Conference in 2006 . $^{44}$

The narrow definition of employment based on a formal contract of employment is increasingly problematic. Changes in labour market practices in industrialized economies pose particular challenges for States whose labour laws extend protection only to workers in formal employment relationships. These problems are only more acute in developing economies, and can have the effect of leaving workers without the most basic social protections.

\section{The structure of labour markets}

In many cases the contract of employment is under pressure as a result of changes to the way in which enterprises acquire labour. In many industrialized economies, the range and complexity of work relationships has significantly expanded. This has been a product of a broad trend amongst firms towards vertical disintegration, that is, the breaking up of large, multi-function corporations into smaller units. Where vertical disintegration and changes to labour market changes are occurring, they are frequently a consequence of privatization, or part of the survival strategy employed by companies in previously sheltered industries as they have been exposed to international competition. Thus, the impact of globalization is a factor in bringing about changes to labour market practices, as is the related phenomenon of the growth in supply chains.

This broad trend towards vertical disintegration has resulted in (a) a proliferation of corporate forms and relations, and (b) a proliferation of people who would previously have been employed inside a firm being engaged in alternative ways, including as independent contractors, through labour hire agencies, or as part of their own businesses (thus contributing to the growth in small businesses). These changes have created problems for labour law, which has increasing difficulty in defining an 'employer' and an 'employee'; yet these are the parties between whom the bilateral employment relationship is assumed to have taken place.

The ineffectiveness of the definition of 'employer' and 'employee' often has adverse effects: the worker can be left completely outside the protection afforded by and flowing from the employment relationship. This sort of exclusion can also have a considerable financial impact in terms of unpaid social security contributions and taxes. In the United States, for example, the Treasury Department estimated in 2000 that misclassification of dependent workers (employees) as independent workers resulted in a loss of US\$2.6 billion each

44 ILO, 2005b. This report formed the basis of a discussion at the International Labour Conference in 2006. 
year in unpaid contributions to social security, the healthcare system (Medicare), and the federal unemployment insurance scheme, as well as US\$1.6 billion in income tax. ${ }^{45}$

Changes to labour market practices in industrialized economies are not, however, the only difficulty facing the concepts used by labour law. Labour markets in many developing economies, or particular sectors of them, have long been dominated by smaller, heterogeneous economic units. In these cases, much activity in the labour market has commonly taken forms that could pose challenges for the application of 'traditional' labour law. However, the extent to which this creates significant difficulties for labour law in practice is also affected by the extent to which workers in developing economy labour markets are own-account workers: many of them are unlikely in any event to be captured by even a broad definition of the concept of 'employee'. In the case of developing economies in particular (but also more generally), States can benefit from having access to recent and comprehensive labour market data in developing labour market policy, including policy on the application of labour law to MSEs.

\section{Identifying an 'employee' and an 'employer'}

The term 'employee' or 'worker' is used to refer to a person who performs services in an employment relationship. Frequently the terms 'employee' or 'worker' are defined by reference to a range of factors including dependency, ${ }^{46}$ or in other cases the idea of direction, authority, control or supervision. ${ }^{47}$ The description of these factors varies in wording and level of detail from one legal system to another. In other cases an 'employee' is defined in relation to the definition of the employment contract or relationship. In most jurisdictions, the concept of a worker in an employment relationship is understood as being different from a self-employed or non-dependent worker.

The 'employer' is generally defined as the person who employs the worker or uses the worker's services. The 'employer' is however an under-defined concept compared with the term 'worker' or 'employee', and has generally been understood as 'a corporate person' or single entity. ${ }^{48}$ This is increasingly problematic as new forms of engagement of workers emerge and grow, including engagement through triangular relationships, and the concept of joint employment.

\section{United States General Accounting Office, 2005, p. 76.}

46 See the following Employment Contracts Acts: Argentina, section 21; El Salvador, section 17; Chile, section 7; Panama, section 62; Colombia, sections 22(1), 23(1); Costa Rica, section 18; Nicaragua, section 19; Mexico, section 20; Peru, Productivity and Labour Competitiveness Act, section 4; Venezuela, section 67.

47 See Benin, section 9; Burkina Faso, section 10; Democratic Republic of the Congo, section 7(c); Gabon, section 18; Niger, section 37; Rwanda, section 5; Portugal, section 10; Finland, Chapter 1, section 1; Qatar, section 1; Bahrain, section 38; Tunisia, section 6; Morocco, section 6; Angola, section 53(2)(f); Botswana, section 2; Slovenia, section 4. For definitions of dependent employment in European Union countries, see the comparative table in Pedersini, 20003.

48 Davies and Freedland, 2005. 


\section{The weakness of the contract of employment in unstable enterprises}

Changes in labour market practices, and the contours of labour markets in developing economies have led to major conceptual and practical difficulties in relying on traditional concepts of the employment relationship and traditional means of identifying which workers are 'employees'. The danger in continuing to use them where they no longer function adequately is that workers may thereby find themselves effectively excluded from basic social protections by the operation of these legal concepts. These difficulties are particularly acute for workers in enterprises - including MSEs - that are not well established, and/or which operate wholly or partly in the informal economy. This is because of two related problems: first, it can be difficult to establish the existence of a contractual relationship without documentation (in other words, because of transience and/or informality), and secondly, the flexibility and fluidity of certain labour market transactions challenge the conceptual coherence of the employment relationship.

For a variety of reasons, many MSEs are unwilling or unable to engage workers on long term, fixed employment arrangements. One reason is that MSEs are often constrained by extremely tight financial margins, and peculiarly exposed to shifts in market conditions. Another is that the entrepreneurs who manage MSEs make strategic choices about the most efficient way to acquire labour. Thus, employment in MSEs may often be of short duration. Workers may experience many changes of employer, coupled with a powerlessness to demand access to the rights that flow from employment according to the law. Even where a work relationship resembles a bilateral employment relationship, it can be difficult to prove the existence of a contract of employment in a court of law. Wage slips may not be provided, wages may have been given in-kind or in cash, and the putative employers frequently do not maintain registers and records, even though they may be required to do so. If there are multiple employers or entities that have influence over the worker's activities, or frequent changes of employers, as is the case for casual workers, the problems only increase, as most legal systems do not recognize triangular or multipolar employment relationships.

A common problem is that the employment relationship may be ambiguous or disguised because workers carry out work for multiple persons, or via an agent or representative. In the case of highly casualized labour, workers may carry out small tasks for many people - even in the course of one day. In other cases, the employment relationship may be 'triangular' in nature, that is, the worker is employed by an enterprise (the 'provider') that performs work for a third party (the 'user') to whom their employer provides labour or services. The most wellknown example is that of contractors and workers employed by private employment agencies. Another common arrangement is franchising. In this case, an enterprise allows another enterprise or a person to use its trademark or product, in principle, on an independent basis. However, the franchisee has financial obligations towards the franchisor, which normally exercises control over the franchised business, including its staff.

Workers in triangular relationships may not have trouble establishing their status as employees, but they frequently face difficulties in identifying who is their employer, what their rights are, and who is responsible for them. Employees may not know, for example, from whom to claim payment of remuneration or compensation for an accident at work, and whether they can file 
a claim against the user when the direct employer disappears or becomes insolvent. In some cases, the relationship may be even more complicated than a triangular relationship. In some supply chains, there may be a number of intermediaries acting in between the worker and the 'user'.

The narrow definition of employment based on a formal employment contract is likely to exclude many workers in MSEs from labour law, and therefore from many forms of social protection. This runs counter to most ILO Conventions, which generally refer to 'workers' rather than 'employees' ${ }^{49}$ In particular, this approach is contrary to the ILO Declaration on Fundamental Principles and Rights at Work, which recognizes the fundamental rights of all workers. It is also inconsistent with promoting a Decent Work agenda in MSEs, and with a number of important development goals.

\section{The scope and coverage of labour laws and MSES}

The research findings show that States generally take one of four broad approaches to the scope and coverage of labour and labour-related laws in relation to MSEs.

a) Full application. A few countries make no special provision for MSEs: at a formal level they are subject to all of the labour laws.

b) Selective exclusions. The second approach, adopted by most States, is to promulgate universal labour laws, but exclude MSEs from the application of particular labour standards.

c) Parallel labour laws. The third approach is to exempt enterprises below a certain threshold size from the general labour laws, and to require MSEs to comply instead with a separate, or parallel labour law regime that is less onerous for these enterprises.

d) Complete exemption. Finally, some countries exclude enterprises with a certain number of employees from all labour laws and regulations.

As we have noted, the rationale for these exclusions appears to lie in an acknowledgement of the operational costs for MSEs of complying with certain labour laws. In some cases, however, there may be other reasons for the exclusion. Workplace consultation mechanisms in the area of health and safety, for example, may be thought unnecessary in MSEs, where communication is potentially more frequent and informal than in larger enterprises. Likewise, excluding MSEs from consultation and notification obligations in relation to collective dismissals may reflect the prospects for informal communication within MSEs, as well as a different impact on the labour market from a collective dismissal in an enterprise of five workers, than in one of, say, 500.

The findings presented below, however, are not based on research that sought to identify why in the case of any particular country or any particular exclusion the policy was adopted. In that sense the findings are somewhat raw.

ILO, 2002b, pp. 28, 45. 
Nevertheless, while it is not necessarily clear in each case presented here why States have elected to exclude MSEs from particular aspects of their labour laws, it is possible to gain an overall impression of the extent to which MSEs are excluded from the scope and coverage of labour laws, regardless of the reason behind the policy in any given case. In the next chapter we present findings in relation to workers' job quality in MSEs that suggest that the practice of excluding MSEs from labour laws may have some significant adverse effects for workers.

\section{a. Full application of labour laws to MSEs}

Few countries do not exclude MSEs from at least some labour and labourrelated laws. An example of a country that does not exclude MSEs from the scope and coverage of any labour laws is China, where labour laws and regulations formally apply to all enterprises, regardless of size.

There are at least two possible reasons why so few countries purport to apply labour law to all enterprises, regardless of their size. One is that there is a deliberate policy goal of assisting MSEs by lightening the regulatory load upon them: it is an acknowledgement by the State of the operational costs that would be imposed by having to comply with these regulatory requirements. A second is the recognition that it is unlikely to be possible for the State to ensure the application in practice of all labour law to MSEs.

\section{b. Selective exclusions}

Most labour law regimes discriminate between enterprises of different sizes in some aspect of their labour laws and regulations. Common distinctions relate to occupational health and safety; collective dismissals; formalized internal labour regulations; the right to enterprise-level trade union representation; mandatory social security contributions; and employee consultation mechanisms. Less common exclusions pertain to minimum wage and paid leave entitlements. These common areas of distinction according to the size of the enterprise, and the countries which have adopted such exclusions, are discussed in more detail below.

Most countries explicitly exclude smaller enterprises from the application of specific labour standards through provisions in their general labour laws. Under section 138 of the Vietnamese Labour Code 1995, for example, an employer that employs fewer than 10 employees must still 'provide its employees with the basic rights and benefits stipulated in this Code', but will be considered for a reduction of or exemption from a number of criteria and procedures stipulated by the Government. The Peruvian government, by contrast, has promulgated a specific law for MSEs. This law, however, provides that most of the universal labour standards apply to this sector. Importantly, this Peruvian law that excludes MSEs from specific labour standards is considered transitional, and was adopted to help facilitate the formalization of MSEs during a five year period. $^{50}$

1. Occupational health and safety. In Chile, Denmark, Namibia, South Africa, Tanzania, Thailand, Uruguay and Viet Nam, there are less onerous 
requirements for employee inspection and consultation with respect to occupational health and safety. In Denmark, the requirement for enterprises to establish a safety committee depends upon the size of the enterprise and the industry in which it is located. In general, only enterprises with 10 or more employees must organize a safety committee. In the construction industry, however, a safety committee must be established for every three employees. Where the work is primarily clerical in nature, a committee is only required for 20 employees or more.

In Namibia, section 42(1) of the Labour Act 2004 provides that workers in enterprises with more than 10 employees may elect a health and safety representative. In South Africa, enterprises with 20 workers or more are required to designate a health and safety representative. Moreover, only enterprises with 10 or more workers are required to contribute to workers' compensation insurance. In Tanzania, internal Workers' Committees, which consult and advise the employer on safety conditions, are only required in enterprises employing 10 or more workers. In Thailand, only enterprises with 50 or more employees are required to appoint a fulltime health and safety officer. In most countries in South Asia, micro-enterprises (often with fewer than 5 or 10 workers) lie outside the ambit of legislation on occupational health and safety. ${ }^{51}$

As noted, in smaller enterprises it may not be as obviously necessary for the creation of a formal consultative mechanism for health and safety issues - it might be that there are greater prospects for ongoing and informal communication around health and safety issues. At the same time, however, these sorts of provisions could have a significant adverse effect on workers: conditions of work in MSEs are generally worse than those prevailing in larger enterprises. Simply excluding smaller enterprises from the scope of health and safety consultation obligations may only contribute to continued poor occupational health and safety outcomes, particularly in cases where the possibilities for ongoing and informal communication are not realized.

Table 1: Formal application of occupational health and safety laws and regulations to MSEs

\begin{tabular}{lclc}
\hline Country & Applies to MSEs & Country & Applies to MSEs \\
\hline Brazil & $\checkmark$ & Namibia & $*$ \\
Chile & $*$ & Nepal & $\checkmark$ \\
China & $\checkmark$ & Peru & $\checkmark$ \\
Denmark & $*$ & Philippines & $*$ \\
Hungary & $\checkmark$ & South Africa & $*$ \\
Indonesia & $\checkmark$ & Thailand & $*$ \\
Kenya & $*$ & Viet Nam & $*$ \\
\hline
\end{tabular}

* Obligations vary according to size of enterprise

51 Chandra and Parasher, undated, p. 7. These are generally countries that followed the British Factory Acts model: see Daza, 2005, p. 24. 
While there are significant regulatory challenges in improving the application and effectiveness of occupational health and safety laws among MSEs, ${ }^{52}$ safe working conditions are essential. Moreover, development theory supports the application of occupational health and safety laws to MSEs, and there are examples of innovative regulatory approaches. These include drawing on the resources and responsibilities of public health authorities, as has been done in the Philippines with the involvement of the ILO, and developing systems of regional representation, as has happened in Sweden. These may prove to be better approaches than simply excluding those enterprises with fewer than a threshold number of employees. In this way also States may increase the likelihood that they will be able to develop health and safety regulation that is responsive to the needs of MSEs: in many cases, existing requirements of health and safety laws may in any event be better suited to larger enterprises.

2. Collective dismissals. In Denmark, statutory requirements for advance notice and consultation in cases of large-scale dismissals only apply to companies employing 20 or more employees. In Indonesia, regulations concerning large-scale retrenchment apply to enterprises that terminate the employment of more than 10 workers in the one workplace. In Australia, enterprises with fewer than 15 employees are not required to notify the government employment services when carrying out collective dismissals. Legislation recently enacted in Australia also excludes these enterprises from the obligation to make statutory redundancy payments.

Table 2: Formal application of laws relating to collective (large-scale) dismissals to MSEs

\begin{tabular}{lclc}
\hline Country & Applies to MSEs & Country & Applies to MSEs \\
\hline Brazil & $\checkmark$ & Namibia & - \\
Chile & $\checkmark$ & Nepal & $*$ \\
China & $\checkmark$ & Peru & $*$ \\
Denmark & $\checkmark$ & Philippines & $\checkmark$ \\
Hungary & $*$ & South Africa & $*$ \\
Indonesia & $\checkmark$ & Thailand & $\checkmark$ \\
Kenya & - & Viet Nam & $\checkmark$ \\
\hline
\end{tabular}

* Obligations vary according to size of enterprise

— information not available

Excluding workers from these sorts of laws, however, is likely to be counter-productive. The underlying purpose of notice and consultation obligations is to give employers and employees the opportunity to work together to develop alternative solutions to termination of employment. Simply leaving workers out of the process means that employers are denied the possibility of discovering an innovative way of restructuring the business to avoid terminations of employment. Workers are also harmed by these sorts of laws, which are antipathetic to fostering workplace participation and skills.

52 For a discussion of the challenge of regulating occupational health and safety in MSEs see Lamm and Walters, 2004, p. 154. 
Here it appears that States should develop a regulatory approach that is more responsive to the particular circumstances of both MSEs and those who work within them. Excluding MSEs from the requirement to notify government authorities in advance of collective dismissals may only reflect common sense, given the scale of the enterprises. It does not necessarily follow, however, that MSEs should be excluded from obligations to notify and to consult with their workers who will be affected by such a decision. Nor does it follow that MSEs should simply be excluded from, for example, statutory severance pay requirements. Or, where that approach is adopted, States might consider providing protection for workers through the social security system. This sort of approach might better balance the need to limit regulatory costs on MSEs, without unduly removing protection for workers.

3. Freedom of association and collective bargaining. Legal frameworks for the registration of trade unions, and also for the process of collective bargaining, typically contain provisions that specify that a union must have a minimum membership either in order to form and to register, and/or in order to be able to engage in collective bargaining. In those countries in which unions are formed and registered at the level of the enterprise, these requirements can prove to be a significant obstacle to workers' exercising their right of association.

In Kenya, employees working within enterprises with at least seven employees have the right to form or join unions of their choice. ${ }^{53}$ In Thailand, the Labour Relations Act 1975, which governs labour relations in the private sector and specifies workers' rights in relation to the establishment of trade unions, does not apply to workers in enterprises with fewer than 10 employees. ${ }^{54}$ Chile, Indonesia and Nepal all impose a minimum number of employees able to form an enterprise-level trade union. In Chile, the minimum number is eight members and in Indonesia and Nepal, the minimum threshold is 10 workers. ${ }^{55}$ As noted, the minimum membership requirement may determine whether or not a union may be registered. It may also determine whether or not a union is empowered to engage in collective bargaining. In Peru, for example, a union must represent at least 20 workers before it can be recognized as an official agent for collective bargaining purposes.

Generally speaking these requirements are intended to ensure that trade unions are viable and representative. These are of course important policy goals. However the rules can also have the effect of excluding significant numbers of workers from the exercise of one of the fundamental labour rights: the freedom of association. These sorts of limitations in practice are all the more problematic given the general trend throughout the world towards the decentralization of collective bargaining. ${ }^{56}$ In that light it may be unlikely that developing States will adopt legal frameworks for trade unions other than at the enterprise level. There

\footnotetext{
53 Bekko and Muchai, 2002.

54 Brown, Thonachaisetavut and Hewison, 2002, p. 9.

55 In Indonesian enterprises with fewer than ten workers, workers are represented by the local manpower office. In Nepal, workers in enterprises employing fewer than ten workers, or workers in the informal sector may form a trade union as article 4 of the Trade Union Law 1993 states that 500 workers of the same industry or occupation from different enterprises or self-employed can establish a national level trade union.
}

$56 \quad$ ILO, 2004a, p. 63. 
are, however several innovative regulatory approaches that States might adopt to promote the exercise by workers of their right to form and join trade unions. These include information and awareness campaigns, and efforts to assist unions to organize workers in MSEs and also in the informal economy.

Table 3: Formal application of freedom of association and collective bargaining laws to MSEs

\begin{tabular}{lclc}
\hline Country & Applies to MSEs & Country & Applies to MSEs \\
\hline Brazil & $\checkmark$ & Namibia & $\checkmark$ \\
Chile & $*$ & Nepal & $*$ \\
China & $\checkmark$ & Peru & $*$ \\
Denmark & $\checkmark$ & Philippines & $\checkmark$ \\
Hungary & $\checkmark$ & South Africa & $\checkmark$ \\
Indonesia & $*$ & Thailand & $*$ \\
Kenya & $*$ & Viet Nam & $*$ \\
\hline
\end{tabular}

* Obligations vary according to size of enterprise

4. Formalized internal labour regulations and reporting requirements. It is common for labour laws to exempt MSEs from the requirement to have written and registered internal regulations specifying the rights and obligations of employers and employees. This is the practice in Chile, India, Indonesia, Viet Nam and Thailand. In Viet Nam, only enterprises with 10 or more employees are required to have 'internal labour regulations' in writing and registered (Labour Code article 82). In Thailand, only enterprises with 20 or more employees are required to form an 'Agreement relating to Conditions of Employment' (Labour Relations Act 1975 section 10). Only enterprises with 10 or more employees are required to formalize 'work rules' and to submit a copy of these rules to the Director General of the Department of Labour Protection and Welfare (Labour Protection Act 1998 sections 108-111). In Chile, enterprises with fewer than 5 workers are exempt from the general obligation to maintain a consolidated registry of remuneration for their employees. They are, however, required to have a registry of hours worked. ${ }^{57}$

Where record-keeping is concerned, a number of other labour law regimes provide exemptions for smaller enterprises. In India the Labour Laws (Exemption from Furnishing Returns and Maintaining Register by Certain Establishments) Act 1988 simplifies the documentation and declarations on wages that 'small enterprises' (10-19 employees) and 'very small enterprises' (up to nine workers) must submit to the labour authority. ${ }^{58}$ Also in India, the Industrial Employment (Standing Orders) Act 1946, which requires Standing

57 Reinecke, 2005, p. 2.

58 Under this law, enterprises that employ between 10 and 19 employees are only required to submit one core return and maintain 3 registers in relation to 9 Acts. Microenterprises (employing no more than 9 persons) are only required to submit a core return and maintain 2 registers. See Chandra and Parashar, undated, pp. 20-21. 
Orders in each enterprise to specify service conditions to workers, only applies to enterprises with more than 100 workers. ${ }^{59}$ In Thailand, only enterprises with 10 or more employees are required to maintain accurate employee records and to make these available to labour inspectors on demand (Labour Protection Act 1998 sections 112-115).

Formalization of working conditions and their recording is an important way of developing and maintaining fair minimum working conditions. It is also an important way of ensuring that workers are aware of their rights within a workplace. Requirements to keep records are important for protecting workers, and in particular for facilitating enforcement of working conditions, whether directly by workers, by trade unions on their behalf, or by the labour administration. Excluding MSEs from these sorts of requirements therefore runs the risk of limiting the extent to which workers are protected by labour law. At the same time, however, this sort of exclusion can be seen as an attempt to be responsive to some of the needs of MSEs. In particular, it acknowledges that their smaller scale may limit their ability to develop and sustain internal administration mechanisms to comply with these requirements.

What the policy of exclusion lacks, however, is a balance that would nevertheless find a way to assure workers of the protective purpose of the laws that generally require employers to formalize certain matters and to keep records of them. Better tailored regulation might, for example, draw on trade unions and other representative organizations to fulfil these laws' functions of informing and protecting workers. Or, the State might promulgate model internal labour regulations, and/or deem them to have been adopted by certain enterprises. In that way workers would be protected, while enterprises would be relieved of a regulatory burden.

5. Social security. A 2005 ILO report found that exclusions from the scope of social security provisions can be found in fewer than 10 per cent of ILO member States. ${ }^{60}$ There are however some important examples of States that exempt enterprises below a certain threshold from the application of social security provisions. In Indonesia and Viet Nam, the compulsory social insurance scheme only applies to enterprises with 10 or more employees. In Jordan, the Social Security Law No. 19 (2000) is limited in coverage to enterprises with five or more employees. ${ }^{61}$

59 Chandra and Parashar, undated, pp. 19-20. The states of Karnataka, West Bengal, Gujarat and Tamil Nadu have amended this general law to increase its application to all enterprise with more than 50 workers.

60 Daza, 2005, p. 24.

61 Allal, 2003, Chapter XI, p. 2. 
Table 4: Formal application of social security laws and regulations to MSEs

\begin{tabular}{lclc}
\hline Country & Applies to MSEs & Country & Applies to MSEs \\
\hline Brazil & $\checkmark$ & Namibia & $\checkmark$ \\
Chile & $\checkmark$ & Nepal & $*$ \\
China & $\checkmark$ & Peru & $\checkmark$ \\
Denmark & $\checkmark$ & Philippines & $\checkmark$ \\
Hungary & $\checkmark$ & South Africa & $>10$ for workers \\
Indonesia & $>10$ & Thailand & $\checkmark$ \\
Kenya & $\checkmark$ & Viet Nam & $>10$ \\
\hline
\end{tabular}

* Obligations vary according to size of enterprise

The ILO Social Security Department has identified two broad strategies for extending social protection to the informal economy: gradually expanding the compulsory coverage of formal systems through the removal of restrictions; and the development of innovative, group-based self-financed schemes. ${ }^{62}$ It should be emphasized that models to extend social security through local or voluntary schemes should be seen as complementary to basic social security provided by the State, not as substitutes. ${ }^{63}$

6. Employee consultation. MSEs are frequently excluded from the operation of laws that provide for the establishment of employee consultation mechanisms, such as works councils. As with the exclusion of MSEs from statutory notification requirements in relation to collective dismissals, this sort of exclusion can have a significantly adverse effect on both workers and enterprises. A few specific examples can illustrate the general point. This is however an area in which innovative regulatory approaches are necessary; both trade unions and States have developed such approaches.

In Indonesia, only an enterprise that employs 50 or more workers must establish a 'bipartite cooperation institution', consisting of employer and worker representatives, to function as a forum for communication and consultation on labour issues within the enterprise. ${ }^{64}$ In Hungary, employee consultation mechanisms, such as works councils, are only required for establishments with more than 15 employees. ${ }^{65}$ In South Africa, a 'workplace forum', intended to

\footnotetext{
62 ILO, 2000a, p. 11.

63 This is emphasized by Kannan in his discussion of Welfare Funds in India. Kannan, 2002.

64 President of Republic of Indonesia Act No. 13, 2003 concerning Manpower, article 106.

65 Labour Code Act No. 22 of 1992, section 43.
} 
deal with non-wage matters and to promote employee participation, only need be established in a workplace with more than 100 employees. ${ }^{66}$

In Denmark, where employee consultation mechanisms are determined by agreement between the two major social partners rather than by statute, provision has been made for different types of employee consultation mechanism depending on the size of the enterprise. In enterprises with five or more employees, workers are entitled to elect a shop steward. In enterprises with more than 35 employees, workers are entitled to establish a 'cooperation committee' (samarbejdsudvalg). Where there are between 35 and 50 employees, this committee consists of two employee representatives and two management employees. Where a cooperation committee is not established in enterprises with 35 employees or more, the Cooperation Agreement between the Danish Confederation of Trade Unions and the Danish Employers Confederation recommends that consultation meetings be held frequently. ${ }^{67}$ The Danish example suggests that innovation is possible, in particular by tailoring the legal requirements to the differing sizes of enterprises. However even in this case the threshold is no lower than five employees, which would exclude a significant proportion of workers in many MSEs.

Table 5: Formal application of employee consultation laws and regulations in MSEs

\begin{tabular}{lclc}
\hline Country & Applies to MSEs & Country & Applies to MSEs \\
\hline Brazil & $*$ & Namibia & $*$ \\
Chile & $*$ & Nepal & $>10$ \\
China & $\checkmark$ & Peru & $*$ \\
Denmark & $*$ & Philippines & $\checkmark$ \\
Hungary & $>15$ & South Africa & $>100$ \\
Indonesia & $>50$ & Thailand & $*$ \\
Kenya & - & Viet Nam & $\checkmark$ \\
\hline
\end{tabular}

* Obligations vary according to size of enterprise

— Information not available

Note: In Nepal, employee consultation mechanisms apply to enterprises of all sizes in industrial areas.

As we have noted in relation to occupational health and safety, and also collective dismissals, there may be some sound reasons for excluding MSEs from some types of consultation mechanisms. Certainly findings referred to elsewhere in this study suggest that labour relations in MSEs are frequently informal. If that is so, then it might be assumed that formal consultation mechanisms would be unnecessary, quite apart from the costs that might be imposed by requiring MSEs to establish them. Once again, however, States might do better in balancing the various objectives of labour market policy by

66 Labour Relations Act of 1995 section 80(1). For the 'general functions' of a workplace forum, see section 79 of the Labour Relations Act of 1995.

67 Jørgensen, 2003. 
finding means to relieve MSEs as well as to protect workers at the same time. A greater role for information and consultation through representative organizations and services from beyond the workplace may prove to be a fruitful source of regulatory innovation.

7. Minimum wage. In some cases, MSEs are formally exempt from the application of a national minimum wage, or may have a lower minimum wage than larger enterprises. The regional minimum wage for MSEs in the Philippines is often set at a lower rate than that applicable to larger enterprises. ${ }^{68}$ The Barangay Micro Business Enterprise Act (Republic Act No. 9178) 2002, enacted to facilitate higher productivity in the MSE sector, exempts eligible enterprises from payment of the minimum wage, providing that they conform to other legislated labour laws and regulations.

Table 6: Formal application of minimum wage laws and regulations to MSEs

\begin{tabular}{lclc}
\hline Country & Applies to MSEs & Country & Applies to MSEs \\
\hline Brazil & $\checkmark$ & Namibia & $*$ \\
Chile & $\checkmark$ & Nepal & $\checkmark$ \\
China & $\checkmark$ & Peru & $\checkmark$ \\
Denmark & $*$ & Philippines & \# \\
Hungary & $\checkmark$ & South Africa & $*$ \\
Indonesia & $\checkmark$ & Thailand & $\checkmark$ \\
Kenya & $\checkmark$ & Viet Nam & $\checkmark$ \\
\hline
\end{tabular}

* Obligations vary according to size of enterprise

\# Microenterprises are exempt from the minimum wage provided they comply with other labour standards.

In some countries without a national minimum wage, minimum wages may be set at the industry level. In South Africa, for example, there are two ways in which enterprises may be bound to observe a minimum wage. Firstly, a collective agreement determined by a sectoral bargaining council may be extended by the Minister of Labour to apply to non-signatories in an industry where the parties to the original agreement are deemed to be sufficiently representative of the industry. Secondly, in areas not covered by bargaining councils, the Employment Conditions Commission may make 'sectoral wage determinations' for certain industries. In making such determinations, the Commission will consider sectoral and regional conditions. ${ }^{69}$

Setting and payment of wages are issues of the highest order for workers, whether or not they work for MSEs. Wage levels are critical for ensuring that

Wage Order No. RB05-10 Providing for New Minimum Wage Rates in Region-V. The minimum wage rate is lowest for enterprises employing no more than 10 workers and increases according to whether the enterprise employs 11-15 workers or more than 15 workers.

69 Du Toit et al., 2003, p. 227 and Hayter, Reinecke and Torres, 2001, pp. 82--83. 
workers and their families are able to avoid poverty, especially in environments in which there is limited social safety protection beyond remuneration for paid work. Wage levels also can have an important effect on overall demand within the economy, leading in turn to stimulation for further growth. For all these reasons, care must be taken in deciding whether and if so how to exclude MSEs from wage-setting provisions of labour laws.

8. Other specific exemptions for MSEs. Other specific exemptions for MSEs from labour and labour-related laws include:

- Exclusions from paid leave requirements: in the Philippines, retail and service establishments regularly employing fewer than 10 workers are not required to provide their employees with paid regular holidays. In Nepal, enterprises with fewer than 10 employees are not required to pay annual or sick leave.

- Regulation of working hours and overtime: In South Africa, enterprises with fewer than 10 workers are limited to a maximum of 15 hours overtime a week. This is in contrast to the general standard of 10 hours a week. In addition, the rate of payment for overtime work is reduced from 'time and a half' to 'time and a third'. ${ }^{70}$

- Provision of health care services: In Chile, enterprises with fewer than 21 females are exempt from the general requirement for enterprises to provide child care services or to arrange for external provision of this service.

- Maternity leave entitlements: In India, the Maternity Benefit Act 1961 only applies to establishments employing 10 or more workers. ${ }^{71}$

\section{c. Parallel labour laws for MSEs}

The third approach to the design of labour laws for MSEs is to promulgate a specific labour law regime for MSEs, that imposes less onerous standards. Nepal and Brazil are two countries that have recently adopted parallel labour regimes for MSEs. They also exempt MSEs from legislation requiring enterprises to share a proportion of profits among their workers. The difference here from other approaches is, in essence, that all relevant provisions and exemptions are brought together into a specific law that addresses the particular topic of labour law and MSEs, instead of exemptions or exclusions appearing in various different laws.

In Nepal, the Labour Act 2048 only applies to enterprises employing 10 or more workers. ${ }^{72}$ The Act also contains a provision specifically enabling the enactment of a special regulatory regime for MSEs. The following statutory regime, which has only six articles (in contrast to over 90 articles in the general Labour Act 2048) and requires MSEs to comply only with only five basic minimum conditions, has been enacted pursuant to this provision:

70 Basic Conditions of Employment Amendment Act No. 122, 2002, section 50(1).

71 Chandra and Parashar, undated, p. 21.

72 An exception to this is enterprises located in industrial areas, which are covered by the Labour Act 2048 regardless of the number of employees. 
In Brazil, a 1999 law applies a simplified and distinct legal regime to MSEs. ${ }^{73}$ This law is enacted pursuant to constitutional provisions that guarantee MSEs 'differential legal treatment' and 'distinct and favoured judicial treatment' with the purpose of promoting MSEs through the provision of simplified administrative, tax, credit and social welfare regimes. ${ }^{74}$ The 1999 law provides MSEs with a distinct legal regime in relation to administration, taxation, social security, labour, credit and business development.

Promulgating a parallel labour law regime for MSEs could have one advantage in particular over the approach of exempting MSEs from specific requirements. That is, it may offer the opportunity to devise an approach to the application of labour law in MSEs that is comprehensive. Obviously it will not be comprehensive in the application of labour laws to MSEs. Rather, it will be comprehensive in the sense that it may represent a complete settlement of the policy issues to be resolved where the application of labour laws to MSEs is concerned. It might therefore prove to be more appropriate and effective than an approach in which MSEs are excluded on a case-by-case basis from particular regulatory requirements. At the same time, however, States will only be able to address the issue from within their particular legal framework and tradition. In civil law countries, for example, it may be more difficult to establish a distinct law on the topic than it is in common law countries.

\section{d. Complete exemption of MSEs from all labour laws}

The fourth and final approach to the scope and coverage of labour laws in relation to MSEs is to exempt enterprises with a certain number of employees from labour regulation entirely. This approach is rarely adopted: a 2005 ILO report noted that only 10 per cent of the 178 ILO member States had legislated provisions that excluded MSEs from the general application of labour law. ${ }^{75}$ In Kuwait, article 3(f) of Law No. 38 of 1964 concerning Labour in the Private Sector excludes 'owners of non-mechanical minor business concerns, normally employing less than five labourers' from the operation of the Act. In Costa Rica and Honduras, the labour laws exempt agricultural or livestock farms which permanently employ no more than five and 10 employees respectively. Article 14 of the Costa Rican Labour Code proceeds to note 'the Executive may determine by decree which rules of this Code will continue to apply to them. In this respect, these will be primarily those which do not involve a serious economic burden to employers'. Tanzania and Pakistan also both exempt enterprises with fewer than 10 workers from national labour laws. ${ }^{76}$

73 By Laws of Micro Enterprises and Small Companies (Law 9841), 5 October 1999. See also Law 9317, 5 December 1996.

74 Constitution of the Federative Republic of Brazil 1988, articles 170, 179.

75 Daza, 2005, pp. 23-24.

76 Dyring Christensen and Goedhuys, 2004, p. 6. 
Legal Provisions Applicable to Industries as well as Enterprises Related to Transport Services Employing less than Ten Workers or Employees 17/12/2049 (Nepal) ${ }^{77}$

1. Issue of appointment letter

An employer must issue an appointment letter. This letter must specify the date of appointment, the status of the office and the salary payable.

\section{Payment of minimum wages}

An employer must pay the minimum wage as determined by His Majesty's Government under section 21 of the Labour Act 2048.

\section{Working hours}

An employer must not employ a worker or labourer for more than eight hours a day and forty-eight hours a week. Overtime employment should be paid at the rate of one and a half of the normal salary calculated at the hourly rate.

\section{Holidays}

An employer must provide one day a week holiday and 13 days a year as paid national holidays. A person who has continuously worked for one year shall also be given half paid fifteen days a year sick leave.

\section{Health security}

An employer must secure the health and safety of the worker and employee at the time of employment. An employer shall not make a worker carry any load or make him do any other physical work which will pose a threat to his health or cause injury. An employer shall have to bear the entire medical expenses for treatment of the injury caused during the course of employment.

6. Additional special provision for transport workers

Transport workers are entitled to the following additional benefits:

6.1 trip allowance;

6.2 allowance (50 per cent of salary) while the vehicle is not in operation due to maintenance or due to not

having a call in the queue system;

6.3 accident insurance;

6.4 provision of first aid box in the vehicle; and

6.5 prohibition of use of alcohol by transportation worker until the vehicle reaches its final destination.

\section{Pitfalls in excluding MSEs from labour laws}

There are a number of problems that are characteristic of the above approaches to the scope and coverage of labour laws in relation to MSEs.

\section{Pitfall 1: Excluding MSEs from the application of certain fundamental labour rights}

Excluding MSE workers from the application of certain labour standards can leave them without protection for many of their fundamental rights at work. There is a clear tension between such approaches and the principle of nondiscrimination that should guarantee equal rights for all workers. ${ }^{78}$ The fact that the capacity of workers in MSEs to form trade unions is significantly impaired by the operation of minimum membership requirements for the formation of trade unions - particularly in systems of enterprise unionism - is also problematic. It should be recalled that ILO Convention No. 87 declares the right

77 Reproduced from Shakya, 2004, p. 10.

78 Reinecke, 2005, p. 3. 
of workers and employers, without distinction whatsoever, to establish and, subject only to the rules of the organization concerned, to join organizations of their own choosing without previous authorization.

Previous work in this area by the ILO has stressed the significance of excluding workers from fundamental standards. Von Potobsky, for example, has noted that the level at which a threshold is set has significant implications in terms of the number of enterprises, and therefore the number of workers that are excluded from the basic standards. ${ }^{79}$ Reinecke and White have also noted that exclusions from fundamental standards can amount to exclusion from hard-won social gains. ${ }^{80}$

\section{Pitfall 2: Over-complex and conflictive labour laws}

The labour law regime in India exemplifies the tendency of voluminous and complex labour laws to increase the transaction costs of compliance for MSEs. A study of labour laws applicable in the Indian state of Uttar Pradesh found that there were 38 central laws and 10 state laws with which enterprises were required to comply. Not only were employers often faced with large numbers of Acts, but it was found that the same words within different Acts might carry different meanings. Employers' organizations often complained that '...they have to maintain too many registers, file too many returns and face too many inspections' ${ }^{81}$ In the face of this 'cacophony of labour laws', small employers are often required to pay significant fees for legal advice. The absence of an integrated and simplified approach to labour laws increases the transaction costs for employers and, as Chandra and Parasher note, may lead small enterprises to conclude that the cost of compliance appears to be greater than the cost of violating the law.

\section{Pitfall 3: Failure to communicate applicable laws to MSES}

It is clear from the experience of Nepal that simplification of labour laws is not sufficient in itself to lead to increased compliance. The Nepalese MSE labour law regime, reproduced above, should be approached with caution as it appears to constitute a significant lowering of standards for the MSE sector. This notwithstanding, the simplified regime appears not to have had any discernible effect on increasing the level of protection enjoyed by MSE workers. In a study of the Nepalese MSE sector, Shakya has noted that the level of awareness among employers of the specific labour regime applicable to them was extremely low. ${ }^{82}$ Similarly, in Peru, despite the existence of a simplified and less onerous parallel labour regime for microenterprises, compliance with labour laws and regulations in the MSE sector remains low. ${ }^{83}$

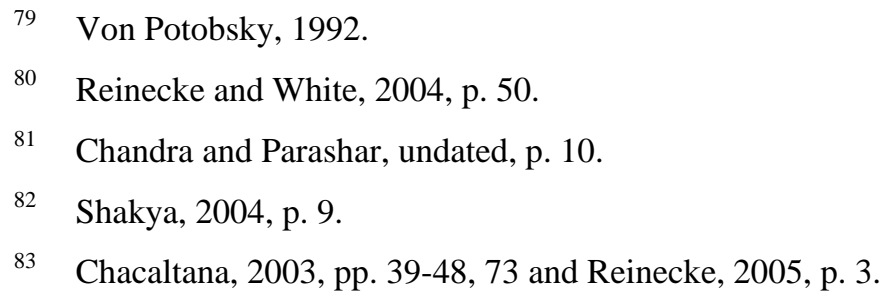




\section{Pitfall 4: Perverse incentives, and long-term costs}

A policy of exclusion for MSEs proceeds from the assumption that it will relieve MSEs of regulatory burdens they are ill-equipped to bear, and which act as unnecessary fetters on their potential for growth. That the majority of States examined for this study exclude MSEs from a large part of their labour law regimes suggests that there are real concerns about the operational cost implications of MSEs having to comply with labour laws. The policy of exclusion of enterprises below a threshold number of employees is not, however, without risk or cost.

A significant risk is the possibility of creating a 'growth trap': a policy provision that has precisely the opposite effect, and acts as a disincentive to further growth. If, for example, all enterprises that engaged fewer than ten workers were excluded from the operation of all labour law (as in Pakistan), then what would be the incentive for an enterprise to engage a tenth worker? At that point, the cost for entry to the formal labour law regime would be far greater than the wages and other costs associated with the tenth worker. Rather, it would be all of those costs, together with the additional costs incurred under the labour law in respect of the first nine workers as well. Frequently these costs would be so significant that it may make more economic sense for the entrepreneur/enterprise to remain below the threshold.

Faced with this disincentive to grow, and to become more formal, an enterprise may respond in ways that are inconsistent with the promotion of a Decent Work Agenda. They may, for example, have (further) resort to acquisition of labour through other means, such as use of casual labour, or labour-hire arrangements. Or, they may refuse to engage workers on standard employment contracts (whether under the common law or otherwise) and instead insist on structuring their contractual arrangements for the engagement of workers under contracts for services: that is, their workers may be 'independent contractors' ${ }^{84}$

The possibility of a growth trap problem is not only significant in its potential impact on particular firms and enterprises. It is potentially a problem at a much deeper level, with the possibility of doing far more harm than good in the longer run. This is because of the strong links between lower productivity in smaller enterprises and lower income in developing economies where there is a preponderance of smaller enterprises. It is generally true that smaller enterprises are less productive. This necessarily means that they, and those who work for them, have lower incomes. It is also generally true that developing economies are dominated by smaller enterprises. It follows that income inequality between developing and industrialized economies is structural. Therefore a policy that effectively creates an incentive for smaller enterprises to remain small could have a very significant counter-productive impact in a developing economy, of further entrenching structural income inequality.

Another way of putting this is to keep in mind the difference between shortrun and long-run costs. Excluding MSEs from labour laws is a policy that responds to their inability to meet certain short-run or operational costs. The risk, however, is that this will result in a significant long-run costs for the economy 
overall. This can come about because enterprises do not grow, do not become more productive, and do not create more quality jobs. So to put it another way, the policy of excluding MSEs from labour laws comes with a significant opportunity cost at the national level. Of course acknowledging this does not mean that the national or macro-level cost must be re-allocated directly to the micro-level enterprise. What it does mean, however, is that the broader field of costs and benefits must be considered in devising policy.

In considering the costs and benefits for MSEs themselves, States might also reconsider the use of bare numerical thresholds as a basis upon which to exclude MSEs from the application of some or all labour law, as such a rule can have market-distorting effects. Chandra and Parashar carried out a study in India that found that many MSE owner/entrepreneurs considered such exclusions to create unfair competition: those below the threshold are able to operate with artificially low labour costs. ${ }^{85}$ Thus there is a deeper problem with excluding MSEs from the application of some labour laws: it can tend to contribute to broader opposition to the application of minimum standards, as entrepreneurs on the 'wrong' side of the threshold agitate for a level playing field with their smaller, less efficient competitors who are nevertheless successful because they are not obliged to comply with basic labour laws. Chandra and Parashar also argue that a further adverse side effect of such thresholds is the temptation to engage in corruption: some employers are tempted to bribe officials in relation to their own failures to comply with labour laws, rather than to comply with them in practice.

Another significant issue that States need to address is the extent to which MSEs can and do comply with applicable laws. As noted, many MSEs do not comply with relevant legal aspects of the regulatory framework, whether labour law or otherwise. On the one hand, continuing to exclude them from the application of particular provisions might compound a culture of non-compliance where it already exists. On the other hand, States cannot simply change the scope and coverage of labour laws in the face of such a culture, and assume that it will change as a result. Hence States must develop innovative and responsive regulatory approaches that include, but are not dependent only upon the application of labour laws.

\section{The application of labour laws to MSEs in practice}

Whatever their scope and coverage, labour laws will have only a negligible impact on working conditions and labour standards if they are not effective in practice. ${ }^{86}$ A perennial challenge posed by the MSE sector, however, is the widespread lack of compliance with labour laws and regulations. Monitoring and enforcement of minimum labour standards in the MSE sector are complicated by their nature as small, discrete and numerous economic units, their geographical dispersion, and their tendency to informality. They are only further compounded

\footnotetext{
85 Chandra and Parashar, undated, pp. 24, 35.

86 Somewhat curiously, it appears that relatively little research has been done on differing levels of compliance within different economic sectors. An exception is a survey in Santiago, Chile which found that employers in four sub-sectors differed in their claims to comply with labour laws. Wormald and Rozas, 1996, pp. 61, 83.
} 
by the proportion of own-account workers, and the difficulty of distinguishing them from those to whom labour law ought to apply. Regardless of these 'structural' difficulties, positive outcomes for the application of labour law can be further constrained by laxity in enforcement of labour standards by State authorities. It is however observed in all developing States and in most developed ones.

The responsibility for addressing these various challenges lies in the first instance with State systems of labour administration, meaning all public administration bodies responsible for and/or engaged in labour administration. This includes ministerial departments, public agencies including regional and local agencies, and any institutional framework for the coordination of such bodies and for consultation with and participation by employers and workers and their organizations. ${ }^{87}$ Moreover, it is of some note that article 7 of Convention 150 on labour administration provides that States should, where necessary, extend the functions of the labour administration to cover those workers who are not in an employment relationship. In addition to the extension of State functions, monitoring of labour standards may also be carried out by trade unions, by corporations through corporate codes of conduct, and by nongovernmental organizations ('NGOs'). As this description of the relevant actors suggests, States both can and must work with a range of other parties to promote and ensure application of labour law.

\section{Obstacles to application of labour law to MSEs in practice}

There are many factors that shape the extent to which State labour administrations achieve satisfactory outcomes in the enforcement and application of labour law to MSEs. Some of these are matters of administrative policy, including choices made in enforcement policy. Other relevant factors are better understood as constraints around which the State administration must work. These include, in some cases, lack of resources, and the wider legal climate within which the State must carry out its function, which may not lend itself to compliance with the law.

Even where labour laws formally apply to MSEs, State authorities may overlook or ignore enforcement in this sector. In Thailand, for example, a 1999 ILO/UNDP report concluded that 'the Royal Thai Government, at all levels, appears to recognize, accept and (indeed) allow the MSE sector not to comply with all of its regulations'. ${ }^{88}$ In the context of Indonesia, Patrick Quinn has observed:

Whilst some see the role of Government as being too interventionist, there is also criticism that despite having a broad regulatory framework, many employment laws are routinely ignored, and that the Ministry often seems unable or unwilling to enforce legal provisions. For example, there is widespread concern on the part of trade unions that little is done to ensure compliance with minimum legal standards, such as those relating to the social security scheme. ${ }^{89}$

White, 1999, p. 58.

89

Quinn, 2003, p. 5.
} 
In addition, however, State authorities often selectively enforce some laws whilst ignoring breaches of others. This approach may effectively leave workers in the informal economy with little or no protection. At the same time, arbitrary application of the law can lead to unpredictable indirect costs to the enterprise.

Where States deliberately overlook or neglect the application of labour law to MSEs, this might be thought of as an administrative practice that is equivalent to excluding MSEs from the formal scope and coverage of labour laws. This, however, is doubly problematic. Firstly, it appears that some States pursue this approach over and above the extent to which MSEs are already excluded from the scope and coverage of labour laws. Secondly, there are significant challenges for good governance when administrative authorities determine that they will not apply those laws that the legislature has identified as necessary for application to MSEs.

The willingness of State officials to pursue those who fail to comply with the law may be influenced by many factors, and some of the pressures on officials may conflict. In particular, some imperatives may suggest it is better to ignore breaches of labour laws, as for example in order to attract external finance for employment and economic growth. ${ }^{90}$ This is identified as a common problem in China, where provincial and district-level officials are said to have ignored labour standards so as to attract FDI and create more jobs. ${ }^{91}$

The discretion that local authorities have under the terms of labour laws may also lead to non-observance of minimum labour standards. Local State authorities in China and Southeast Asia often have wide discretion to administer the national labour laws and regulations. Articles 36 and 37 of the Chinese Labour Code 1995, for example, provide for an 8 hour work day and a 44 hour work week. An enterprise that cannot comply with this standard 'due to the special nature of its production' may however apply to the administrative department of labour for an extension of this limit. In several districts of Guangdong province, firms are able to extend working hours well beyond this maximum by obtaining permission from the local authorities. The Vietnamese Labour Code 1995 provides that enterprises with fewer than 10 employees must provide their employees with the 'basic rights and benefits as stipulated in this Code', but then notes that such enterprises will be considered by government for a reduction of or exemption from a number of criteria and procedures. ${ }^{92}$

There are many obvious dangers with labour laws giving this sort of administrative discretion to State authorities without appropriate guidance as to how it is to be exercised. Firstly, there is the possibility of inconsistent - and indeed discriminatory - application of the enforcement power. This is incompatible with a Decent Work approach, which stresses the importance of rights at work for all who work. Secondly, there may be a risk of corruption. Therefore, where administrative discretion in law enforcement is given to local level authorities, it is best to ensure that there are clear criteria to guide its exercise.

Cooke, 2005, pp. 33-34.

91 Frenkel and Kuruvilla, 2002, pp. 387, 400.

$92 \quad$ Labour Code 1995, section 138.
} 
Even where the State administration has the clear will to enforce labour laws in MSEs, and is doing so within a legal framework that is suited to the task, basic practical problems may impede progress. In many countries, widespread violations of minimum labour standards are in part a product of the lack of adequate resources available to support inspection and enforcement mechanisms. Labour administrations, particularly in developing countries, often lack the personnel, equipment, skills and training to ensure effective implementation of labour laws and regulations. ${ }^{93}$ In Kenya, for example, Bekko and Muchai found that resource and personnel constraints on the Directorate of Occupational Health and Safety meant that in practice it can only afford to visit medium and large enterprises. ${ }^{94}$ As empirical evidence suggests a strong correlation between MSE compliance with regulations and the number of inspections made by authorities, the limited capacity of labour administrations to inspect enterprises clearly has a negative impact upon job quality in this sector. ${ }^{95}$

There are other problems that may be associated with resource deficits or wider difficulties emanating from the legal and administrative culture. These include deliberate action by entrepreneurs to frustrate the efforts of the labour administration to carry out its role. In China, for example, firms are known to undermine the work of labour inspectors by producing false documentation and coaching workers to indicate compliance with the law. ${ }^{96}$ High levels of corruption may also undermine State systems of labour inspection. ${ }^{97}$

More broadly, practical deficiencies in implementing formal laws and regulations in developing countries may often be exacerbated by the weak status of law in general. In the most extreme cases - in places where the law has been suspended, or basic freedoms abrogated, for example during civil strife or constitutional crisis, or under the rule of non-democratic regimes - the confidence of the population in the entire legal system may be significantly diminished. Where that happens, the ability of the State to rely on legal means to achieve any social policy outcome, including the application of labour law to MSEs, is significantly impaired.

In other circumstances, cultural or political influences may reduce the regulatory strength of labour law. Cooney and Mitchell have emphasized the way in which law in East Asia often has little capacity to significantly influence other social systems, such as the State or the market. ${ }^{98}$ State authorities, for example, often do not distinguish between labour law and labour policy. A further crucial implication of this structural weakness of law is that labour markets in many developing countries, including China and Viet Nam, often appear to operate

93 In 2001 in Thailand, for example, each labour inspector was responsible for approximately 1,000 establishments, each health and safety inspector was responsible for approximately 1,680 establishments, while labour relations officials were each responsible for around 1,800 establishments. Brown, Thonachaisetavut and Hewison, 2002, p. 30.

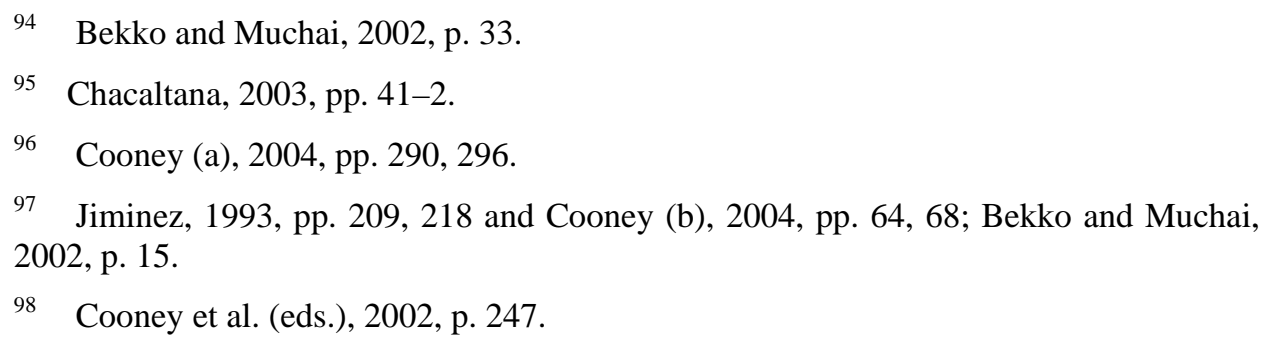


with no reference to the formal legal system. ${ }^{99}$ In addition, regulatory cultures may tolerate non-compliance and corruption. ${ }^{100}$ Legal institutions assigned with the role of generating legal norms and enforcing labour laws may be too institutionally weak to perform this function effectively. This is the case in China, Viet Nam and Indonesia. ${ }^{101}$ These broad considerations should not detract from the continuing importance of State-based law. They do, however, highlight that it may be both appropriate and necessary to look beyond traditional regulatory mechanisms. In particular, States may find it effective to seek to develop regulatory mechanisms that include locally tailored regulatory and enforcement solutions.

\section{Special approaches to enforcement and application of labour laws to MSEs}

Some State labour administrations have sought to adapt the administrative framework to the needs of MSEs by creating distinct structures or programmes targeted at this sector. In some places States have established particular departments or bureaux with responsibility for assisting MSEs, while in others, States have developed inspection and enforcement strategies targeted specifically at the sector.

Examples of MSE-specific bureaucracies include the Directorate for the Promotion of the Informal Sector, within the Directorate General of Employment and Vocational Training in Burkina Faso; and the Self-Employment and MicroEnterprise Programme in Peru (PRODAME) in Peru. ${ }^{102}$ These departments generally appear to be focused on improving the productivity of MSEs, and facilitating MSE entry into the formal economy. They do not appear to focus directly on promoting compliance with labour standards in the MSE sector. For example, PRODAME's principal objectives are to foster job opportunities through the creation of MSEs; to formalize and legalize MSEs already in operation; and to reduce the time and cost required to set up an enterprise through simplifying administrative procedures; and finally to provide training on the creation and formalization of business. ${ }^{103}$ Whether or not these efforts are specifically targeted at labour law and its application to MSEs, they do suggest that States may be able to develop bureaucratic approaches targeted to the MSEs, in the hope of producing positive outcomes for the application of labour law.

A second approach adopted by some State labour administrations has been to develop inspection strategies more focused on MSEs. In Peru, for example, the Micro and Small Enterprise (Promotion and Formalization) Act 2003 stipulates an annual inspection target of 20 per cent of registered microenterprises. In Chile, a recently introduced scheme permits MSEs with fewer than 10 workers to substitute a fine for infringement of the labour law for a compulsory training course. This approach is predicated on the assumption that non-compliance in MSEs is often attributable to a lack of knowledge and

\footnotetext{
99 Nicholson, 2002; Zhu, 2002, pp. 122, 157.

100 Cooney (a), 2004, p. 294.

101 Cooney et al., 2002, p. 253.

102 Daza, 2005, pp. 48-50.

103 Chacaltana, 2003, p. 20.
} 
information, rather than on bad faith. During 2004, a total of 1,368 employers of micro enterprises had attended training courses. Although a joint impact evaluation by the ILO and the Peruvian Direcciòn del Trabajo is still underway, preliminary findings suggest that the introduction of the training course has been successful. As Reinecke has noted, the most critical indicator for the success of this novel scheme will be the extent to which MSEs re-offend after completion with the course. This is currently being evaluated.

The Chilean Labour Code also establishes a system of sanctions that are progressively more severe as the number of workers in an enterprise increases. For example, fines for infringement of labour laws are lower for enterprises with fewer than 50 workers than for larger enterprises. ${ }^{104}$ In the Philippines, enterprises with fewer than five workers which are found to have breached labour laws and regulations during inspections are usually given 'technical advice' by the State inspectorate and are given one year to comply with labour standards. ${ }^{105}$

\section{Institutions and strategies to enforce the law}

Some States have adopted innovative regulatory approaches to the application of labour law in practice. In some cases they rely on an institutional framework that includes actors other than the State itself, and modes of regulation beyond simple enforcement activity. This requires consideration of the role of trade unions, the extent of knowledge of the law and its requirements (and how to improve that), the educative role of State officials, and the effects of market-based approaches to enforcement.

1. The role of trade unions. Trade unions may play an important role in ensuring compliance with labour-related laws. The capacity of trade unions to monitor enforcement of minimum labour standards in the MSE sector is however severely limited in developing countries due to the low level of unionization: the low union density in MSEs generally equates to a weak union influence. As strong trade union representation can translate into greater pressure on labour administrations to inspect enterprises, the weak union presence in MSEs can contribute to the problem of regulatory enforcement in this sector. ${ }^{106}$ There are however innovative organizing strategies that can be adopted to overcome some of the difficulties experienced by unions operating in the informal economy. Moreover, the assumption that there is a link between high union density and significant trade union influence over state enforcement practices does not always follow, and in some cases the opposite may also be true. In addition, there can be differences in the influence of trade unions depending upon the sector of economy activity. ${ }^{107}$ The challenge for States is to find ways to facilitate the development and the success of these strategic approaches.

2. Legal literacy. A widespread reason for failure to comply with labour laws and regulations is that there is a general lack of awareness by both employers and workers of relevant regulatory requirements. In Nepal, for

\footnotetext{
104 Reinecke, 2005, pp. 4-6.

105 Ofreneo, 1994, p. 13.

106 ILO, 1986, p. 6.

107 Rueda, 2002; Fashoyin, 2002.
} 
example, despite the existence of a special simplified legal regime for MSEs, many are still unaware of their responsibilities regarding labour standards. ${ }^{108}$ In southern China, a recent survey of small commercial businesses found that over 75 per cent of workers reported that they did not know what labour regulations existed to protect them. The same survey found that 57 per cent of MSE employers did not know what legal regulations they were required to comply with. ${ }^{109}$ In South Africa, Godfrey and Theron observed from their research into small business and labour standards that the level of awareness about basic employment standards among small business owners was 'generally low' ${ }^{110}$ ILO reports have suggested that lack of compliance with labour regulations by MSE employers is often attributable to a lack of knowledge and understanding of their legal obligations rather than to bad faith. ${ }^{111}$ For workers, greater legal literacy may result in stronger and more organized demands for higher labour standards.

Thus, higher levels of 'legal literacy' could play a critical role in ensuring minimum labour standards are implemented in the MSE sector. This has been highlighted in the ILO's Job Creation in Small and Medium-Sized Enterprises Recommendation 1998 (No. 189), which emphasized that States should make available measures to MSEs for 'assistance in understanding and applying labour legislation, including provisions on workers' rights, as well as in human resource development and the promotion of gender equality'. The State may also play an important role in educating workers and employers about their respective rights and obligations; education and information campaigns can serve as a useful element of a broader regulatory strategy.

3. The role of labour inspectors in educating employers and workers. Recent ILO projects have demonstrated that compliance with labour laws may be facilitated when labour inspectors adopt an educative role rather than simply a policing one. An ILO report on the informal economy observed that '[e]xperience gained from ... practical interventions suggests that it may be more effective if labour inspectors are reoriented from an approach that emphasizes enforcement (which often opens up opportunities for corruption and harassment) to a role that is educational and persuasive, transparent and participatory., ${ }^{, 12}$ Pilot studies in four countries have trialled a new approach to labour inspection in which labour inspectors are trained to use non-confrontational and cooperative methods and to work with employers to increase compliance with labour laws. Through this approach, employers were able to understand that improved conditions at the workplace would benefit both themselves and the workers. ${ }^{113}$

\footnotetext{
108 Shakya, 2004, p. 11.

109 Cooke, 2005, pp. 19, 30.

110 Godfrey and Theron, 1999, pp. 54-55.

111 The ILO's WISE programme is based on this understanding. This conclusion is supported by Godfrey and Theron's research into the small business sector in South Africa. They observed that 'As regards firms which were not complying with labour regulations, this seemed to be more often out of ignorance than willful defiance', ibid. p. 56.

112 ILO, 2002b, pp. 53-54.

113 ILO/IPEC, 2001, p. 36.
} 
4. Legal protection for employees who complain to state authorities. Educating workers about their rights will have little impact if workers are not protected from retribution for seeking to enforce them. Research into the MSE sector in China suggests that even where workers are aware of minimum wage provisions or stipulations on maximum overtime, they are reluctant to seek to enforce their rights due to fear of job loss if they complain. ${ }^{114}$ Similarly, workers in Indonesia apparently do not report hazardous working conditions, as the statutory prohibition on employers retaliating against employees is not enforced. ${ }^{115}$ Workers may be reluctant to report breaches of labour laws to labour administrative authorities not only for fear of retaliation, but also because they often do not have confidence in the administrative and judicial procedures available. ${ }^{116}$ Finally, the 'familial-style' labour relations in many MSEs may contribute to the reluctance of workers to submit complaints or ask for assistance from workers' representative organizations. ${ }^{117}$ For all of these reasons, it is important for States to support their legal and law enforcement regimes with adequate protection against retaliation for those who complain to the authorities.

5. Market-based regulation - Global production chains and MSEs. Corporate Social Responsibility (CSR) initiatives have the potential to influence MSEs through direct supply chain relationships, as well as through the development of legislation, and international standardization and certification. ${ }^{118}$ The literature on CSR is vast; what follows is a brief overview of the principal strengths and weaknesses of the CSR approach, as it may apply to MSEs. Where CSR initiatives are developed and implemented through social dialogue mechanisms, they can be consistent with and a significant supplement to ILO standards and national laws. ${ }^{119}$

The CSR approach embodies the potential for MSEs that lie outside the formal domestic legal framework due to their size, informality or the failure of State regulation, to be drawn into a regulatory framework in which certain standards of production are demanded by the market. CSR approaches are generally a type of 'market-based regulation', as they are initiated privately and use market mechanisms in their enforcement. A principal tool of CSR initiatives has been the corporate code of conduct. ${ }^{120}$ These codes are designed to address the social and/or environmental impacts of a firm's activities. Codes of conduct are often produced by individual firms or on an industry basis. Recent decades have also seen the development of international guidelines on corporate social

\footnotetext{
114 Cooke, 2005, HRM, Work and Employment in China, pp. 144-145.

115 'Labour Law in Indonesia'

<http://www.sweatshops-retail.org/NRF\%20website/Indonesia.htm> on 15 July 2005.

116 Cooney (b), 2004, pp. 64, 68.

117 Servais, 1992, pp. 299, 309; Cooke, 2005, pp. 31-32.

118 Raynard and Forstater, 2002, p. 3.

119 'Information Note on Corporate Social Responsibility and International Labour Standards' (GB 288/WP/SDG/3) and 'Keynote Address by Juan Somavia, Director General of the ILO to the International Symposium for Employers' Organizations on "Evolving Corporate Social Responsibility Debate: Issues for Employers and their Organizations”’ (Geneva, 5 October 2005).

120 Urminsky defines a 'code of conduct' as a 'written policy, or statement of principles, intended to serve as the basis for a commitment to particular enterprise conduct'. Urminsky (ed.), 2001, p. 13.
} 
responsibility, the three main documents arguably being the ILO's Tripartite Declaration of Principles Concerning Multinational Enterprises and Social Policy, the OECD's Guidelines for Multinational Enterprises, and the United Nations' Global Compact.

Proponents of market-based regulation suggest that firms in supply chains based in developed countries can exert a form of global governance on their internationally dispersed suppliers that is more effective in ensuring compliance with local standards than local governance alone. ${ }^{121}$ Self-regulation by companies also minimizes compliance costs for government, and potentially makes regulation adaptive to the specific conditions of a firm or industry. ${ }^{122}$ Empirical evidence suggests that codes of conduct have in some cases produced tangible improvements in labour conditions within firms located in developing countries. ${ }^{123}$ A recent study commissioned by the ILO's SEED programme, although limited by its narrow focus on footwear clusters in the Sinos Valley, Brazil, concluded that 'any standard demanded through the tight value chain governance of 'directed networks'... tends to be quickly implemented by developing country producers and effectively monitored by buyers. ${ }^{124}$

There are, however limits to the capacity of market-based regulation to lead to improved job quality for MSE workers. ${ }^{125}$ This is for five reasons. Firstly, codes of conduct are voluntary in nature. They are frequently driven by public relations concerns, and the number of companies that have adopted codes of conduct to date has been limited. Those firms not in the public eye, especially those that are not engaged in producing consumer goods, have little incentive to improve working conditions. ${ }^{126}$

Secondly, codes may also be limited in their application to a firm's most immediate suppliers, and may fail to cover workers further along the commodity supply chain where the most vulnerable workers are found. Worse, codes of conduct may operate to the detriment of workers in MSEs: firms in other parts of the commodity chain that find it difficult to monitor the implementation of codes of conduct within large numbers of smaller suppliers may choose instead to centralize production, and to limit the number of suppliers. ${ }^{127}$

Thirdly, codes often do not include all essential labour standards. For example, while the prevention of child labour is a common focus of firms, most

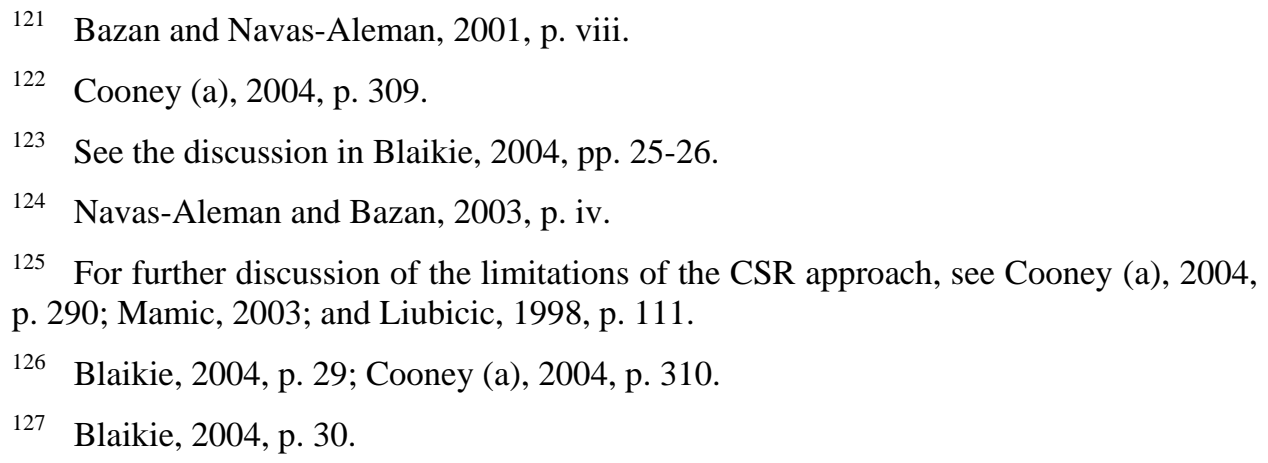


codes do not promote collective bargaining ${ }^{128}$ or other internationally recognized labour standards. ${ }^{129}$

Fourthly, codes are not generally applied to the industry or region: they only apply to firms in a particular supply chain. Once workers are dismissed or production moves to another location, workers previously protected by the codes may be adversely affected. ${ }^{130}$

Finally, codes generally do not adhere to a participatory regulatory model. They are often designed with little or no consultation with the relevant stakeholders - especially the workers in developing countries to whom they are intended to apply - and they frequently do too little to involve workers in monitoring. The failure to include workers and other parties undermines one of the supposed strengths of codes: their potential to be 'context-sensitive'. This sort of imposition of labour standards from above also risks undermining worker-management co-regulation through collective bargaining and cooperative committees.

These shortcomings of codes of conduct and CSR initiatives more broadly suggest that, even if market-based governance does exert a positive influence on some aspects of labour standards, it alone can not ensure job quality for MSE workers. There are examples where market and State-based regulation have been combined; whereby private codes of conduct have become bolstered and legalized after a period of voluntary implementation. One such example is the Australian Homeworkers Code of Practice. Recognizing that market-based approaches to regulation in the textile clothing and footwear industry were bringing about undesirable outcomes for labour conditions, state governments have enacted various versions of 'Supply Chain Regulation'. ${ }^{131}$ This regulation is an example of a responsive model of regulation which involves the social partners in its design and implementation. In other words, both the design and the implementation of the regulatory model take place at a level other than the State. Unions and employers (manufacturer and retailer representatives) sit on committees which oversee the implementation of the code. Unions have an inspection, monitoring and enforcement role. Manufacturers and retailers are responsible for providing information about the actors in the supply chain.

\footnotetext{
128 See Ferguson's study of 18 UK Codes: Ferguson, 1998. For similar findings in relation to US Company codes, see Jenkins, 2001.

129 A study of 140 codes of conduct in the OECD inventory found that more than half the codes only dealt with three issues: a general commitment to a reasonable working environment, an agreement to comply with local laws, and protection against discrimination and harassment. The ILO core labour standards were only mentioned in 10 codes. See ibid. p. 21.

130 Cooney (a), 2004, pp. 311-313.

131 The Industrial Relations (Fair Work) Act 2005 (South Australia) amended the Industrial and Employee Relations Act 1994 (South Australia); Schedule 2 of the Industrial Relations (Ethical Clothing Trades) Act 2001(NSW) amended the Industrial Relations Act 1996 (NSW); the Outworkers (Improved Protection) Act 2003 (Victoria); and the Industrial Relations and Other Acts Amendment Act 2005 (Queensland) amended the Industrial Relations Act 1999 (Queensland).
} 


\section{Conclusion}

Labour law often has limited application to MSEs, leaving workers without its protection. Changes in labour market practices in industrialized economies, and the structure of economic activity in developing economies both make it problematic for States to rely on the traditional labour law concepts of 'employee' and 'employer' as the basis to determine the scope and coverage of labour law. Increasingly, workers in all parts of the economy, but particularly in MSEs, are not legally engaged in ways that would bring them within the scope and coverage of labour law. In addition, States have generally adopted a policy of excluding MSEs from the scope and coverage of some of their labour laws; in a few cases some enterprises are excluded altogether. Exclusions, however increase the proportion of workers that are excluded from the formal coverage of labour law, and therefore unable to have access to the social and economic benefits it might deliver. The situation is only further compounded by the fact that in most cases States experience significant difficulty in applying labour law to MSEs in practice. This may be a product of several different causes, including the logistical difficulty of dealing with the scale and variety of MSEs, deliberate policy, misuse of the discretion given to State authorities, corruption, and lack of skills and resources.

However it comes about, the failure to apply labour law in practice to those enterprises within its scope and coverage has the effect of excluding workers who should be able to rely on its protection. At the same time, States' practices in excluding MSEs from the scope and coverage of labour law, and in taking inconsistent approaches to the application of labour law in practice pose difficulties for MSEs and their owner-entrepreneurs. Instead of a simple and clear regulatory framework, they can be faced with an uncertain patchwork of legal obligations, and too little certainty about State enforcement policy and practice.

Nonetheless, there is evidence that States can develop innovative approaches to the design of labour laws, and to their enforcement in practice, that may have the capacity to contribute significantly to the achievement of a Decent Work Agenda for MSEs, while also benefiting MSEs themselves. These approaches include developing and enhancing the role of trade unions as participants in the regulatory process; improving knowledge of legal requirements (legal literacy); placing emphasis on educating workers and employers about how to comply with their legal obligations; ensuring that workers are protected if they make complaints to the authorities; and drawing on the growing range of corporate social responsibility initiatives, as a supplement to existing laws and enforcement processes. 


\section{CHAPTER 3}

\section{LABOUR LAW, JOB QUALITY AND FORMALIZATION OF MSES}

Chapter summary

- Job quality for workers in MSEs falls far below the level necessary to promote or achieve Decent Work.

- There is little evidence to suggest that excluding MSEs from labour laws, or failing to apply them in practice, has major positive effects on MSE growth and economic development.

- $\quad$ There are substantial benefits that can be gained from compliance with labour laws.

- $\quad$ Surveys across seven countries have found that MSE owners do not regard the costs of complying with labour laws as a major constraint on MSE growth.

- Evidence suggests MSE owners make strategic choices about which elements of their regulatory environment they will comply with. This suggests that they will respond to innovative regulatory approaches targeted specifically at MSEs.

\section{Introduction}

The previous chapter was about States' practices in the application of labour law to MSEs: it showed that many States exclude MSEs from the scope or coverage of some or all of their labour laws. It also showed that there are significant problems with the application of labour law to MSEs in practice. This chapter presents the findings of research on what must be two key policy goals for States seeking both to promote and to harness the growth potential of MSEs. These are improving the job quality of workers in MSEs, and encouraging MSEs to grow and to participate in the formal economy.

Improving job quality is a vital imperative for MSE workers, with important potential benefits for MSEs themselves. Among other things, improved job quality is an important way that workers can avoid poverty, and can remain out of its reach. Poverty is a constant risk for workers in MSEs, where working conditions are often unsafe, and formal social protection schemes frequently do not apply. Previous research has shown that MSEs account for over 90 per cent of enterprises where working conditions are very poor, and where workers are excluded from labour protection. ${ }^{132}$ For MSEs themselves, there is a direct link between higher job quality and higher productivity: workers with better job quality are more contented, skilled and productive. Thus, there are significant short, medium and long-term economic benefits to be gained from designing a regulatory environment for MSEs that promotes job quality.

This study suggests that States' practices in excluding MSEs from the scope and coverage of labour law, and in not applying labour law to MSEs in practice, are problematic from the point of view of the two key policy goals of improving job quality, and of encouraging the formalization of MSEs. The findings in Chapter 2 showed that MSEs are frequently excluded from the application of labour law, either formally or in practice. The findings in this chapter show that job quality in MSEs is very poor. As labour law can be a key means of requiring and encouraging decent working conditions, this study therefore suggests that

132 ILO, 2004b, p. 17. 
workers may not be well served by a policy of excluding MSEs from the application of labour laws, either formally or in practice. Excluding MSEs from labour law may not have significant positive effects in encouraging MSEs to participate in the formal economy. MSE owner-managers do not regard the impact of compliance with labour laws to be the most significant factor in deciding whether and how to comply with regulatory requirements affecting their business: they do not see labour laws as a major constraint on their enterprises' growth potential.

Taken together, these findings suggest that a policy of excluding MSEs from the scope and coverage of labour laws is adverse to the goal of a Decent Work agenda. So too are enforcement approaches that do not come to grips with the challenges of applying labour law to MSEs in practice. There is little clear evidence that a policy of excluding MSEs from labour law in the hope that this will stimulate their growth - and thus their entry into the formal economy - has little impact. It is difficult, however, to identify sufficient current research or data from which to draw firm conclusions about the positive effect for MSEs of being excluded from labour laws, in isolation from other policy approaches and aspects of the regulatory framework. If, however, there is little positive impact on MSEs from excluding them from the application of labour law, States may only be depriving themselves of longer term benefits, in pursuit of the relatively short term gains that are thought to come from 'facilitating' the growth of MSEs by this policy. Moreover, they are failing to promote and protect the basic rights of workers in a way that is fundamentally inconsistent with the Decent Work agenda: the improvement of job quality requires that States adopt a rights-based approach to the application of labour law, without distinction whatsoever.

\section{Labour law and job quality in MSEs}

\section{Defining job quality}

'Job quality' implies a wide range of standards at work that affect 'the economic, social and psychological well-being of workers. ${ }^{, 133}$ This study considers the matters identified below, which are governed by labour and labour related laws, as having effects on workers' job quality.

\section{Fundamental rights: Freedom of association}

Trade unions are a vital means by which workers are able to organize to represent their interests and to improve their job quality. Union density in MSEs is however generally very low. In Chile in 2000, only 4.2 per cent of microenterprises (two to nine workers) and 9.7 per cent of small enterprises (10-49 workers) had a trade union. ${ }^{134}$ In Argentina, trade union density in enterprises with up to five workers in 2001 was only 13 per cent (compared to 49 per cent for salaried workers in enterprises with six or more employees) ${ }^{135}$ In Brazil, the unionization rates for the same year were six and 24 per cent respectively. An

\footnotetext{
133 Reinecke and White, 2004, p. 32.

134 Flores, 2003, p. 18.

135 Reinecke, 2005, p. 10.
} 
exception to low union density in the MSE sector is Denmark, where 87 per cent of workers in firms with one to 10 employees were unionized in $1994 .{ }^{136}$

Job quality indicators:

Matters regulated by the worker's contract:

- Remuneration levels, including salary, working hours, fringe benefits and equal opportunities

- Job security, where workers are provided with a degree of long-term stability

- Social protection, including mechanisms for health, life, disability and unemployment insurance, as well as pension schemes, child care, and maternity leave

- Freedom of association and free choice of employment

Work environment and conditions:

- Occupational safety and health

- Adequacy of working conditions to prevent occupational accidents and diseases

- Control of environmental and physical hazards, as well as the promotion of health in the workplace Investment in worker productivity and advancement:

- Human resource development, where workers are treated as a valuable asset of the enterprise and are provided with education and training opportunities, prospects of promotion and incentives for improvement;

- Management and organization, including freedom of association and mechanisms for participation and consultation.

In many countries, legal requirements relating to the registration of trade unions may contribute to the levels of union membership. Many countries' labour laws require a trade union to have a minimum of ten or more members before it may be registered, or participate in collective bargaining. These sorts of rules obviously may operate as a significant limitation on the ability of workers to organize. In addition to the impact of the legal regime, there are significant practical difficulties for trade unions seeking to organize workers in MSEs. These include workers' knowledge of and attitude toward unions, the nature of work relations within MSEs, the geographical dispersion of MSEs, and lack of job security.

One of the most fundamental difficulties is that many workers are unaware of trade unions and the role that they may play in promoting workers' job quality. Where workers in the MSE sector do know of trade unions, they may feel that union membership has nothing to offer them. ${ }^{137}$ A field survey of restaurants in the MSE sector in Nepal reached findings consistent with these general patterns. Only 6.7 per cent of workers surveyed were aware of the existence of trade unions. ${ }^{138}$ Perhaps not surprisingly, only six of the 358 workers surveyed -0.02 per cent - were members of a trade union. A further problem arises where workers are unwilling or afraid to participate in a trade union because of employer hostility. Inadequate protection against acts of anti-union discrimination (either in law or in practice) contributes to the reluctance of many MSE workers to join a trade union, for fear of losing their jobs. There is only

136 QUIT (Grupo d'Estudies Sociologics Sobre la Vida Cuotidiana I el Treball) and IRES (Institut de Recherches économiques et sociales), 1999.

137 Morton, 2004, p. 12; Joshi, 1997, p. 54.

138 Chapagain, 2001, p. 25. 
likely to be more reluctance where employment is precarious, as it tends to be in many MSEs. In Kenya, for example, many MSE employers are opposed to trade union activities, and this makes many workers reluctant to become union members. ${ }^{139}$

The very nature of work relations in MSEs imposes another practical limitation on the ability of workers to form unions in the MSE sector. Many MSEs are operated by (sometimes extended) families, so that familial-style work relations predominate. This may inhibit the extent to which workers are willing or able to request assistance from a workers' representative within an enterprise, or from a local trade union organization. ${ }^{140}$

There are other obstacles to the operation of effective trade unions for workers in MSEs. Firstly, they are typically widely dispersed geographically. Secondly, work relations and continuity of employment are often precarious in MSEs. Both these factors make it hard for workers to form unions, and for the unions they may form to function effectively. In particular, it is difficult for workers' organizations, where formed, to operate in a stable, continuous and effective manner.

This range of obstacles to the formation of trade unions, and to their ability to enrol members and to represent workers engaged in MSEs leads to the result that many workers are unable to experience the benefits that can flow from workplace representation and participation. So too, States and MSEs themselves are denied positive benefits. From their point of view, trade unions could be a key institution through which workers can express views about, and participate in aspects of enterprise growth and economic management. Trade unions can also provide an important means of educating and informing workers about their rights, in a way that (among other things) may be more cost-effective than direct action by the State. This all suggests that States should closely examine legal frameworks that may constrain the effective establishment and functioning of trade unions, and consider innovative ways of encouraging and improving workplace representation through trade unions. Examples of these strategies are examined in the subsequent chapters.

\section{Fundamental rights: The right to collective bargaining}

Collective bargaining is very limited in MSEs. ${ }^{141}$ Generally, the smaller an enterprise, the less likely it is to be covered by a collective agreement. Figure 2a indicates the share of enterprises in South Africa with workers covered by collective agreements, according to enterprise size.

\footnotetext{
139 Bekko and Muchai, 2002, p. xi.

140 The reluctance of employers and employees to be represented by trade unions because of the 'family-style' labour relations in MSEs is also observed in Europe. Biagi, 1995, pp. 439, 454.

141 Biagi, 1995, p. 456.
} 
Figure 2a: Collective bargaining by enterprise size, South Africa, 1999

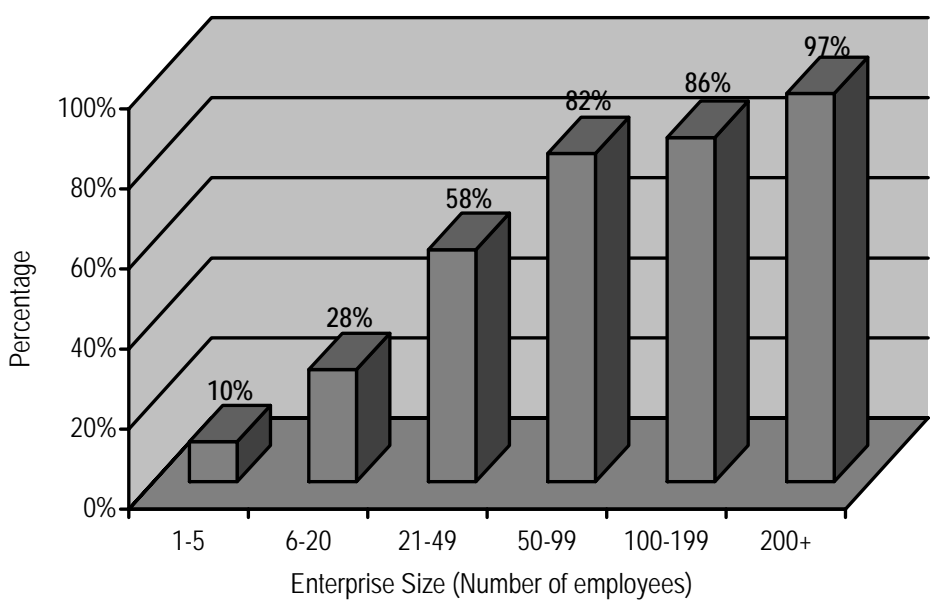

Note: Figure $2 \mathrm{a}$ is based on surveys in South Africa of 792 MSEs (1-49 workers) in various economic sectors, and 325 manufacturing enterprises with 50 or more workers. Data drawn from Reinecke and White (2004) p. 105.

The absence of collective agreements in the MSE sector is particularly acute in countries in which enterprise unionism is dominant, including most Latin American nations. (Here again, legal procedures and structures for the registration of trade unions can play a significant role). Figure $2 \mathrm{~b}$ demonstrates the percentage of workers covered by collectively bargained agreements in Chile, according to enterprise size. It does not present data for enterprises with fewer than ten workers, which would include most MSEs. It does graphically demonstrate, however, that there is a much greater chance of workers being covered by a collective agreement in larger enterprises.

Figure 2b: Collective bargaining by enterprise size, Chile, 1998

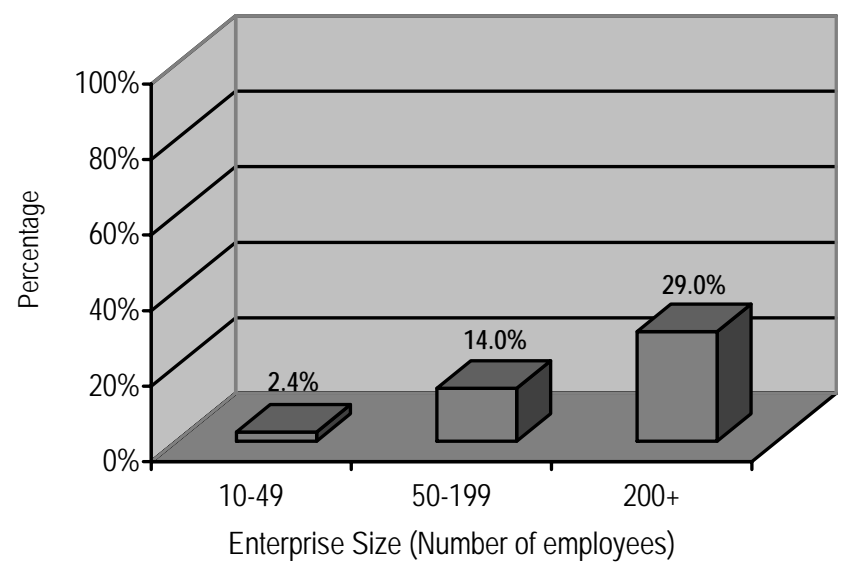

Note: Data for Figure 2b from G Reinecke, 'Labour and Labour Related Laws in Micro and Small Enterprises: Cases from Latin America', p. 11. 
Even where collective bargaining is possible, or is encouraged by law within MSEs, a lack of enforcement may mean that they do not comply with relevant regulations. ${ }^{142}$ Trade union officials in developing countries may also lack the bargaining resources, skills and capacities to bargain effectively. ${ }^{143}$

Workers in MSEs are however not always unprotected by collective bargaining agreements. In some States, collective agreements at higher levels may be universally binding, and in these cases, MSE workers may enjoy the benefits of collective agreements even where there are no trade union members within the particular enterprise. In Spain, for example, only 16 per cent of employees in the mid-1990s were unionized, but collective agreements covered 82 per cent of the workforce. In France, the figures for 1995 were 12 per cent and 80 per cent respectively. In Denmark, collective agreement coverage in 2000 reached 83 per cent of the workforce. ${ }^{144}$ However, in countries where coverage of collective agreements is higher, it still tends to decline as the size of the enterprise decreases. For example, in Denmark, only around 35 per cent of enterprises with fewer than 10 employees were covered by a collective agreement. $^{145}$

A second way in which States might overcome the shortfall in collective bargaining in MSEs is by providing for the coverage of collective agreements to be extended by administrative or legislative authority to cover all enterprises within an industry. This is an important means by which many States may be able to achieve several interlinked policy goals. By leaving the negotiation of working conditions in the first instance to parties in the industry or sector concerned, the government may be reasonably assured that the outcomes will reflect fair but sustainable working conditions. Thus, the State avoids the risk of imposing unsustainable burdens on MSEs. At the same time, however, it is then able to offer appropriate protection for workers across whole industries, thus assuring them of some measure of Decent Work. Examples of this approach may be found in both South Africa and in Namibia.

In South Africa, collective agreements may be extended to non-parties (firms that are not part of a bargaining council) within specified industries in two principal ways. Firstly, the Minister may extend a collective agreement reached by a sectoral bargaining council where either: (i) the Minister is requested to do so by a bargaining council under section 32(1) of the Labour Relations Act 66 of 1995; or (ii) where the Minister is satisfied that the parties to the original agreement are 'sufficiently representative within the registered scope of the bargaining council in the area in respect of which the extension is sought' and that failure to extend the agreement may undermine collective bargaining at the sectoral level. ${ }^{146}$ Secondly, the Minister may, under the Basic Conditions of Employment Act 1997, request the Employment Conditions Commission (a statutory body appointed by the Minister) to investigate employment conditions in a particular industry and make recommendations for a sectoral determination of wages and other conditions. In 1999, the Minister gazetted a small business

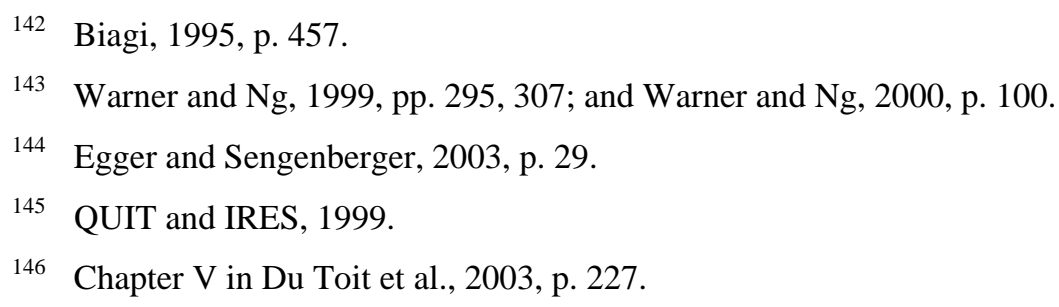


determination which provides concessions for enterprises with five or fewer employees. ${ }^{147}$

In Namibia, the Minister of Labour and Manpower Development may extend the operation of a collective agreement to cover an entire industry. The Labour Act 2004 stipulates matters that the Minister must consider in deciding whether to mandate the extension of a collective agreement. Where the criteria are satisfied, the Minister must extend the agreement. ${ }^{148}$ Agreements have been extended in the construction industry, and also in agriculture. The extension of the agreement in agriculture is particularly important as a means of setting minimum standards in a sector where a significant proportion of the Namibian workforce may be found. Of course it nevertheless begs the question whether the terms of the agreement will be observed and (if needs be) enforced across the sector. The case of Namibia, however, also highlights the significant potential weakness of this regulatory approach: if the parties in an industry are unable or unwilling to reach an agreement, or if they reach one that is not suitable for extension, then many workers across the sector may remain without regulation of some important basic working conditions. In the case of Namibia, for example, a large proportion of the workforce is engaged in domestic service, where there is no collective agreement. Thus, these workers have no minimum wage, and are limited to the basic working conditions prescribed by the Labour Act 1992.

The case of Namibia shows that, from the point of view of a Decent Work agenda and the rights of workers, there is a weakness in relying upon a mechanism of extending collective agreements to cover all workers in an industry. It necessarily follows that where workers are poorly organized and trade unions are weak, that there is a lower likelihood of the parties negotiating any agreement at all, much less one that might be suitable of extension to an entire industry.

\section{Fundamental rights: The elimination of forced labour}

Forced or compulsory labour is contrary to the ILO's most-widely ratified core standard, the Forced Labour Convention, 1930 (No. 29), ${ }^{149}$ and cognate provisions in other international human rights instruments. ${ }^{150}$ Forced or compulsory labour is also contrary to national laws in virtually every country in the world. ${ }^{151}$ Nevertheless the ILO's most recent global estimate is that 12.3

\footnotetext{
147 In making this determination, the Minister overrode the recommendations of the Employment Conditions Commission, which had supported only those concessions that were directly related to difficulties created by having few workers. See Goldman, 2003, p. 34 and Du Toit et al., p. 524. For an analysis and discussion of the impact of various labour standards and regulations on SMEs in South Africa, see Godfrey and Theron, 1999, and Theron and Godfrey, 2001.

148 Labour Act 2004, section 69(4). See Fenwick, 2005, p. 28.

149 As at 31 August 2005 the instrument had been ratified by 168 of the ILO's 178 members: <www.ilo.org>. The principal obligation it imposes on states parties is to eradicate the use of forced or compulsory labour in all its forms: article 1.

150 Universal Declaration of Human Rights 1948, article 4 and International Covenant on Civil and Political Rights 1966, article 8.

151 Ziskind, 1980, p. 253.
} 
million people are subjected to forced labour. ${ }^{152}$ Moreover, almost 65 per cent of forced labour in the regions of the Asia-Pacific, Latin America and the Caribbean, sub-Saharan Africa, Northern Africa and the Middle East is privatelyimposed for economic exploitation. This suggests that forced labour is likely to be found in the informal economy, and may also be a problem in MSEs.

A particularly significant problem is the case of women who are subjected to forced labour in the form of commercial sexual exploitation. In many cases this form of work is lawful, and therefore has the potential to be or to become part of the formal economy. Nevertheless, women who have been trafficked into it are victims of forced labour, regardless of whether the work or the enterprise may be characterized as belonging to the formal or the informal economy, and whether it is done in MSEs or otherwise. It may be observed also that forced labour for commercial sexual exploitation represents 11 per cent of all cases of forced labour - that is, some 1,353 million people around the world. Of these, 98 per cent are women and girls.

Other common types of forced labour that may be found among MSEs include the well-known case of bonded labourers in South Asia. In India, for example, bonded labour is commonly found in agriculture and brick-making, ${ }^{153}$ work which may commonly be done in MSEs, even though bonded labour has been unlawful in India at least since the introduction of the Bonded Labour System (Abolition) Act, 1976. ${ }^{154}$ Another well-known example is the situation of impoverished rural workers in Brazil. There have been many instances in the last ten to fifteen years of these workers being subject to forced labour, particularly through the abuse of labour contracting systems. Generally they are engaged in seasonal work in clearing forests, making charcoal, or a variety of other agricultural activities, particularly harvesting. Once again, these workers are subjected to forced labour contrary to relevant law, and are working in a sector where small-holdings are common and enforcement is difficult at the best of times.

The ILO's instruments on forced labour, particularly Convention 29, are among the most widely ratified of its Conventions. The prohibition on the use of forced labour should be considered a peremptory norm of international law: that is, no State may allow the exaction of forced labour. ${ }^{155}$ As noted, most States have national legislation that itself prohibits recourse to forced or compulsory labour. Nevertheless, the practice continues. Thus, even some of the most abhorrent work practices may persist in spite of the formal application of legal rules to prohibit them. This suggests again that, from the point of view of Decent Work for workers in MSEs, States should consider carefully whether, and if so how, to exclude MSEs from the application of the requirements of particular labour laws. It also suggests that the application of formal rules may not, by itself, be a particularly effective regulatory strategy. The importance of legal rules as an element of an innovative regulatory approach is taken up in the following chapter.

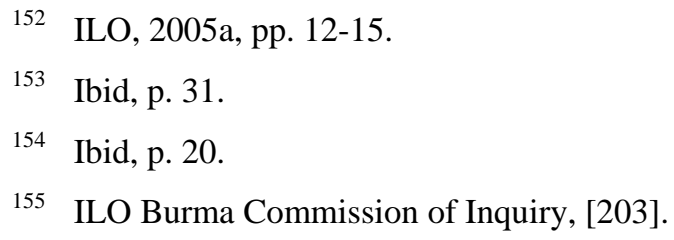




\section{Fundamental rights: The abolition of child labour}

Child labour is contrary to the widely ratified Convention on the Worst Forms of Child Labour, 1999 (No. 182), and cognate provisions elsewhere in international law. ${ }^{156}$ Most countries in the world, including all surveyed for this study, impose prohibitions on child labour at the national level. ${ }^{157}$ Although there have been some successes in reducing the level of child labour - in Thailand, for example, official figures suggest a significant reduction since the late $1980 \mathrm{~s}^{158}-$ it remains a widespread problem throughout the world. In 2002 the ILO estimated that there were 211 million children engaged in economic activity, of whom 186 million were engaged in the worst forms of child labour. ${ }^{159}$ Some 5 million out of the 211 million child labour were in developed and transition countries (split roughly evenly), but the balance were in the developing regions of the world, with over 127 million in Asia and the Pacific.

The ILO has noted that the vast majority of child labourers are to be found in the informal economy. Often however children are engaged in forms of work that are linked to the formal economy, including agriculture, mining, fishing and manufacturing. ${ }^{160}$ Whether in the informal economy or otherwise, there is a significant likelihood that child labour will be found in MSEs, rather than in medium or large private enterprises, or in the government sector. Indeed much child labour is performed in household enterprises that use unpaid family labour. For example, in Nepal, a recent survey into the MSE restaurant sector found that half the workers in this sector were between the ages of five and seventeen. ${ }^{161}$

The persistence of child labour is testament principally to the persistence of poverty. ${ }^{162}$ As with forced labour, the persistence of child labour in the face of legal requirements intended to prohibit it, suggests that labour law alone may not be the best or the only useful policy instrument that States might deploy in addressing broader issues of Decent Work and job quality in MSEs. At the same time, however, it does not suggest that labour law is not an important element of a State's overall response: as the discussion in the following chapter emphasizes, law must play a key role as goal and as guide in any overall strategy of innovative labour regulation.

\footnotetext{
156 Convention on the Rights of the Child, 1989, article 32.

157 It is common for national labour legislation to prohibit child labour under a certain age and to regulate the specific types of work and hours of work for children between certain ages.
}

\footnotetext{
158 Figures cited in Brown, Thonachaisetavut and Hewison, 2002, p. 21. Brown et al. question the official figures - noting that the rate of child labour remains high in Thailand and that the officially-recorded decline in enterprises breaching the laws may be due to, post economic crisis, pressure on inspectors to turn a blind eye to laws to encourage economic recovery or the closure of many small firms that were hit hardest by the crisis.

159 ILO, 2002a, p. 16.

160 ILO, 2002a, pp. 22-23.

161 Chapagain, 2001, p. 25.

162 ILO, 2002a; Arat, 2002, p. 177.
} 


\section{Fundamental rights: Freedom from discrimination in the workplace}

Discrimination at work is endemic in MSEs, where working conditions are in any event generally far worse than elsewhere in the labour market. This is yet another area in which labour market practices and outcomes do not meet the goals of a Decent Work agenda, and are frequently contrary to existing requirements of labour and human rights laws. A particularly significant problem throughout the world is discrimination at work on the grounds of gender.

Women are usually over-represented as workers in MSEs. ${ }^{163}$ Studies carried out in Zimbabwe in the early 1990s, for example, found that 97 per cent of all enterprises were micro-enterprises (being those with five or fewer employees) and that of these, 67 per cent were run by women. ${ }^{164}$ Similarly, in Taiwan a 1998 study found that SMEs employed more than 50 per cent of the labour force, and a 1992 study found that more than two thirds of the workers in these firms were women. (That study also found that over 75 per cent of these women did not receive a wage. $)^{165}$

Furthermore, these estimates are likely to significantly under-estimate women's participation. Firstly, because women are more likely than men to be performing types of work that may be done within or for MSEs but which are less likely to be visible and counted. These include domestic service and home work, and production for private consumption rather than for sale. Secondly, women are often engaged in agriculture, which many countries exclude from their data. ${ }^{166}$ Thirdly, many countries' labour force data is not disaggregated so to be able to identify the proportion of women in MSE work.

There are several, interlinked reasons why women are over-represented in MSEs. Unemployment and underemployment in the formal economy are obviously significant push factors: unemployment tends to affect women disproportionately, so they are compelled to work in the MSE sector in order to satisfy family and household responsibilities. ${ }^{167}$ To the extent that unemployment has increased as a result of changes introduced in the spirit of globalization or to implement structural adjustment policies, these phenomena may be seen to have contributed. ${ }^{168}$ In some parts of the world, legal or other constraints on women's labour force participation leave them with few options other than to develop MSEs, or to participate in the informal economy. In South Asia, for example, restrictions on women working in field agriculture have for many years led women in rural areas to engage in various types of self-employment.

Social and cultural traditions may also constrain the outcomes of women's economic participation. In some cases women may be discouraged from

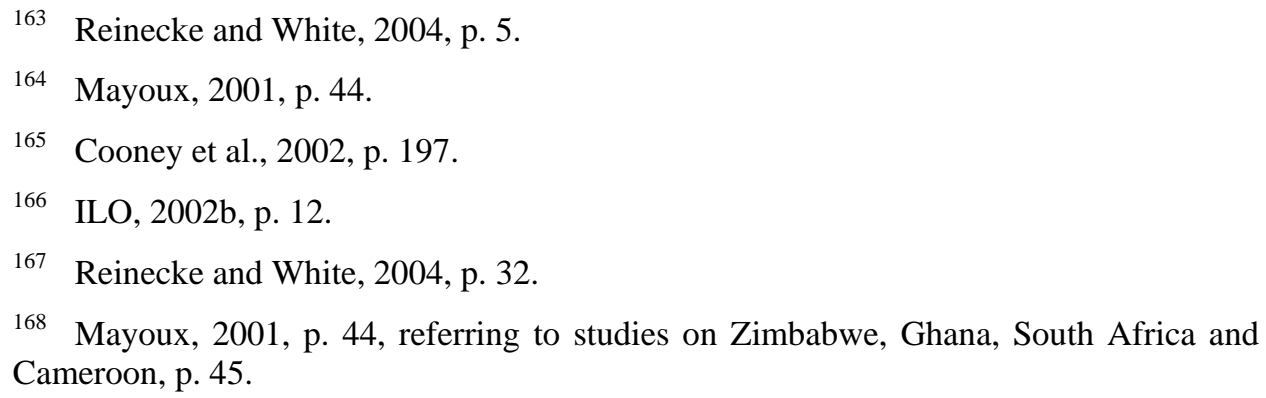


becoming entrepreneurs. ${ }^{169}$ Mayoux reports that in some African customary legal systems, for example, women are defined as minors, as a result of which they are 'denied independent access to land, credit and an independent status in other types of financial transactions. ${ }^{, 170}$ But many of these limitations inhibit women’s participation regardless of cultural traditions. Women everywhere have difficulty in getting access to finance or credit, and to information, productive resources and markets. Frequently they are unable to exercise formal property ownership or make use of property, which can limit their ability to register a business, or to secure credit to develop it. Women's skills and education may be inadequate to the task of entrepreneurship, and if they do start a business, women must overcome the hurdles of market saturation and compliance costs. ${ }^{171}$ While these problems are not peculiar to women, they can combine to have a particularly discriminatory effect on women's participation.

A related difficulty for women is that they generally have worse access to markets and marketing through networks, at a time when these are more important due to globalization. This problem is compounded by their lack of the skills that would be needed to enter new markets, and further by their limited access to labour. Whereas most self-employed men are able to depend upon a woman (or women) to carry out much household labour, women obviously cannot do so. This is a significant limitation on women's ability to run and to develop MSEs. ${ }^{172}$

A major constraint on women's ability to develop their economic participation and to grow their MSEs is the level of their income and the proportion of it that is available for entrepreneurial activity. Women's income is generally lower than men's. Women also frequently have less control over how their income is disbursed (generally as a result of gendered assumptions about roles and responsibilities). Moreover women generally bear the costs of reproductive labour and associated health care, in the absence of state supported services. ${ }^{173}$

Low income levels for women are endemic, and emblematic of the unsatisfactory working conditions they must endure: 'the majority - and particularly poorer women and women in the South - are locked into low income, low profit and low investment activities. ${ }^{174}$ While there are cases in which women are establishing 'dynamic, modern and successful MSEs', in many cases women in the informal economy suffer the worst working conditions of all, with their opportunities 'often concentrated in the most fragile segment of survivalist micro-enterprises, where incomes tend to be very low.' ${ }^{175}$ While working conditions for women in developing countries are no doubt far worse than in casualized (feminized) work in the formal sector of developed economies, it bears emphasizing that conditions for women are still generally

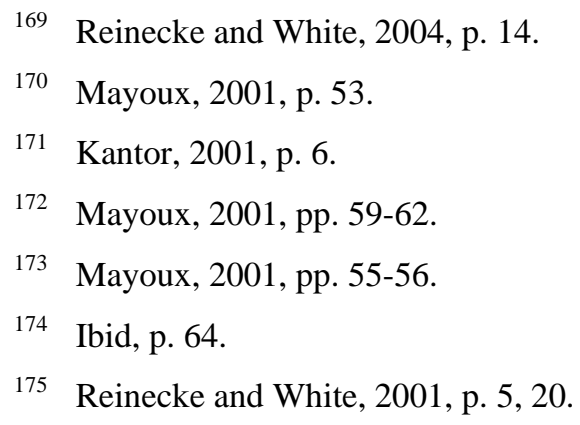


worse there than they are for men. Systems in the developed world that are intended to deliver flexible work together with security do not necessarily deliver high quality outcomes: the underlying reality is that women's work is largely precarious. ${ }^{176}$

Men often occupy a higher proportion of jobs in the formal economy. As noted above, the problems associated with poor working conditions and the lack of enforcement of labour standards in MSEs affect women most acutely. Pressures towards international integration and flexible work patterns have often impacted most negatively upon women, who are forced into insecure, low paid work. In addition, women are often most affected by the difficulties associated with balancing work and family. Women are most vulnerable to workplace abuse, such as sexual harassment. ${ }^{177}$ Women also constitute the large majority of home-workers, who often work in cramped conditions with poor lighting and ventilation. ${ }^{178}$

Overcoming discrimination at work must be a key plank of a Decent Work agenda: it is crucial for promoting and ensuring respect for all workers' fundamental rights. Eliminating discrimination in the labour market is also, however, economically sound: artificial constraints on the allocation of labour according to workers' and employers' free choices can only lead to inefficient outcomes, and the failure to capitalize as far as possible on the potential for economic growth in a States' human capital. The complex causes of ongoing gender discrimination in the workplace suggest, again, that labour law (or human rights law) alone cannot be the only means of overcoming the problem, however, it must play a key role as an element of a State's regulatory strategy, and no less so where the specific target of that regulatory strategy is MSEs.

\section{Remuneration and working time}

Empirical evidence suggests that average incomes in the MSE sector are lower than in larger enterprises. ${ }^{179}$ In industrialized countries, average income levels in MSEs tend to be lower than in larger enterprises. ${ }^{180}$ While evidence for industrializing countries is more limited, existing surveys suggest that incomes also tend to increase with firm size. In Chile, a 1998 national survey found that small enterprise workers earn approximately 50 per cent of the income of those in large enterprises. The percentage of workers in micro-enterprises earning below the minimum wage was 14.7 per cent, which is almost five times the figure for medium and large enterprises. Cooke concluded from a survey of employers and workers in 24 micro and small commercial/retail shops in southern China that wages in MSEs were significantly lower than those in larger firms. ${ }^{181}$

176 Fredman, 2004, p. 299. Fredman observes that '[f]lexibility proceeds apace but security remains a rhetorical gesture'.

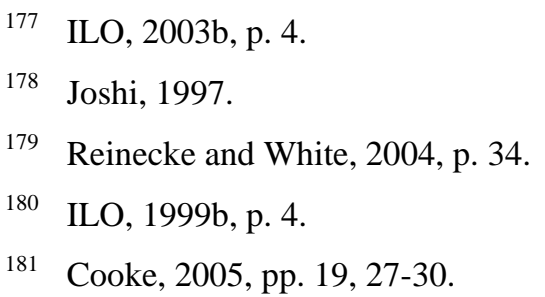


Working hours in MSEs tend to be longer than in larger enterprises. Studies in China, Viet Nam, Nepal, Thailand, and the Philippines all suggest that workers in the MSE sector work well beyond the statutory maximum number of working hours, that they are often required to work overtime with little notice, and that they often do so without compensation. ${ }^{182}$ MSE workers in Chile also work longer hours on average than the legally stipulated maximum, as do workers in many other enterprises. ${ }^{183}$

Drawing upon labour force survey data from Chile and Peru, Figure 9 demonstrates the correlation between enterprise size and lower job quality according to the indicators of average earnings and hours worked per week.

Table 7: Average earnings and hours worked per week for Chile and Peru, 2000

\begin{tabular}{|c|c|c|c|c|c|c|c|c|}
\hline & \multicolumn{4}{|c|}{ Chile } & \multicolumn{4}{|c|}{ Peru } \\
\hline & $\begin{array}{r}\text { Self- } \\
\text { employed }\end{array}$ & Micro & Small & $\begin{array}{l}\text { Medium } \\
\text { \& Large }\end{array}$ & Micro & Small & Medium & Large \\
\hline $\begin{array}{l}\text { Average earnings } \\
\text { (Total average } \\
\text { earnings }=100 \text { ) }\end{array}$ & 92.1 & 98.5 & 99.8 & 110.3 & 75.6 & 142.7 & 234.6 & 295.2 \\
\hline $\begin{array}{l}\text { Hours worked per } \\
\text { week }\end{array}$ & 51.0 & 50.5 & 50.5 & 50.6 & 42.0 & 43.6 & 51.5 & 49.8 \\
\hline
\end{tabular}

Note: A micro-enterprise is defined as an enterprise which employs 2-9 workers. For Peru, it includes self-employed. A small enterprise employs 10-49 workers and medium and large enterprises employ over 50 and 200 workers respectively. Average earnings for Chile refer to 1998. Source: Reinecke and White, 2004, p. 36.

These findings in relation to remuneration and working time are very significant, as these working conditions are absolutely fundamental for the maintenance of Decent Work. Without adequate income workers may fall into poverty or remain impoverished. The adverse effects of working without proper limits on compulsory working time, and their observation in practice, include illhealth for workers, and loss of those individuals' time as members of their families and wider communities. There are also risks for enterprises in terms of workers becoming fatigued, leading to lower productivity and higher risks to workplace health and safety.

These findings illustrate some of the major findings presented in Chapter 2: many States exclude MSEs from key aspects of their labour laws, including those relating to minimum wages. In some cases States effectively permit longer working hours in MSEs, allowing a higher maximum number of hours overtime a week for smaller enterprises. In the case of both wages and working time, many MSE workers are likely to be adversely affected also by the fact that whatever labour laws provide, there is a significant chance that they will not be obeyed in practice, and/or that the State will not enforce them.

A key rationale for excluding MSEs from the requirements of particular elements of labour law is that they are seen to impose unsustainable operational costs on MSEs. That is, States accept that the regulatory burden may well act as too great a brake on entrepreneurial activity, and constrain the capacity of MSEs to stabilize and to grow. The findings here suggest, however, that there are

182 Zheng, Lu and Idris, 2005, p. 4; Pham Thi Thu Hang, 2002, pp. 33-34; Noerlund, 1998, pp. 155, 166-168; Chapagain, 2001, pp. 22-23; Brown, Thonachaisetavut and Hewison, 2002, p. 17; and Bacungan and Ofreneo, 2002, pp. 110-111.

183 Flores, 2003, pp. 15-17. 
significant adverse effects for workers in such policies, whether they are exclusions from the formal scope or coverage of labour law, or failures to enforce and to apply the law in practice.

The challenge that States must then face is how to address these significant adverse effects, while at the same time endeavouring to continue to propagate MSE stability and growth. Here again, the application of labour law is at least one of the main policy interventions that States should consider. Labour law has a role to play as part of an innovative and responsive approach to labour regulation. It seems unlikely, however, that merely addressing the formal and practical application of labour laws to MSEs would bring about significant change that would benefit workers. Taking wages as an example, it is arguably cost-effective and economically logical for an enterprise to pay lower than minimum wages, especially where there is a significant pool of workers prepared to accept those wages. ${ }^{184}$ Thus, an innovative approach to labour regulation must be designed as part of a broader approach to economic development.

\section{Job security}

Instability and insecurity are pervasive in MSE work. ${ }^{185}$ In Brazil, despite the existence of relatively high levels of employment protection, a recent study has found significantly higher job creation and destruction rates for micro and small firms. ${ }^{186}$ High labour turnover in enterprises may operate as a disincentive for training and investment and thus further inhibit the economic and social development of both the enterprise and the individual worker. ${ }^{187}$ Even where laws regulating termination of employment formally apply to MSEs, the lack of enforcement often leaves workers vulnerable to arbitrary dismissal and with little effective means of redress.

Economic crises are often felt acutely by workers in MSEs, which are often the most vulnerable to bankruptcy. The 1998 economic crisis in Chile, for example, forced many MSEs into insolvency. MSEs that survived the crisis tended to economize by ceasing social security payments and reducing labour standards. ${ }^{188}$

The Danish 'flexicurity' model provides a contrast to the relatively high levels of job insecurity and vulnerability often experienced by MSE workers. In Denmark, relatively low levels of statutory employment protection are offset by the provision of high levels of income protection to unemployed persons, together with active labour market policies. This 'golden triangle' makes it relatively easy for employers to dismiss workers, while protecting unemployed workers from loss of both income and employability. In addition, access to publicly financed training schemes is relatively easy and everyone has access to the public employment services. This system provides Denmark with a high level

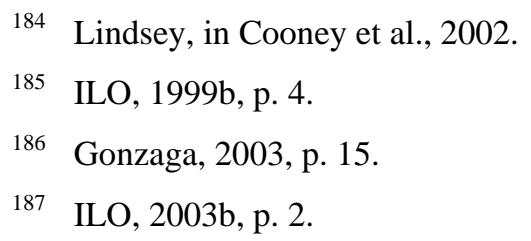

188 An ILO study of 300 MSEs in rural and urban Chile found that MSEs who survived the crisis of 1998-99 did not undertake radical employment reduction strategies but rather restructured employment by diminishing work hours and directly affecting job quality. Cited in Flores, 2003, p. 11. 
of labour mobility and flexibility while ensuring workers continue to feel a comparatively low level of job insecurity. ${ }^{189}$

While the Danish model has been successful, it is not obvious that all States would be able to emulate it. A developing economy in particular would face a significant range of challenges in attempting to implement its own version of 'flexicurity'. A key difficulty would be to generate a sustainable flow of revenue with which to support systems designed to provide security to workers in transition through the labour market. Whereas majority of MSEs, in an industrialized economy such as Denmark, participate fully in the formal economy, in a developing economy however majority of MSEs have at best a semi-formal and sometimes changing status with manifold difficulties. Among the inter-related areas of policy that States would therefore need to address are: linkages between formal and informal labour market institutions, extending social security coverage, strengthening employment services, the social partners and the labour administration, and promoting training. ${ }^{190}$ The application of labour law to MSEs, and innovative approaches to labour regulation would need to take their place in this broader universe of policy approaches and interventions.

\section{Social protection}

Most MSE workers lack any form of social protection, which includes mechanisms for health, life, disability and unemployment insurance, as well as pension schemes, childcare and maternity leave. ${ }^{191}$ In Latin America, it has been estimated that only 28.1 per cent of workers in micro enterprises (one to five workers) make social security contributions, ${ }^{192}$ and in Viet Nam, that 83.7 per cent of MSEs do not pay social security contributions. ${ }^{193}$ Research into compliance with social security provision in Chile found that the proportion of workers protected by social security increased with the size of the enterprise: while 58.3 per cent of workers in micro-enterprises enjoyed social security coverage, this rose to 82.3 per cent of workers in small enterprises and over 90 per cent for medium and large enterprise workers. ${ }^{194}$ Cooke found from his survey of MSEs in southern China that the level of social security enjoyed by workers was significantly lower than for larger enterprises, with over 80 per cent of workers' surveyed reporting that their employers did not pay into any pension or medical insurance scheme on their behalf, regardless of the legal requirements to do so. ${ }^{195}$

Workers in MSEs are also less likely to receive paid leave. A survey of MSEs in 2001 by the Vietnam Chamber of Commerce and Industry found that

\footnotetext{
189 The Danish feeling of job insecurity is the lowest in the European Union. OECD, 1999; Egger and Sengenberger, 2003 and Kongshøj Madsen, 1999. For a critical evaluation of the Danish model, see Kongshøj Madsen, 2002, p. 243.

190 De Gobbi, 2005, pp. 20-22.

191 ILO, 1999b, pp. 1-2.

192 This should be contrasted to 79.3 per cent of workers in private enterprises with 6 or more workers and the public sector: cited in Reinecke, 2005, p. 8.

193 Vietnam Chamber of Commerce and Industry, as cited in Pham, 2002, p. 32.

194 Flores, 2003, p. 17.

195 Cooke, 2005, p. 30.
} 
only 36.8 per cent of MSEs provided paid sick leave to their workers, as required by law. The same survey found that 88.1 per cent of MSE employers did not pay their female workers maternity benefits as required by law. In Kenya, a study of the MSE Bakery and Confectionary sub-sector found that, despite being legally entitled to a minimum of 21 days annual leave with full pay after every 12 consecutive months of service, workers in this sub-sector were not granted annual leave of any duration. The study also found that workers were not provided with sick pay or maternity leave as required by law. ${ }^{196}$

Making social security contributions on behalf of workers is an obvious and immediate cost to any enterprise, whether an MSE or otherwise. As we showed in Chapter 2, States have commonly responded to this by excluding MSEs from the requirement to make social security contributions. Ensuring social protection, however, is a key responsibility of the State, and a major element of a Decent Work agenda. The findings presented here suggest that it is one that requires particular attention in the short term. As we discuss further in the next chapter, several States have developed innovative ways to increase the scope of coverage of social security and social protection, including by gradually extending coverage to smaller enterprises in general, and/or to regions or industries in which smaller enterprises predominate.

Figure 3: MSEs providing social security coverage, 2001

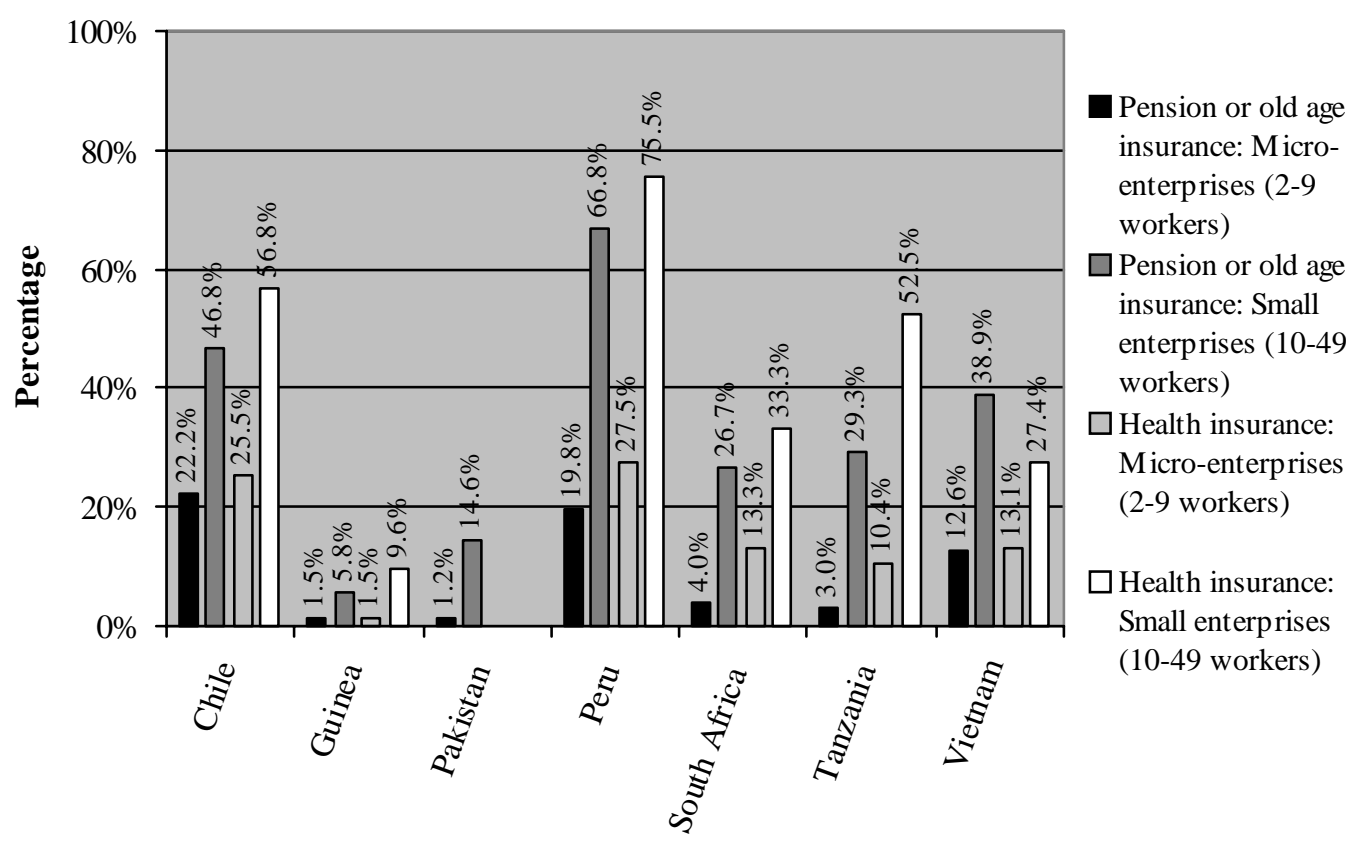

Note: Data refers to answers provided by enterprise owner-managers. A positive answer does not necessarily imply social security for the entire workforce in that enterprise. In Chile, contributions to the pension scheme and health insurance are paid entirely by the employees, which may mean MSE owner-managers did not mention social security as a benefit. For Pakistan, the question refers to 'pension/insurance scheme'.

Source: ILO MSE Surveys 2001, as cited in Reinecke and White, 2004, p. 101. 


\section{Occupational health and safety}

Workers in MSEs are more frequently exposed to workplace hazards and suffer more work-related injuries and illnesses than employees in larger workplaces. ${ }^{197}$ Compliance with occupational health and safety regulations in MSEs is very limited. ${ }^{198}$ In Chile, MSEs are more likely to breach occupational health and safety laws than larger enterprises. ${ }^{199}$ In China, lack of facilities for basic hygiene, frequent industrial accidents, and exposure to air and noise pollution and to high temperatures are widespread. $^{200}$ In Indonesia, commentators have observed that compliance with universal occupational health and safety standards is also very low. ${ }^{201}$ In Viet Nam, a recent survey conducted by the Ministry of Labour, Invalids and Social Affairs indicated that around eighty per cent of MSEs reported not using protective work clothing or applying the concept of safety at work. ${ }^{202}$ In Ghana, an ILO study has found that workers in MSEs often work in unsafe and unhealthy work environments. ${ }^{203}$

The methodology of this study makes it difficult to say whether these findings are a result of MSEs being excluded from the coverage of relevant aspects of labour laws. In many cases the exclusions in this area (identified in Chapter 2) were from requirements to consult employees in a formal structure about occupational health and safety, rather than exclusions from employers' obligations to provide a work environment that is safe and without risks to health. It might be noted, however, that if the rationale for excluding MSEs from the requirement to establish formal consultation mechanisms is that the nature of work in MSEs means that there is a greater level of ongoing interaction and communication, then it is not obvious that it is leading to satisfactory health and safety outcomes. At all events, the safety of workers must be a paramount concern of any employer, whether in an MSE or otherwise. For the State, securing the health and safety of workers must be a crucial element of a Decent Work agenda. Without a policy approach that addresses this, the risk is only of longer-term increases in costs to enterprises and to the State, and/or to informal social protection mechanisms where formal mechanisms are inadequate. One approach to the many difficulties of applying health and safety laws to very small enterprises is to draw on representative structures in the trade union movement, and give them a role at the regional level, as happens in Sweden. ${ }^{204}$

\section{Human resource development}

MSE employers often are unaware of, or cannot easily access, training opportunities. Larger enterprises generally benefit more from state provided

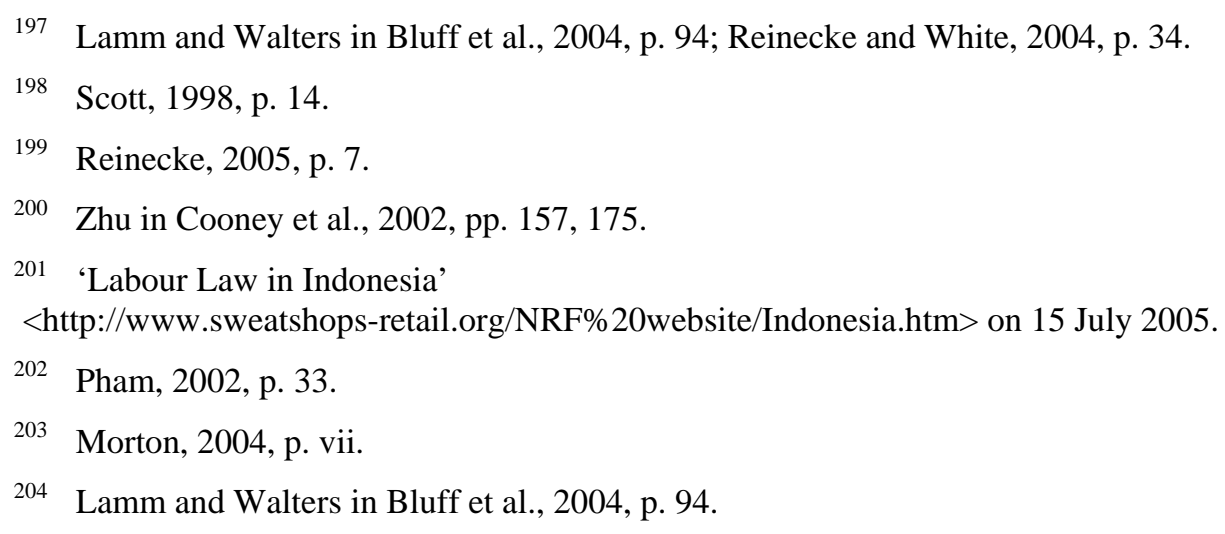


training opportunities than smaller enterprises. In Chile, the SENCE Reform 1996 (Servicio Nacional de Capacitacion y Empleo) was designed to improve access for MSEs to training opportunities. However, evaluations of the service conclude that medium and large enterprises were the main beneficiaries. Flores suggests that the study indicates that 'MSEs are failing to access the private organizations that are providing public facilities under government supervision and subsidy ${ }^{205}$ Where non-compliance with minimum labour standards in MSEs is often attributed to a lack of knowledge and information on the part of MSE employers, training may perform a critical role in improving job quality in this sector. As we note in the next chapter, education, information and training all have key roles to play in part of an overall approach by the State to labour regulation.

\section{Management and organization}

Research suggests that labour relations in small firms differ significantly from those experienced in larger firms. Typically, they are described as being more 'informal' in nature. ${ }^{206}$ The informality of labour relations in the MSE sector is often attributable to the close personal or familial relations between MSE employers and workers. ${ }^{207}$ Owner-managers generally enjoy a more dominant role in determining how the business is to be run and the nature of terms and conditions of work for their employees. In China, for example, research suggests that workers in the MSE sector generally accept the terms and conditions offered to them rather than considering bargaining for increased wages or conditions. ${ }^{208}$ There appear, however, to be large discrepancies according to the country context. In Ghana, a survey of MSEs found that 60 per cent of employees surveyed felt that they were consulted always or usually with regard to decisions that affected their work. Seventy-four per cent of employers reported consulting with their employees always or usually. ${ }^{209}$

Cultural factors clearly play an important role in determining the nature of labour relations in small firms. It has been suggested, for example, that in China labour relations in small firms reflect to some degree the 'Chinese values' of maintenance of social relationships and maintenance of harmony, with overt confrontation as a last resort. ${ }^{210}$ In Viet Nam, Nguyen and Bryant note that 'appeals to family loyalty and the good of the family business will take precedence over individual needs'. ${ }^{211}$ In Thailand, researchers have questioned the way in which formal labour laws and regulations fit with the 'distinctive character of Thai industrial relations'. Researchers often highlight the paternalistic nature of management in Thai enterprises and the docility and

\footnotetext{
205 Flores, 2003, pp. 157, 17.

206 Cooke, 2005, pp. 31-32.

207 In Viet Nam, SMEs rely largely on their families and friends as the main sources of capital and labour. Nguyen and Bryant, 2004, pp. 595, 598.

208 Cooke, HRM, Work and Employment in China, 2005, pp. 76-77.

209 Morton, 2004, p. 12.

210 Cooke, 2005, p. 31.

211 Nguyen and Bryant, 2004, pp. 598-599.
} 
powerlessness of the individual employee. ${ }^{212}$ Social norms relating to gender and forms of disciplinary power may also influence workplace relations. ${ }^{213}$ In contrast, in Denmark, a recent ILO report found that the success of Danish small firms is built on their willingness to cooperate with each other, and on the strength of social dialogue between workers' and employers' representatives. It is further supported by the broader regulatory and market environment including in product and technology development, export promotion, credit financing, workforce training, and social and labour market security. ${ }^{214}$

\section{Other factors affecting MSE job quality}

While the aggregate picture suggests working conditions improve as the size of the enterprise increases, there are important exceptions to this rule. For example, a 1990 ILO study found that in some countries, the differences associated with enterprise size were greater than in others. This suggests that there are other factors influencing labour standards. One variable identified as influencing the quality of work in MSEs is the economic sector in which they are located. Research in China has found significantly higher rates of lead poisoning in smaller enterprises in the lead sector, but much higher dust levels in larger enterprises in brick making and mining sectors. Research in the UK suggests that small enterprises in particular sectors may provide better incomes and working conditions than their counterparts in other sectors. ${ }^{215}$

The geographical location of the MSE may also affect the incomes and working conditions of its workers. Average pay for a rural worker in Viet Nam is about half that of an urban worker and the hours of work are, on average, significantly longer. ${ }^{216}$ In the Philippines, non-compliance with minimum wage and other labour standards is higher in the regions outside metro Manila. ${ }^{217}$ This suggests that the States' regulatory policy for labour and labour related laws in MSEs must be designed so as to take into account important regional and other geographic variations. In particular, it suggests that the resources of the labour administration should not be concentrated or located predominantly only in the major urban areas.

\section{Formalization of MSEs}

It is widely accepted that 'formalization' of MSEs is desirable in economic development terms. Previous studies have noted that government policy to promote formalization is a key factor, and have noted the argument that labour laws are one of the main regulatory obstacles to business formalization. ${ }^{218}$ The present study suggests, however, that the relationship between 'formalization'

\footnotetext{
212 Manusphaibool, in Deery and Mitchell (eds.), 1993, pp. 262-263.

213 See Cooney and Mitchell's brief discussion of norms operating in the workplace, in Cooney et al., 2002, pp. 264-266.

214 Egger and Sengenberger, 2003, p. 46.

215 Sengenberger, Loveman and Pierre (eds.) in ILOb, 1999, p. 5.

216 Pham, 2002, p. 29.

217 Ofreneo, 1994, p. 12.

218 Reinecke and White, 2004, p. 68.
} 
and MSE attitudes to labour and labour-related laws is complex. The argument that application of labour laws to MSEs would inevitably entail 'over-regulation' of business which impedes economic growth is a simplistic one: it overlooks many of the benefits that 'compliance' can have for MSEs. It also fails to take into account a diverse range of regulatory practices that government can employ to facilitate desired policy objectives in this area. At the same time, there is no clear and compelling evidence that excluding MSEs from the application of labour laws, either formally or in practice, is a significant factor in promoting formalization. It is difficult, however, to obtain data to address this issue. A key deficiency is that many States do not have accurate or recent labour market data. Those States that do develop and promulgate such data often do not disaggregate it by reference to MSEs, so it is difficult at best to isolate the effect on them of labour law, as distinct from other factors that may affect their economic performance and growth.

\section{Numbers of formalized enterprises: An indicator of successful outreach to MSEs}

MSEs are most likely to operate formally in an environment that is conducive to investment and business, and in which compliance with regulations is not prohibitively costly. ${ }^{219}$ The cost of conforming to regulatory requirements for MSEs is however often disproportionately higher than for larger enterprises. ${ }^{220}$ Reforms aimed at simplifying and reducing the cost of registration are generally therefore of greatest benefit to MSEs, as costs of registration procedures are largely fixed, and compliance with enterprise laws generally accounts for a significant percentage of MSEs' total cost structure. ${ }^{221}$ The ILO has noted in its Job Creation in Small and Medium-Sized Enterprises Recommendation 1998 (No. 189) that unduly burdensome regulation should be lifted, but linked this to the importance of job quality, calling for States to remove 'inappropriate, inadequate or overly burdensome registration, licensing, reporting and other administrative requirements, including those which are disincentives to the hiring of personnel, without prejudicing the level of conditions of employment, the effectiveness of labour inspection or the system of supervision of working conditions and related measures.'

Measuring the impact of different regulatory structures upon levels of enterprise formality is however problematic. Among other things, it can be very difficult in practice to distinguish the formalization of pre-existing enterprises from changes in legal status, or the start-up of new enterprises. ${ }^{222}$ Moreover, as noted, key labour market data including information on productivity and employment is often not disaggregated by reference to size of enterprise.

A limited amount of research has been done on these issues in Latin America. Research from Chile suggests that the risk of incurring fines or sanctions is not alone sufficient to motivate enterprises to formalize their

\footnotetext{
219 ILO, 2002b, p. 27.

220 Flores, 2003, p. 19.

221 Reinecke and White, 2004, p. 90.

222 Reinecke, 2005, p. 11.
} 
business without concurrent benefits. ${ }^{223}$ Similarly, from her research into the informal MSE sector in Lima, Peru, Zuin concluded that the simplification of, and cost reduction in registration was not sufficient to foster formalization. Incentives, such as access to credit or to markets, were essential in inducing enterprises to join the formal sector. ${ }^{224}$

Although it is very difficult to measure the extent to which regulatory reform succeeds, it appears that the Peruvian approach of establishing a parallel labour law regime for MSEs has not been successful. In late 2004, only 1,243 enterprises had registered under the special labour regime. This number may be compared with more than 300,000 enterprises that had registered under a regime that provides tax incentives for micro-enterprises. The failure of the Peruvian scheme is attributed largely to the onerous administrative requirements. In Shanghai, by contrast, efforts to promote employment through 'informal labour organizations' have arguably facilitated the formalization of some MSEs. The Shanghai approach is outlined in some detail later in this report.

\section{Costs and benefits of compliance with labour and labour-related laws}

The cost in money and time for registration of a new enterprise is often viewed as an important contributing factor to informality. Registration procedures in some countries may be costly and time-consuming. Reducing the cost and difficulty of registration for enterprises should therefore facilitate their entry into the formal economy. Workers within these MSEs are then theoretically subject to formal labour laws and regulations, and to inspection and monitoring by State agencies, as well as by other actors in the domain of enforcement, such as trade unions. According to an ILO SEED Progress Report, workers in the formal economy are more likely to enjoy social protection:

As wages in micro and small enterprises are often low, workers find it difficult to save for periods of illness or injury. Their ability to benefit from national social insurance, such as health care and unemployment insurance, is dependent upon the firm being part of the formal economy and on the employer paying contributions into these schemes. ${ }^{225}$

It is evident then that formalization alone cannot guarantee improvements in labour standards for MSE workers. ${ }^{226}$ Given that labour standards are frequently not applied in practice among MSEs, it is unclear whether policies aimed at facilitating the registration of MSEs actually contribute to improved job quality. Nevertheless, the approach of facilitating formalization has significant potential: in many countries the different administrative steps required to formalize are inter-related, which at least makes it more likely for a formalized enterprise to comply with labour law. Moreover, occupational health and safety is one area in which empirical evidence suggests that it is possible to devise regulatory requirements that will be within both the economic and the knowledge

\footnotetext{
223 Ibid., p. 6.

224 Zuin, 2004, p. 1.

225 ILO, 2004b, p. 17.

226 Zuin, 2004, p. 24.
} 
constraints of MSE employers. ${ }^{227}$ This is a significant finding: good occupational health and safety outcomes are critical for maintaining and developing workers' productivity; these in turn are closely linked to development goals and stimulation of greater growth.

Where social security is concerned, however, ill-designed or overly burdensome schemes may increase the cost of compliance, and provide further disincentives for MSEs to comply with legislation, and to formalize operations more generally. In Viet Nam, for example, the low rate of social security contributions by both employers and employees has been attributed in part to the fact that the social insurance scheme limits labour mobility and because many employees don't trust the State to deliver funds when they are entitled. ${ }^{228}$ In a 2003 draft report, Allal suggests that the failure of many employers and employees to make mandatory social security contributions may be attributable to the prohibitive costs of the scheme in MSEs. In a study on the informal sector in Ecuador, both workers and employers attributed their low participation in social security schemes to low salaries and low profit margins of the enterprise, which precluded them from contributing to the schemes. ${ }^{229}$

While it is common for commentators to emphasize the economic limitations on MSEs in providing decent work for employees, research has emphasized that the basis on which MSEs compete may have a critical influence on the level of job quality enjoyed by its workers. A World Bank survey of manufacturing enterprises in Malaysia found that size itself was not necessarily a limiting factor on enterprises achieving higher efficiency or job quality. Efficient enterprises in Malaysia tended to compete on the basis of emphasizing and ensuring quality. They were also active in acquiring technology through licensing, joint venture and exports. They emphasized training and practiced human resource development policies that encouraged job stability and the acquisition of further skills. ${ }^{230}$ This finding was supported by a study conducted by the ILO in the late 1990s of export processing zones. The study found that quality conscious and innovative enterprises were 'invariably setting standards which are higher than national norms for wages, working conditions, health and safety and training'. As noted in Job Quality and Small Enterprises, the evidence suggesting that enterprises that compete on the basis of quality are more likely to provide higher remuneration and working conditions has important implications for strategies to raise job quality in MSEs.

A 1995 OECD survey of MSEs in the informal economy in seven countries found that the main reason MSE employers gave for failure to comply with minimum wage legislation was that the cost was too high and that it is a fixed cost. Revenues of MSEs fluctuate too much to allow the MSEs to pay fairly good wages on a regular basis. While some employers may pay below the minimum wage when business is poor, some also grant bonuses and payment in kind when business is good.

\footnotetext{
227 Scott, 1998, pp. 19-20.

228 Nicholson, in Cooney et al. (eds.), 2002, pp. 142-143.

229 Allal, 2003, p. 2.

230 Cited in ILO, 1999b, p. 5.
} 
Research into the Nepalese MSE sector found that one of the main reasons offered by employers for not conforming to minimum labour standards was that employees preferred to work for longer than the legislated 8 hour day in return for the provision of lodging and food. By working overtime, the workers can receive meals for the day, and are often assured somewhere to spend the night. In this way, they are able to meet the two principal costs for workers in urban areas. $^{231}$

\section{Growth constraints: What does the evidence say?}

The argument in favour of excluding MSEs from the application of labour laws is that this will lighten their regulatory burdens, encouraging entrepreneurship and growth. Against this is the concern that exemptions for MSEs from labour law requirements may create a 'growth trap': as enterprises grow close to the relevant threshold they may choose to remain small so as to avoid additional regulation and related costs.

As we have noted, data on the extent to which labour laws and regulations influence the investment and employment behaviour of MSEs is difficult to obtain. Surveys that have been done for the ILO have tended to focus on employers' subjective perceptions of growth constraints, rather than on any objective criteria by which growth constraints might be measured. This does not mean that the data has no value: employers' perceptions are clearly very influential, as they constitute the basis upon which the entrepreneurs make investment and employment decisions. ${ }^{232}$ Research done for the ILO's IFP/SEED suggests that MSE employers do not identify labour laws and regulations as a principal growth constraint. ${ }^{233}$ MSE employers generally identify access to credit and markets as the main obstacles to small enterprise development. ${ }^{234}$ Regarding government regulation, MSE employers appear most negative towards taxation, which most MSEs surveyed identified as the leading legal constraint on their business. ${ }^{235}$

\footnotetext{
231 Chapagain, 2001, p. 26.

232 Drying Christensen and Goedhuys, 2004, p. 2.
}

233 The IFP/SEED Programme was initiated in 2001 by a research study entitled 'Do Decent Jobs Require Good Policies - an Assessment of the Impact of Policy and Legal Environments on the Creation and Improvement of Jobs within Small Enterprises'. The study involved surveys of approximately 300 MSEs in each of 7 countries: Chile, Guinea, Pakistan, Peru, South Africa, Tanzania and Viet Nam. Ibid., pp. 34-36.

234 Reinecke, 2005. In relation to Tanzania, Olomi has also concluded that access to markets rather than policy and regulatory frameworks exert the strongest influence on the decision of MSEs to employ more workers and on the quality of employment provided. Olomi, 2005, p. 2. Similarly, in South Africa, Godfrey and Theron have found that small businesses regard the lack of promotion of the small enterprise sector (especially a lack of access to credit) as a growth constraint at least on par with labour standards: Godfrey and Theron, 1999, p. 57.

235 See the OECD’s survey of MSEs in Algeria, Ecuador, Jamaica, Niger, Swaziland, Thailand and Tunisia. Each country survey involved 300 enterprises, from self-employed to enterprises with up to 20 workers. Morrison, 1995. 
The conclusion that MSE employers do not regard labour regulation as a principal growth constraint is supported by a 1995 OECD survey of seven countries. This survey suggests that MSEs do not regard labour laws as significantly hampering their operations or preventing them from expanding. Also supporting this conclusion, a recent survey of MSEs in Uttar Pradesh, India, found that around 80 per cent of MSE entrepreneurs surveyed perceived labour laws as having no influence on decisions to invest in expansion of the business. ${ }^{236}$

Focusing on the policy environment alone, the IFP/SEED survey of seven countries found that labour costs, labour regulation, government policies and taxation are perceived as the least conducive factors for employment creation. ${ }^{237}$ The table below, drawn from the research carried out by the ILO's IFP/SEED, shows how different factors affect the decisions of MSE employers to improve working conditions.

These findings suggest that 'entrepreneurs view taxation and policies, albeit low in terms of ranking, as conflicting with their willingness to improve working conditions'.

The IFP/SEED survey also found that MSE employers were more willing to provide benefits to workers that they regard as contributing to enterprise performance. Examples include on-the-job training, productivity incentives, salary increases and safe working conditions. ${ }^{238}$ MSE employers are less willing to comply with labour regulations pertaining to written contracts, insurance schemes and parental leave.

These findings have significant implications for State-directed regulation of labour and employment in MSEs. In the first place, they clearly show that MSE owners do not consider the costs associated with compliance with labour laws to be a significant constraint on the potential for their enterprise to growth. As against this, it might be noted that an important possible weakness with this data is that it may be drawn from surveys of people for whom the cost of applying with labour law is theoretical: many MSEs are excluded from labour law formally, or do not comply in practice. Thus, asking this group whether the application of labour law may significantly constrain their enterprises' growth may not have produced significant results. As against that, however, it is clear from the data that MSE entrepreneurs make strategic decisions about which elements of the regulatory environment most affect their decisions about regulatory compliance. This suggests that the State should develop regulatory policies that take this into account; that is, regulatory approaches that are 'responsive' to the nature of the regulated community. A related point is that the findings suggest that entrepreneurs themselves do not necessarily oppose the application of labour law, or the increase in compliance costs which that may bring. This has important implications for States' ability to develop innovative regulatory approaches in consultation with the social partners themselves.

\footnotetext{
236 Singh, Joshi and Mehta et al., 2004.

237 Drying Christensen and Goedhuys, 2004, p. viii.

238 Ibid., pp. 42-43.
} 


\section{Figure 4: Ranking of factors influencing decisions related to working conditions}

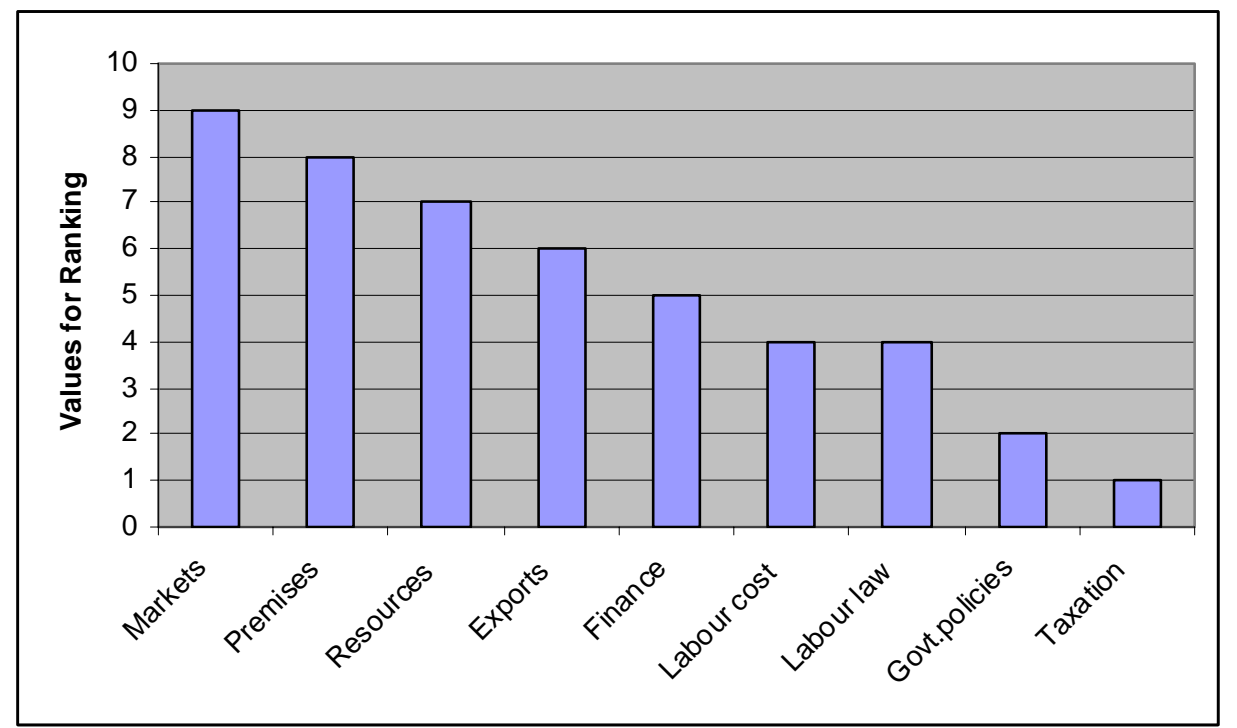

Source: Drying Christensen and Goedhuys, 2004.

A key issue that States must come to grips with in designing those innovative approaches to labour regulation is a full appreciation of the costs and benefits of the application of labour law to MSEs. Without doubt, requiring all enterprises to comply with all elements of the labour law framework would be likely to impose costs that many smaller enterprises simply could not bear. This fact is presumably what underlies the widespread policy of excluding MSEs from some parts of, or (in some cases) all labour and labour-related laws. This approach, however, focuses only on the immediate, operational costs that enterprises incur in complying with labour laws. It may overlook, and fail to account for the longer-run benefits that can flow to enterprises from compliance with labour law, in the form of more skilled, contented and productive workers. In other words, it overlooks the distinction between short-run and long-run costs, and indeed runs the risk of creating and continuing to impose significant longrun costs at a broader level than the particular enterprise. Keeping enterprises small will tend to keep them less productive than larger enterprises. This in turn will tend to contribute to continued lower incomes where there is a predominance of smaller enterprises, as in the majority of developing economies. It may therefore have harmful developmental effects at the macro level.

It is also important for States to consider the significance of the finding that MSE owner/entrepreneurs do not consider the application of labour law to be a major constraint on their growth. What this suggests is that States might better support MSEs by focusing their policy energies on interventions that support the development and growth of the markets in which MSEs might themselves develop and grow. Among other things, they may find it effective to develop and apply strategies to support and enhance product markets. Enterprises that compete in product markets on the basis of product quality do so best by developing an enterprise culture that depends upon higher skills and productivity among their workforce. In other words, they also need to compete in the labour market on the basis of job quality. ${ }^{239}$ Thus, economic development strategies that encourage enterprise growth and competition in product markets may itself lead 
to better compliance with labour law, especially where it is retained as a key element of an innovative labour regulatory strategy.

\section{Labour law, gender and geography}

MSEs display great variety of form and function. That combination of ubiquity and heterogeneity - of sameness and difference - is important for the design of innovative ('responsive') regulatory policies. MSEs are, in particular, vital sources of employment and growth for both men and for women, and in both rural and urban areas. States must therefore endeavour to take into account these key variables in designing labour regulation for MSEs.

There is little empirical information available on the proportion of MSEs owned by men and women and on the influence of female ownership on rates of formalization. In Zimbabwe, a 1991 study found that women run 67 per cent of micro and small enterprises, while the enterprises run by men tend to have a larger average number of employees. ${ }^{240}$ There is also evidence that females are dominant in certain sectors of the economy, such as those with low barriers to entry, low skill requirements and low financial returns. ${ }^{241}$ Female entrepreneurs often face greater formal and practical constraints relating to securing resources and property, income generation, access to credit and financial services; accessing opportunities for developing relevant skills and training; and accessing market support.

While the relevance of gender-specific features of male and female entrepreneurs differs according to the particular country context, empirical research suggests that there are certain identifiable gender characteristics in enterprises run by men and women. ${ }^{242}$ Enterprises run by women tend to be younger and smaller in terms of the number of workers and the value of fixed assets. Women tend to rely more on unpaid family labour and to use less modern technology. Enterprises run by females also tend to be concentrated in low investment sub-sectors that build on their traditional skills, but which are less remunerative. Women also register their enterprise less frequently than men, and often operate within the home. A survey of several African and Asian countries found the contrast in registration most striking in Tunisia and Zimbabwe, where 90 per cent and 22 per cent respectively of the male-owned enterprises were registered; in contrast to 48 and two per cent respectively for female-owned enterprises. In the Philippines, gender appears a much less significant factor in determining whether an enterprise is registered. ${ }^{243}$

There is, however, no strong evidence to suggest that female-run enterprises are less successful in expanding employment. ${ }^{244}$ While there appears to be a

\footnotetext{
240 Marcucci, 2001, p. 12.

241 ILO, 2002b, p. 96.

242 Marcucci, 2001, pp. 47-48.

243 Ibid, pp. 51-52; Drying Christensen and Goedhuys, 2004, p. 26.

244 In Peru, around 80 per cent of the female entrepreneurs surveyed have succeeded in growing their business, in contrast to around 72 per cent for male entrepreneurs. It is observed that there is no significant difference in the likelihood of expansion in Chile, South Africa, Pakistan and Viet Nam.
} 
dearth of evidence on the attitude and levels of compliance with labour laws and regulations according to the gender of the enterprise owner, a survey of MSEs in Chile found that female employers were more likely to respect legal obligations than male employers. ${ }^{245}$

The rate of formalization of MSEs with various state authorities appears to vary according to the size of the enterprise and its geographical location. An IFP/SEED study of approximately 300 MSEs in 7 countries (Chile, Guinea, Pakistan, Peru, South Africa, Tanzania and Viet Nam) has found that, with the exception of Guinea, small enterprises (more than 10 employees) are registered with revenue authorities at a higher rate than micro-enterprises (1-9 employees). ${ }^{246}$ Urban-based enterprises are more likely to be registered than rural-based enterprises. ${ }^{247}$ Registration with labour departments also appears to vary according to the size of the enterprise. Generally, small enterprises are registered at higher rates than micro enterprises, with the exception of Viet Nam. ${ }^{248}$ Christensen and Goedhuys conclude from their analysis of the IFP/SEED survey that it suggests 'a robust correlation between the degree of compliance with labour regulations and the size of the enterprise; as the enterprise grows compliance increases.'

\section{Conclusion}

The findings clearly show that job quality in MSEs is almost universally low, whether considered from the point of view of observance of fundamental labour rights, or key working conditions such as wages and working time. Chapter 2 showed that the majority of States exclude MSEs from some part of their labour laws. There is therefore a correlation between exclusion from labour law and poor job quality. However, it is difficult to conclude on the basis of this study, given its methodology, that there is also a causal relationship. Nevertheless, the correlation is significant, as labour law has significant potential to contribute positively to the promotion and enforcement of job quality. It is at least not possible to exclude the hypothesis that excluding MSEs from the application of labour law has an adverse effect on workers' job quality.

The findings are also significant in another respect: they do not clearly establish that excluding MSEs from the application of labour law to MSEs has a significant positive impact on whether or not MSEs seek to formalize. Indeed, there is limited data presently available that would make it possible to isolate the effect of labour law and the costs associated with compliance on MSEs. At the same time, there is some empirical evidence to suggest that MSE owner/entrepreneurs do not themselves consider compliance with labour law likely to be a significant constraint on their enterprises' potential for growth. This in turn suggests that there may be room for the State to develop regulatory

\footnotetext{
245 Reinecke, 2005, p. 9.

246 See 'Table 10: Business Income Tax Registration by Size’, in Drying Christensen and Goedhuys, 2004, p. 25.

247 Ibid. See 'Table 11: Business Income Tax Registration by Size and Location'.

248 Drying Christensen and Goedhuys, pp. 26-27. The lower rate of registration for Viet Nam may be explained by the fact that registration with labour departments is not compulsory in Viet Nam.
} 
approaches that involve greater application of labour law to MSEs, without running the perceived risk of restraining their potential for growth.

Taken together, these are significant findings: they suggest among other things that from the point of view of job quality - of Decent Work - that there may be a pressing need for greater application of labour law, both in its scope and coverage, and in its application in practice. As we note in the next two chapters, there is an important link here to key development goals, in particular the generation of greater 'human capability' and the significance of this in turn for economic development more generally. At the same time, however, considering how to promote job quality in MSEs, while encouraging them to participate in the formal economy, requires States to consider the place of labour law within their overall policy approach: if the strength of markets is the greatest influence on the profitability and growth of MSEs, then regulatory strategies that focus energy in this direction must also be developed. 


\section{CHAPTER 4 \\ CREATING AN ENABLING ENVIRONMENT THROUGH INNOVATIVE LABOUR REGULATION}

\section{Chapter summary}

- $\quad$ States can adopt innovative approaches to the application of labour law to MSEs that promote Decent Work as part of a broader regulatory environment that facilitates MSE growth and formalization.

- The question for States is not whether or not they should regulate but how they can make regulation more effective.

- Carefully designed labour law and labour regulation frameworks can play an important positive role in promoting a Decent Work agenda for MSEs.

- A number of States have developed and implemented innovative approaches to the formal and practical application of labour laws to MSEs.

\section{Introduction}

This chapter suggests ways in which States can adopt innovative approaches to the application of labour law to MSEs: it shows how States can promote Decent Work as part of a broader regulatory environment that can facilitate MSE growth and formalization. The chapter first considers how States might draw on development theory, comparative law analysis, and regulation theory to establish a coherent approach to labour regulation policy. It then presents examples of innovative approaches to labour regulation, and explains how they illustrate aspects of the theoretical approaches to policy development.

\section{A theoretical framework for developing and assessing innovative regulation}

Improvements in job quality are inextricably bound up with the need to pursue the twin goals of alleviating poverty while increasing enterprise productivity. As these are the two major preoccupations of development economics it is necessary to recall that some in this field argue that the simplification of business regulation and increased labour flexibility (amongst other measures) offer the most likely route to improved economic performance. This view is advocated, for example, in the recent report of the Commission on the Private Sector and Development entitled Unleashing Entrepreneurship: Making Business Work for the Poor, which relies on the World Bank's regular review of doing business. ${ }^{249}$ The World Bank’s report Doing Business in 2005 asserts: '[with] rigid employment regulation, few people will be hired, with women, young and low-skilled workers hurt the most. Their only choice is to seek jobs in the informal sector. ${ }^{250}$

In a global survey of States' practices in relation to employment termination regulation, the ILO has previously identified significant flaws with this concept

249 United Nations Development Programme, 2004.

250 World Bank, 2005, p. 3. 
of perceived rigidity in employment regulation. Among other things, it overlooks the critical question of whether this type of increased flexibility will lead to the creation of jobs of sufficient quality - that is, of Decent Work. Often the work that is created by greater flexibility is insecure, casual and/or part-time work. It is also true that employment protection measures can stimulate longer-term positive benefits by giving employers an incentive to invest in the training and skills of their workers (and therefore their productivity), and so also in the profitability of their enterprise. ${ }^{251}$ It should also be noted that the OECD has suggested that dismissal costs alone may not be a significant factor in determining levels of employment, when wage levels and the macroeconomic environment are taken into account. ${ }^{252}$

The findings of this study into the scope and design of labour law and its application to MSEs also show that there are several major flaws with an approach that sees regulation as causing unnecessary rigidity in the labour market. Firstly, many countries have already introduced considerable flexibilities, and the labour supply has become more elastic, but this has not led to employment growth in the formal economy. Instead, there has been growth in the informal economy, accompanied by decreasing real wages, contributing to a vicious cycle of underdevelopment and increased vulnerability. ${ }^{253}$ Secondly, given low levels of enforcement and compliance with labour laws, it is difficult to conclude that labour laws are to blame for the relative size of the formal and informal economies, or for the proportion of MSEs in the economy. ${ }^{254}$ Indeed, there are various economic explanations for the growth of the informal economy in many countries around the world that are unrelated to the nature of the labour laws. Thus there is no reason to think that labour regulation cannot help to facilitate development.

It should also be noted that limiting regulation of employment security in the name of greater labour market flexibility (a key example for the World Bank's case that regulation should be wound back) may lead to unanticipated types of rigidity in the labour market. ILO research carried out in Central and Eastern Europe, for example, suggests that workers may not have trust that new jobs are quality and sustainable, which can discourage them from taking up new employment opportunities. This can lead to inefficiency if it prevents workers from moving to more productive forms of work as they become available.

These considerations suggest again that the question for States is not whether to regulate, or how much to regulate labour markets, but rather what sort of regulation will be simplest and most effective. As the World Bank itself has noted, a positive climate for doing business - one that is cost-effective - is not one without protection, or without regulation. ${ }^{255}$ The World Bank has also acknowledged the importance of regulating to protect workers' fundamental rights, which is 'the minimum regulation necessary for the effective functioning

\footnotetext{
251 ILO, 2000b, pp. 11-14.

252 OECD, 1999, pp. 75-82.

253 Mkandawire and Rodriguez, 2000, p. 14.

254 The collection of papers in the special addition of the Journal of Labour Economics (1995) titled Labour Market Flexibility in Developing Countries demonstrate how difficult it is to generalize about the effect of labour market regulation across regions.

255 World Bank, 2006, p. 4.
} 
of labour markets. ${ }^{256}$ This concept of the necessary minimum content of labour market regulation shows therefore the link between sound labour market regulation and job quality, that is, with Decent Work. It also shows again that the choice for States is not between regulation or absence of regulation, but about types of regulation.

\section{Theories of development}

There are three approaches to development that can help the formulation of policy for Decent Work in MSEs, while promoting formalization:

a. Sen's human capability approach; ${ }^{257}$

b. Development Economics; and

C. New Institutional Economics. ${ }^{258}$

a. Human Capability Approach. The framework has been utilized by policy makers in various institutions around the world, including the UNDP. ${ }^{259}$ According to this approach, human capabilities are directly relevant to people's well-being and freedom, while indirectly they have the capacity to influence social change and economic production. ${ }^{260}$ Sen's notions of freedom, well-being and social change have clear corollaries in the basic labour law concepts of freedom of association, the social protection afforded by labour standards, and the political and technical roles of trade unions, employers' associations and tripartite institutions.

There are also clear links to the role of the labour market, which involves matching capacity with opportunities. ${ }^{261}$ Thus, in the context of labour, 'capacity' refers to the skills, knowledge and attitudes of people (workers), and how, in using these skills, they can take advantage of the labour market and other 'opportunities' available to them. In this sense 'opportunities' means the alternatives available to people to use their capacity (their skills, knowledge and attitudes) as a way in which to gain financial or personal reward. ${ }^{262}$ This study has shown that job quality in MSEs is almost uniformly low, and that this is

256 World Bank, 2004, p. 29.

257 Sen's capability approach was developed gradually over a number of years and his writing spans various disciplines. An understanding of the capability approach therefore requires reading a varied body of work. Many of the problems in interpreting Sen's work were clarified in his 1993 overview article: 'Capability and well-being' in Nussbaum and Sen (eds.), 1993, p. 30.

258 Other approaches to development may also be used to develop an understanding of labour regulation, including those that focus on sustainable livelihoods, and empowerment: see Trebilcock, 2006, p. 63.

259 The Chief Executive of the Department of Labour, John Chetwin, requested his staff to 'begin a project to establish a framework for developing policies relating to the development of New Zealand's human capability', Department of Labour, Corporate Plan 1999-2000, 3, cited in Tipples, 2004, p. 57.

\footnotetext{
260 Sen, 1999, pp. 296-97.

261 Bartley et al., 2001, p. 149.

262 Tipples, 2004, p. 5.
} 
deeply linked to both skills and to productivity. From a human capability point of view, this means that the capabilities of workers are underdeveloped.

The Human Capability approach can also be used to examine efficiency issues. ${ }^{263}$ As might be expected, numerous studies have connected growth in human capabilities (or human development) with productivity growth. Statistical analysis of the clothing and engineering industries in Sri Lanka, to cite just one example, showed that the skill and education levels of workers and entrepreneurs were positively related to the rate of technical change of the firm. ${ }^{264}$

Sen has also explicitly linked the human capability approach with the ILO's Decent Work Agenda. In his address to the ILO Conference in 1999, Sen praised the Decent Work Agenda's goal of promoting 'opportunities for women and men to obtain decent and productive work, in conditions of freedom, equity, security and human dignity, ${ }^{265}$ He also drew attention to the rights-based formulation in the Decent Work Agenda, which extends beyond a legislative notion of rights to a formulation based on social ethics. Thus, rights at work can be seen as preexisting legal recognition: the fundamental rights at work that underpin the Decent Work Agenda inhere in all workers, regardless of whether or how they receive formal legal recognition. Sen goes on to show that the Decent Work Agenda extends beyond the need to adopt legal frameworks:

the invitation is not merely to fresh legislation, important as it is, since the realization of rights can also be helped by other developments, such as the creation of new institutions, better working of existing institutions and, last but not least, by a general political and social commitment to work for the appropriate functioning of social, political and economic arrangements to facilitate recognized rights.

This is consistent with the focus of this study not only on the standards which are to be enforced, but on the regulatory techniques and institutional configurations through which people's rights and opportunities may be extended and realized.

b. Development Economics. This theory also supports the view that labour regulation for job quality and higher productivity is necessary for economic development. From the perspective of development economics, the persistence of a large informal or unregulated workforce is an obstacle to industrial upgrading, and therefore an impediment to economic development. In the simplest terms, economic development involves shifting resources away from diminishing return activities towards increasing return activities: increasing return activities are closely associated with higher levels of real incomes in a 'virtuous circle'. The opposite is also true: the 'vicious cycle' of diminishing return activities and lower incomes. Thus economic development requires industrial upgrading, which depends on organizational learning and capital

\footnotetext{
263 Sen, 1992, pp. 6-8, 25, 136-138.

264 Deraniyagala, 1995 cited in Ranis, 2004.

265 This address can be found at

$<$ http://www.ilo.org/public/english/standards/relm/ilc/ilc87/a-sen.htm> Sen also praised the universality of coverage of the Decent Work Agenda, as it includes 'not just workers in the organized sector, nor only wage workers, but also unregulated wage workers, the self-employed and homeworkers.'
} 
investment to improve the position of firms or nations in international trade networks. ${ }^{266}$

Development therefore depends in large part on fostering 'economically nutritious' activities, which develop both forward and backward linkages into the local economy. Complex manufacturing activities, for example, are nutritious because enterprises do not develop capabilities in isolation. Rather, they operate (depending on the industry) in a dense network of formal and informal relationships with suppliers, customers, competitors, consultants, and technology research and educational institutions. These networks take the form of complex, long-lasting contractual and non-contractual relations. These linkages help firms to deal with each other, to gain access to expensive information and facilities, and to create information, skills and standards that all firms need but no individual firm will generate on its own. ${ }^{267}$

Much of the development literature on micro-enterprises explores options for access to capital and finance. ${ }^{268}$ However, there are many labour issues that remain under-explored. Low wages, for example, generate low aggregate demand, stifling local demand for new industrial products, and undermining the extent to which the local economy is integrated or interlinked. ${ }^{269}$ Child labour is a major barrier to participation in education. Hidden employment reduces access to vocational training and further specialization or upgrading of skills; access to vocational training is also virtually impossible where employment is precarious, as it can be given the nature of work in MSEs, and the typically long working hours. These obstacles further undermine opportunities for industrial upgrading.

Easing the regulatory burden on MSEs to reducing their overheads - by excluding them from the scope and coverage of labour law, or from its application in practice - is sometimes promoted as a means to develop greater efficiency. However it can only contribute to increases in efficiency to a limited extent, and generally only in low skill and low capital base production. The OECD has recognized in its report Promoting SMEs for Development: 'SME development strategy must be integrated in the broader national development strategy, and/or poverty reduction and growth strategy of transition and developing countries' ${ }^{270}$ From the point of view of development economics, the key question is not whether to exclude MSEs from labour regulation, but how to implement systems of labour regulation that might facilitate industrial upgrading among MSEs.

c. New Institutional Economics. In any event, the role of regulatory systems and good governance are increasingly widely accepted in development theory, in part due to the insights of New Institutional Economics. ${ }^{271}$ A key aspect here is that unlike neo-classical economics, New Institutional Economics places

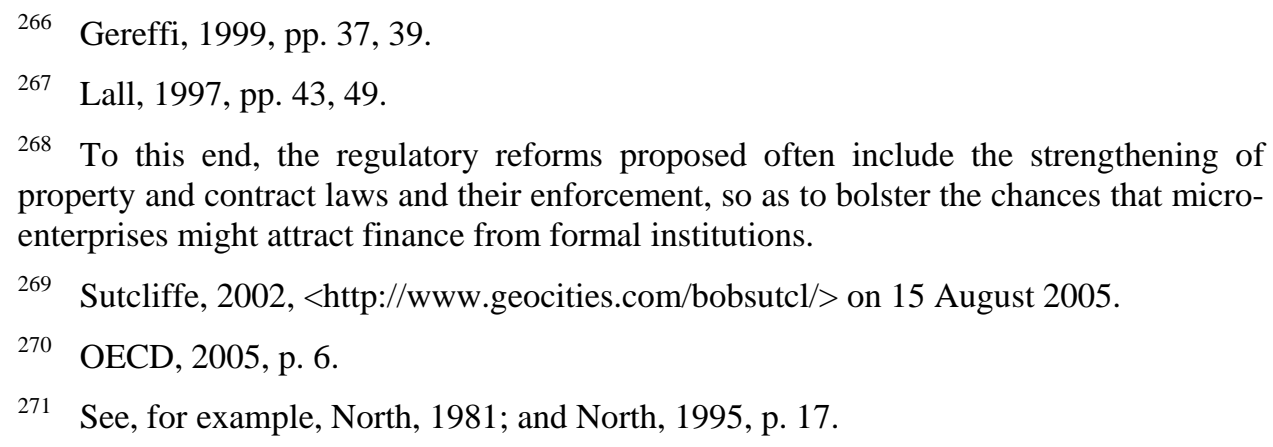
property and contract laws and their enforcement, so as to bolster the chances that microenterprises might attract finance from formal institutions.

269 Sutcliffe, 2002, <http://www.geocities.com/bobsutcl/> on 15 August 2005.

270 OECD, 2005, p. 6.

271 See, for example, North, 1981; and North, 1995, p. 17. 
significant emphasis on the role of the State. From this point of view, the State is not merely a benign actor in the development process: 'getting the prices right' can only have the desired effect in a regulatory environment in which property rights are established and protected, so that there are sound incentives for competitive market conditions. The market and the State are therefore not in opposition to each other, because it is State regulation and institutions that constitute the market. Thus, an efficient market requires efficient institutions.

New Institutional Economics suggests that legal and other institutions including, for example, labour regulation - have an important role to play in shaping a regulatory environment that can lead to development. In a large-scale complex economy, for example, networks of interdependence widen. While this increases the possibility of developing economically nutritious activity, it also creates risks of significant inefficiency: the impersonal exchange process gives considerable scope for opportunistic behaviour, and unnecessarily high transaction costs. ${ }^{272}$ In developed countries there are complex institutional structures that constrain participants' behaviour, reduce the uncertainty of social interaction, and prevent transactions from being too costly. Thus, economic institutions are necessary to capture the productivity gains of larger scale and improved technology. In under-developed economies, by contrast, these institutional structures are often non-existent, weak or poorly devised due to lack of State capacity (or legitimacy) to act as guarantor of rights and institutions. In some cases, the problem is that the State is too predatory in its own demands, or is captured by special interest groups or lobbies that do not have an 'encompassing interest' in the productivity of the society and may prolong inefficient property rights.

It can be difficult to develop regulatory principles in the abstract by drawing on New Institutional Economics; a nuanced view suggests that a key factor in reform outcomes is regulatory design at the national or local level. ${ }^{273}$ This suggests that regulation must be developed by each State for its own environment. States must design their policy and regulation in light of a cultural and historical understanding of the development of their own institutions: it is necessary to understand why the current arrangements exist and how change might occur. Importantly, also, an understanding of the distribution of power and material resources is required in order to understand the political settlement which resulted in a given institutional arrangement or which might result in a desired institutional change.

\section{Legal institutions and comparative labour law}

Comparative lawyers' analyses of laws and legal institutions that have been introduced (or in some cases imposed) as part of development reforms show that they are often 'poorly designed, inflexible and lacking local support'. ${ }^{274}$ The insights of comparative law suggest that it is necessary to pay close attention to

\footnotetext{
272 Bardhan, 2005, pp. 499, 512.

273 This is a tension in North's work reflecting his commitment to the framework of choice-theoretic economics and his awareness of the limitations which it imposes when it comes to the analysis of change: Harriss, 2002.

274 Lindsey, 2007; Stewart, 2003, p. 139; Darian-Smith, 2000, p. 809; Pistor and Wellons, 1999; Chossudovsky, 1997; Hoogvelt, 2001; and Escobar, 1995.
} 
how changes to laws operate in practice, and that care must be taken to develop laws and legal institutions suited to the local circumstances. A lot of comparative legal scholarship refers to this as the question whether laws, legal concepts and legal institutions may be 'borrowed' from one environment and 'transplanted' into another, and if so, what may be the outcome.

According to one view, collective labour laws are unlikely to serve as good models for other jurisdictions: 'political' factors have a significant influence. Individual employment laws (or rights) may however have something to offer. ${ }^{275}$ Thus, States may be able to adopt labour laws that provide individual rights and conditions - as for example relating to wage and hour regulation, or even perhaps termination of employment - but not those laws for collective mechanisms such as those regulating the formation and activities of trade unions and, in particular, collective bargaining.

More recently it has been suggested that what determines the success of designing a legal institution based on one from elsewhere is whether there is an 'organic relationship' between the law adopted and the social need to which it is addressed; the law must also have the capacity to contribute to national economic performance. ${ }^{276}$ These must be key considerations in the design of labour laws as elements of the regulatory environment for MSEs: it is unlikely to be possible simply to borrow a legal concept, or an administrative approach to law enforcement, from one environment and to use it effectively in another. While certain basic principles might be used, flexibility - or 'responsive regulation' will be critical. To put it another way, decisions about the scope and coverage of labour law, and how it is applied in practice, will need to be locally developed. Moreover, their success is highly likely to depend heavily on whether they are suited to the particular social and economic circumstances in which they are to operate. In the area of collective labour law, this may include, among other things, whether the social partners have the skills they need to operate in a new legal environment. ${ }^{277}$

Recent comparative analysis of labour laws in East Asia suggests that simply adopting approaches used by other States will not necessarily lead to the same results as were achieved elsewhere. ${ }^{278}$ The operation of new labour laws in practice may be particularly affected by the legal culture in which they are to operate. ${ }^{279}$ One potential obstacle is the continuing importance of traditional legal rules or practices. Where these traditions endure they may, for example, lead people to prefer alternative means of resolving disputes to those that are provided in formal law, including labour law. This might also be a product of the familial style labour relations that are typical of work in MSEs. A second

\footnotetext{
275 Kahn-Freund, 1974, p. 1.

276 Hepple, 1999, pp. 1-3.

277 Fenwick, 2005.

278 Cooney et al. (eds.), 2002.

279 Ibid., pp. 258-263; p. 133. The notion that culture may affect the development and operation of legal institutions is echoed in other disciplines, including legal anthropology (Chanock, 2001); Chanock, 1985 and also political science (Candiland and Sil, 2001). It is also consistent with a more nuanced version of New Institutional Economics, which also emphasizes the importance of having an understanding of the history, culture and political background of institutions and the environments in which they operate.
} 
important aspect of legal culture is the general environment of law and governance. Many States have significant weaknesses in their ability to develop and enforce the rule of law generally, which can have a major impact on the success of regulation that relies on the use of laws passed and enforced by the State.

If legal systems are weak generally, this will also limit their ability to have an impact on other social systems, including the labour market. But this does not mean that there is no room for the State to develop legal solutions to the problems of job quality in MSEs, and formalization of MSEs in the interests of development. In fact the use of labour regulation is entirely consistent with the general approach that the ILO has promoted for some time ${ }^{280}$ and with some of the basic tenets of (for example) New Institutional Economics. Both suggest that laws and legal institutions do matter. What matters most, however, is that States, particularly those that suffer from important institutional weaknesses, must take care in their regulatory design to be flexible in their expectations of introduced or newly developed legal concepts and institutions. Moreover, they might for this reason, and for others, consider a range of other regulatory approaches to achieve their policy goal of Decent Work in MSEs. ${ }^{281}$

\section{Theories of regulation}

Economic development and job quality are compatible and mutually reinforcing policy objectives. Job quality is a critical element in the successful achievement of economic development through the promotion of Decent Work. Regulatory action by the State is however essential to create an environment in which the recognition and maintenance of labour standards and social rights are core aspects in the construction and regulation of the markets in which MSEs operate. Key social rights that can contribute positively to the operation of labour markets include education and health, each of which make significant contributions to developing workers' human capabilities, and in turn their productivity as participants in labour markets. Where labour law is concerned, States can and should adopt a wholistic and responsive approach to its scope and coverage, and its application in practice, to contribute to job quality in MSEs. Taking a responsive approach to regulation does not mean abandoning the use of law, or of sanctions for failure to comply with legal requirements: it simply means that States should be flexible about using different regulatory techniques to achieve particular policy goals.

Taking a responsive approach to regulation will enable States to move beyond the traditional approach of regulation, which relies heavily on rules backed by sanctions, monitored and enforced by government agencies. The latter approach to regulation is often associated with high levels of prescription - that is, as the name of the concept suggests, with high levels of control. It is this sort of regulation that critics argue has harmful economic effects, and is the target of the argument that States should 'deregulate'. This study suggests that the approach of excluding MSEs from the scope and coverage of labour laws is

\footnotetext{
280 Maldonado, 1995, p. 705; ILOb, 2002, and Reinecke and White, 2004.

281 Servais likewise emphasizes that States must decide on the most appropriate forms of regulation and that a 'satisfactory mix... depends on the circumstances in each country, in particular in a democratic society, on the degree of social consensus that can be attained': Servais, 2001, pp. 339, 352.
} 
problematic: among other things it appears to be positively associated with poor job quality in MSEs. Neither is it clear from this study that excluding MSEs from the application of labour law has had significant measurable positive effects in terms of levels of MSEs growth and formalization. Moreover, there is evidence to suggest that labour market 'deregulation' has frequently been associated with growth in the informal economy. The answer therefore is for States to take innovative, responsive approaches to regulation, not to abandon their policy goals to an unregulated market.

An innovative approach to labour regulation requires a clear understanding that 'regulation' has a wide meaning. A useful definition is 'the intentional activity of attempting to control, order or influence the behaviour of others according to defined standards or purposes. ${ }^{, 282}$ This definition recognizes that the State cannot usually achieve its regulatory goals alone: it is not the only actor with power to achieve policy goals. It also recognizes that regulation is a process involving the regulator - the State - and the regulated community - in this case, MSEs. The concept of a regulatory process that is fluid and ongoing is similar to the finding that MSE owner-entrepreneurs make strategic decisions about compliance with regulatory requirements, and may move backwards and forwards between degrees of formality and informality. In each case what is clear is that merely laying down rules will not of itself lead people to comply with them: the State must be prepared to use a wide range of techniques to achieve its policy goals, and also to constantly review and assess the effectiveness of its policy approach.

Using this broad concept of 'regulation' opens up the space for States to design new regulatory strategies. They may be hybrid: using both government and non-government actors; multi-faceted: using a number of different strategies simultaneously or sequentially; and they may be indirect. ${ }^{283}$ Thus State regulation can work alongside - and in some cases coordinate - other forms of regulation, including some types of self-regulation.

This does not mean that States should abandon traditional regulatory approaches; there will always be an important role for State regulation, including State regulation by means of formal law. What it means is that there are other forms of regulation which may prove more effective at achieving public policy objectives in a given social context. Other forms of regulation might also better capture other important values, such as fostering participatory democracy on behalf of groups with relatively little economic or political power. A number of States have adopted innovative approaches to regulating MSEs for Decent Work that are consistent with this broad definition of regulation, and of how policy goals might be achieved.

It also follows that adopting a responsive approach to regulation does not mean that States should abandon their key policy goals: it only means that they can pursue those goals by other approaches. This is a particularly important insight for developing States, which in many cases may have limited capacity to achieve their goals through traditional forms of regulation. Indeed, responsive regulation will often work best where the State continues to use institutional structures that regulate policy goals, and sanctions to enforce those goals. They 
can and perhaps should be retained as the apex of an 'enforcement pyramid'; on this view they are necessary to ensure that other techniques are effective. ${ }^{284} \mathrm{At}$ the same time, however, use of a broad range of techniques enables the State to develop approaches that take into account the fact that members of the regulated community will respond differently, according to a range of factors including preference, ideology, and perception of the regulatory goal.

What this approach to regulation suggests is that States might search for more innovative forms of regulation than the prescriptive approach that has been commonly associated with 'command and control' regulation, and which can lead to unnecessary rigidity. They might also develop processes and institutions to involve those affected by regulation both in making the rules, as well as in the processes of monitoring and enforcing them. Some of the more effective innovative regulatory approaches have succeeded precisely because they have been inclusive and participatory in their design and implementation.

States might therefore take one of a number of broad approaches to creating an enabling regulatory environment for MSEs, based on the responsive recognition and application of labour rights and standards. Importantly, they might do so as well as creating laws that set out minimum labour standards and recognize basic labour rights. Three different regulatory techniques may prove particularly fruitful:
a. Education and information;
b. Provision of financial subsidies and other incentives; and
c. Innovative procedural regulation.

Many of these practices are already being utilized to encourage formalization of MSEs, and more specifically to promote enforcement of labour standards and rights for workers in MSEs.

a. Providing education and information. This is a key regulatory strategy, and something that governments do to help influence behaviour. Public information campaigns and face-to-face education and training programmes are frequently used to raise awareness of the harmful effects of certain activities, or the advantages of engaging in socially beneficial practices. ${ }^{285}$ Information is therefore likely to be an essential component of an effective labour law system. This is especially true in relation to MSEs. For example, access to information is a key element of MSEs' decisions to comply with legal regulation. ${ }^{286}$ Information that educates MSEs about the benefits of formalization and about improvements in job quality for economic performance may overcome one of the key obstacles to formalization, and to labour law compliance among MSEs. In addition, government has an important role to play in raising awareness of existing labour laws among workers who may not be aware of their rights and entitlements. Low levels of legal literacy have an adverse impact on job quality

\footnotetext{
284 The notion of an 'enforcement pyramid' was developed by Ayres and Braithwaite, 1992.

285 For a recent consideration, see Sunstein, 2005.

286 Reinecke and White, 2004, p. 63.
} 
and productivity, but can be addressed by education and information, both for workers and for the owner-managers of MSEs.

b. Providing financial subsidies or incentives. In the area of labour regulation, for example, the State might offer subsidies to employers to engage unskilled workers, on condition that the employer provide a certain type or amount of training to the worker. Financial incentives or subsidies are therefore a way that States can encourage compliance using different incentives than the ones that underlie traditional forms of regulation. According to that approach, people will alter their behaviour to comply with legal rules, in order to avoid sanctions against non-compliance. Thus, the 'incentive' for compliance is the avoidance of financial costs (or in some cases, imprisonment). This is similar to the use of taxation to discourage undesirable behaviour, as well as to perform its revenue collection function. ${ }^{287}$ Using financial incentives is a way of providing positive incentives to comply with particular requirements.

States can draw on their wealth to encourage compliance by using 'economic policy instruments' to modify the behaviour of other levels of government, and/or of private actors (both for-profit and non-profit organizations). Examples of economic policy instruments include financial subsidies, conditional grants, and access to government contracts, as well as instruments that involve government payments, and tax concessions or incentives, where the government waives full compliance with tax laws. ${ }^{288}$ Where access to government contracts is concerned, Reinecke and White have already suggested that this may be a useful incentive to MSEs to assume more formal status. ${ }^{289}$

Economic policy instruments promote State policy by altering the cost of certain behaviour. They may offer the 'reward' of a subsidy, or reduce the 'disincentive' of taxation, in return for compliance. The use of these instruments is often justified on the basis that it involves the replacement of coercion and control (and prescription and rigidity) with a system that offers market incentives in order to encourage desired behaviour in the form of compliance with regulatory goals. The use of financial incentives to promote desired behaviour has been observed in a number of different areas of government activity, including job creation and environmental protection. ${ }^{290}$

Another way of using financial incentives as part of a regulatory strategy to achieve policy goals is through the use of government contracts with private, voluntary or quasi-public providers. This approach to regulation is based on the idea that private sector activity can be controlled through contractual or other agreements with government. Government contracts essentially involve exchange of public wealth for the provision of a good or performance of a service by a private actor. The primary means by which the government secures the cooperation of an external actor is through the offer of a subsidy or fee, while

\footnotetext{
287 Daintith, 1988, p. 1; Ogus, 1998, p. 767.

288 The term 'economic policy instruments' is drawn from Daintith, above.

289 Reinecke and White, 2004, p. 45.

290 Howse, 1993, p. 455; Grabosky, 1995, p. 257; and Baldwin, 1997. A number of studies have identified financial subsidies as a common instrument of job creation policy: see Howe, 2001, p. 242.
} 
the contract is used as a means of attaching conditions to, or 'regulating', that subsidy. The external organization consents to the attachment of these conditions because of the incentive provided by the contract payments.

In the context of debates about the effectiveness of different forms of regulation, economic policy instruments such as financial subsidies and incentives are frequently portrayed as 'soft' or 'light-touch' regulation, as distinct from 'hard' legal regulation. ${ }^{291}$ Regulating by means of economic incentives or disincentives is a technique by which governments have endeavoured to promote external satisfaction of public policy objectives where legal coercion is seen to be inappropriate or ineffective. ${ }^{292}$ In other words, a perceived advantage of economic policy instruments as a form of state regulation of the private sector is the capacity of such instruments to be 'responsive' to existing values and social ordering. ${ }^{293}$ It is argued that by advancing policy objectives based on the ideal of social or redistributive justice in a way that avoids 'intrusive interference with private social and economic arrangements and market allocation decisions', regulation is likely to be more effective. ${ }^{294}$ This sort of approach could prove to be a more effective alternative than, for example, excluding MSEs from the scope and coverage of labour law. Like that approach, however, the use of financial incentives can be a way of responding to MSEs' sensitivity to the operational cost of compliance with labour laws. Unlike excluding them from the scope and coverage of labour laws, however, the use of financial incentives could be a way to encourage them to comply with their requirements, thereby offering greater protection for workers and better prospects for Decent Work.

c. Innovative procedural regulation. This involves strategies that facilitate the participation of private regulatory actors, including MSEs, workers, trade unions, NGOs and bodies such as the ILO in the formulation and implementation of policy. ${ }^{295}$ These approaches are sometimes referred to as 'self-regulation' or 'co-regulation', but these terms can be misleading where there is a clear role for the State in establishing and overseeing the procedures and institutions established. As Servais has emphasized, the State sill has an important role to play: 'to recognize these actors, to promote their development and improve their access to information (by removing obstacles such as anti-union practices), to recognize the institutions they create (for example, by taking part in their creation) and to facilitate relations between them. ${ }^{296}$ Indeed, the State has a special, and often challenging role in facilitating the involvement of private actors in regulatory strategies targeting MSEs and the informal economy: 'this mission [of the State] has a special dimension when it comes to specific kinds of

\footnotetext{
291 The terms 'soft' and 'light-touch' regulation are frequently used in relation to legal instruments in Europe: see Dickens, 2004, pp. 595, 608.

292 Gunningham and Grabosky with Sinclair, 1998, p. 70; Ogus, 1998, p. 96; Braithwaite, 2002, p. 12.

293 Parker et al., 2004, p. 11. The notion of 'responsive regulation' is a consistent theme in the regulatory literature.

294 Howse, 1993, p. 471.

295 Mayntz, 1983, p. 123. The term ‘innovative command and control regulation' could also be applied: Gunningham, Grabosky and Sinclair, 1998, p. 47.

296 Servais, 1992, p. 357.
} 
activity, such as those in the informal sector or small-and medium-sized businesses, where social dialogue is more difficult to put into practice'.

Innovative procedural regulation may include programmes that encourage MSEs and workers, together with unions, local government agencies or NGOs to formulate compliance plans with respect to labour laws that are suited to the challenges facing MSEs in particular contexts. This avoids the problems that arise from exempting or not enforcing labour laws against MSEs, while acknowledging the disincentives that often lead to avoidance of labour laws by MSEs. It would also enable governments to ensure that compliance is supportive of economic development. ${ }^{297}$ This regulatory approach also encompasses socalled ‘corporate social responsibility' initiatives such as supply chain regulation.

These different regulatory instruments might all be used in a complementary way to further 'responsive regulation', without losing sight of the policy goals that they are intended to further. In other words, States will still need to set rules that establish standards of expected conduct, and provide sanctions for non-compliance that can be enforced in certain circumstances. Without them, incentives and other forms of 'self-regulation' and 'co-regulation' are unlikely to be effective on their own. In short, States must adopt an integrated approach to the design and implementation of a labour law framework for Decent Work in MSEs, and one that must in turn be integrated into the broader policy agenda of creating an enabling regulatory environment.

\section{A principled approach to innovative labour regulation}

Carefully designed labour law and labour regulation frameworks can play a useful role in promoting a Decent Work Agenda for MSEs. They are also compatible with the pursuit of the key development goals of poverty reduction and improved enterprise productivity. The human capability approach to development suggests the need for emphasis on basic freedoms and rights, together with attention to development of skills. These are likely to be closely associated with higher productivity. Both skills and higher productivity are conducive to - and reinforced and required by - an approach to development that seeks to achieve industrial upgrading through the propagation of economically nutritious activity. This in turn suggests a need for sound market institutions, in order to moderate the functioning - and contribute to the efficiency - of complex market interactions. These will then have the effect of contributing to further economic development - particularly by the generation of skills and needs that individual actors may not have sufficient incentive to pursue - and thus further development of human capability.

Labour law is one of the key institutions that can play a role in achieving these positive development outcomes. In its insistence on fundamental rights it is a basis for securing essential freedoms; in its guise as a means of regulating labour quality, it is a way of developing human skills and capabilities. Labour law's ability to regulate labour costs also makes it an important tool for market regulation: it is a way of overcoming unfair competition that distorts markets. Comparative law suggests, however, that it is not simply a matter of copying, or adopting, laws, legal institutions or concepts from other environments in which 
they may have been associated with positive outcomes, in the simple hope that they will operate similarly in a new environment. Rather, it is necessary to have a subtle understanding of the history, the politics and the 'culture' of the environment that is now to be developed, whether by labour law or otherwise. In other words, local or national conditions are critical considerations in the design of a regulatory framework for labour law.

Thus, a responsive approach to regulation is likely to offer a better range of tools to achieve the policy goal - in this case the promotion of Decent Work in MSEs, together with encouragement to MSEs to formalize. Just as comparative law shows that local conditions matter, regulation theory teaches that there are many and varied ways of pursuing policy goals. Indeed, regulation theory has much to offer those who would seek to reform law in developing economies, by suggesting a variety of techniques that might be adopted in preference (or addition) to the simple borrowing of legal institutions from elsewhere. Thus, regulation theory offers useful insights into how to achieve the policy goals of economic and human development. These insights are likely to be particularly useful in their application to the case of developing economies, where the State is in any case frequently unable to achieve its goals by traditional means of direct regulation.

\section{Innovative approaches to labour regulation for MSEs}

\section{The scope of the employment relationship}

The key preliminary issue that shapes the scope and coverage of most labour related laws is the scope of the employment relationship. Much labour law applies only to those workers who are parties to a formal employment relationship, that is, to those workers who have a contract of employment. This creates significant possibilities for vulnerability and social exclusion. This is, of course, an issue of longstanding importance to labour lawyers in all parts of the world, and to the ILO, which will examine the issue in depth at the International Labour Conference to be held in 2006. Thus a threshold issue in determining the scope and coverage of labour law in relation to MSEs is whether - and if so, how - to adopt a definition of the employment relationship that seeks to ensure that labour law is broad and inclusive.

States around the world have responded to this issue in many different ways. Four of the possible options are outlined in the ILO's report, The Employment Relationship, which will form the basis of the forthcoming Conference discussion. ${ }^{298}$

a. States may try to redefine more precisely the employment relationship, irrespective of the form of the contract, or to establish mechanisms to adjust the scope of the law in line with changing needs.

b. States may delineate more clearly the boundary between dependent and independent work. 
c. States may combine the first two approaches: in some cases provisions have been introduced into legislation to deal with certain types of work that had previously been inadequately defined.

d. States might extend the protection of the employment contract to equivalent contracts.

A different approach is to allocate rights and benefits, and to deliver social policy, in ways that are simply not connected to the employment relationship. ${ }^{299}$ Many States have recognized the need to complement labour law with universal entitlements based on citizenship or residence, in particular to ensure effective protection for those working in the informal economy. In India in 2004, for example, the Government appointed a National Commission on Enterprises in the Unorganized and Informal Sector, which also has a mandate to examine how best to provide social security and protection for workers in these sectors.

Following are several examples of States' practices in adopting innovative approaches to the scope of the employment relationship. The examples included here are provided simply to illustrate aspects of a problem that affects labour law systems across the world, and that is the subject of lengthy debate and analysis. ${ }^{300}$

\section{Expanding the employment relationship through} the presumption of employee status

\section{South Africa}

In South Africa, a person is presumed to be an employee if one of the following indicators is present:

- $\quad$ the manner in which the person works is subject to the control or direction of another person;

- $\quad$ the person's hours of work are subject to the control or direction of another person;

- $\quad$ in the case of a person who works for an organization, the person is part of that organization;

- the person has worked for that other person for an average of at least 40 hours per month over the last three months;

- the person is economically dependent on the other person for whom that person works or renders services;

- $\quad$ the person is provided with tools of trade or work equipment by the other person; or

- the person only works for or renders services to one person. ${ }^{301}$

299 This approach was outlined in A. Supiot et al., 1998.

$<$ http://europa.eu.int/comm/employment_social/labour_law/publications?en.htm> on 25 August 2005, and has also been canvassed in India's Second National Commission on Labour: available at <http://labourbureau.nic.in/main2.html>.

300 ILO, 2005b; Collins, Davies and Rideout (eds.) 2001; Stone, 2004.

301 Basic Conditions of Employment Act 1997 ('BCEA'), section 83A, introduced by the Basic Conditions of Employment Amendment Act 2002, section 21. 


\section{Expanding the employment relationship through an expanded concept of the employer}

\section{Botswana}

In Botswana, the employer is defined as any person who has entered into a contract of employment to hire the labour of any person, including the Government or a public authority, or the person who owns or is carrying on for the time being or is responsible for the management of the undertaking, business or enterprise of whatever kind in which the employee is engaged. ${ }^{302}$

\section{The Philippines}

The legislation of the Philippines defines an employer of homeworkers in terms of specific aspects pertaining to the situation of the employer, and in terms of the employer's relationship with the worker. Employer, in this context, means any natural or artificial person who, for his own account or benefit, or on behalf of any person residing outside the Philippines, directly or indirectly, or through any employee, agent, contractor, subcontractor, or any other person, delivers or causes to be delivered, or sells, any goods or articles to be processed in or about a home and thereafter to be returned or to be disposed of or distributed in accordance with his direction, and then re-buys them himself or through another after such processing. ${ }^{303}$

\section{Australia}

In Australia, state governments have enacted various versions of 'Supply Chain Regulation' in the textile, clothing and footwear (TCF) industry designed to improve the conditions of homeworkers. ${ }^{304}$ There have been four types of legislative intervention encompassed in recent legislative programmes by state governments. Firstly, there has been legislative amendment that significantly extends the scope of industrial statutes to deal with work arrangements and contracts beyond the traditional employment relationship (South Australia). Secondly, there have been legislative amendments that have attempted to clarify the employment status of outworkers (deeming provisions). Thirdly, there are prescriptive legislative provisions that impose obligations on successive steps in the chain of contracting out work (other than the retail sector) for ensuring that outworkers receive their lawful entitlements (rights of recovery). As a final step in regulating supply chains in their entirety there are legislative provisions that provide for the making of mandatory codes that may apply to the retailer sector (mandatory retailer codes).

In summary, this regulation imposes responsibilities on all major players in the TCF industry for the performance of work by outworkers, including principal manufacturers and retailers. ${ }^{305}$

302 Botswana, Employment Act, 1982 section 2. For similar definitions see Lesotho, Labour Code Order, 1992 (Order No. 24 of 1992) section 3; Nigeria, Labour Act (Chapter 198), 1974 (No. 21), section 91(1); Bangladesh, Employment of Labour (Standing Orders) Act, 1965 (Act VIII of 1965), section 2.

303 Omnibus Rules Implementing the Labour Code, Rule XIV, section 2(b).

304 The Industrial Relations (Fair Work) Act 2005 (South Australia) amended the Industrial and Employee Relations Act 1994 (South Australia; Schedule 2 of the Industrial Relations (Ethical Clothing Trades) Act 2001(NSW) amended the Industrial Relations Act 1996 (NSW); the Outworkers (Improved Protection) Act 2003 (Victoria); and the Industrial Relations and Other Acts Amendment Act 2005 (Queensland) amended the Industrial Relations Act 1999 (Queensland).

305 Marshall, article available from the author: s.marshall@unimelb.edu.au; Nossar, Johnstone and Quinlan, 2004, pp. 137, 146. 


\section{Innovative approaches to the scope and coverage of labour laws}

Some States have sought to protect workers in MSEs by adopting innovative mechanisms that are designed to extend social security schemes and other forms of worker protection. These policies are examples of 'responsive' labour regulation: they have been designed and implemented by a range of interested actors, including government, trade unions and non-government organizations. They are responsive also in that by emphasizing progressive application of the law - as for example in Thailand - they acknowledge the needs and capabilities of the regulated community.

These strategies also help to achieve key development goals, in particular by protecting human capabilities and skills. They demonstrate that the task of providing social security in developing economies is not impossible. Each of these schemes should contribute to labour market flexibility by socializing risk and, in the case of the Indian examples, facilitating a democratic allocation of risk. ${ }^{306}$ This, in turn, buffers workers from the impact of adjustments and facilitates innovation and industrial upgrading.

\section{Extending social insurance to MSE workers in Thailand}

In Thailand, the social insurance scheme, which upon its establishment in 1991 was limited in scope to workers in enterprises with 20 or more employees, has been progressively extended to provide a wider range of benefits and to cover all enterprises. ${ }^{307}$ The Thai social insurance scheme now covers unemployment benefits, healthcare, invalidity, sickness, maternity protection and workers' compensation. ${ }^{308}$ The scheme consists of compulsory contributions by employers, employees and the government. The contributions required and benefits provided by the scheme are envisaged to be increased progressively.

The extension of the social insurance scheme to micro-enterprises (fewer than 10 workers) in 2002 meant extending coverage to a further three and a half million workers in 1,200,000 enterprises. ${ }^{309}$

\footnotetext{
306 Sen has pointed to the absence of protective security in countries in which income inequality increased after crises:

<http://www.ilo.org/public/english/standards/relm/ilc/ilc87/a-sen.htm> on 25 August 2005.

307 See 'Technical Note on the Extension of Social Security to the Informal Sector in Thailand', 2004.

308 The Social Security Act No. 1 1990; Social Security Act No. 2 1994; Social Security Act No. 31999 and the Workmen's Compensation Act B.E. 2537 1997. The social security acts and the workers' compensation act were both extended to cover enterprises with fewer than ten employees in 2002.
}

309 Daza, 2005, p. 47. 


\section{Social protection in the informal sector (Welfare Funds in Kerala, India) 310}

Welfare Funds emerged in India in the late 1960s as a collective response to the insecurity and vulnerability experienced by workers. They provide a basic level of social security and welfare assistance to workers in the informal economy.

The funds are generally created by legislation, and organized according to occupations or sectors. While the benefits delivered by the funds vary, they generally provide health cover, unemployment relief, a gratuity upon retirement, a monthly pension, disability and accident cover, educational assistance, household assistance, marriage assistance and funeral expenses.

The basic model of the Welfare Fund has the following characteristics:

- creation of a tripartite body consisting of workers' representatives, employers and the government. The government has veto power on policy issues;

- a bureaucratic organizational model with the chief executive appointed by the government and staff drawn from government departments;

- mandatory financial contributions from workers and employers, with the exception of a few 'voluntary' funds; and

- minimal financial contributions by government, except in cases where the government is the employer or where the paying capacity of the workers is deemed very low.

In 1995, around 50 per cent of workers in the informal economy in Kerala were members of a welfare fund. The continuance of the funds for more than thirty years suggests some measure of success and popularity.

There are, however, some weaknesses to the welfare fund model. First, the scope and benefits of the scheme are limited by the structural characteristics of a low income economy. In other words, it can only capture certain workers, and only offer them limited benefits. Some welfare funds are struggling to remain viable in the face of the recalcitrance of employers. Funds vary significantly in the quality of administration and the benefits they provide. The cost of administering the funds remains a problem. The funds in maledominated sectors are stronger than those in female-dominated sectors. Finally, there were favourable factors that led to the development of the funds in India which may not be present in other countries. For example, the working poor in Kerala enjoy a comparatively high literacy rate and a high degree of consciousness of their rights, and workers enjoy a history of mobilization and organization in the informal economy. Moreover, the Indian model requires political parties to take up the legitimate demands of workers in the informal economy as part of their political agendas.

\section{Collective representation and security for women in the informal sector (India)}

The Self-Employed Women's Association (SEWA) provides collective representation and security for women workers in the informal economy in India. This is a demographic group that is often excluded from trade union representation and activity, and subject to poor working and living conditions.

Membership of SEWA consists of three broad categories of 'self-employed women': home-based workers; small petty traders, vendors and hawkers; and providers of services and manual labour. SEWA provides its members with supportive services such as savings and credit, health care, child care, insurance, legal aid, capacity building and communication services.

SEWA has grown significantly since its inception in 1972: the national coverage now exceeds $200,000.311$ It provides services in a decentralized and low-cost manner and is a successful model for organizing informal workers.

The SEWA approach depends upon a relatively high level of political and social awareness among female workers. It also relies upon freedom of association. SEWA promotes self-reliance by private actors.

310 This case study is drawn from Kannan, 2002.

311 'Women Organising for Social Protection: The Self-Employed Women's Association Integrated Insurance Scheme, India', ILO, 2001f, p. 5. See also $<$ www.sewa.org $>$ 


\section{Innovation in the application of labour law}

For a variety of reasons, the application of labour law to MSEs in practice is a key challenge for many developing States. Despite this, many States persist with a traditional regulatory approach. That is, they rely on the notion that MSEs will respond to the risk of punitive fines or punishments for failure to comply with minimum labour standards. In other words, the incentive for MSEs to comply with minimum standards is that by doing so they avoid sanctions that would otherwise apply to them.

Some States however have adopted more responsive regulatory approaches. Chile appears to have had some positive results with an inspection system that is adapted to the realities of MSEs. Under this approach, in addition to inspections in response to complaints from workers, sensitive economic sectors have been covered by scheduled inspections which combine the traditional tools of labour inspection with an analysis of compliance in specific sectors and information campaigns. Moreover, inspection programmes have focused on particular sectors with a high share of MSEs, such as clothing production. While inspectors continue to visit larger enterprises more often than MSEs (as in other countries), a Chilean survey of 300 enterprises found that around 11 per cent had been visited by labour inspectors during the previous 2 years. ${ }^{312}$ Thus, the State has played a key regulatory role, but one that is responsive to the key interests of the regulated community: the need for workers to be protected by compliance with labour law, and the need for owner-managers of MSEs to have some degree of certainty in carrying on their work.

Indonesia has adopted a rather different approach to labour law enforcement. Recent reforms encompassing a decentralization of the labour administrative framework have led to greater presence and accountability of the department at the local level. However, this decentralization has been described as a double-edged sword: local Manpower Departments are often ill-equipped and ill-trained for addressing many labour issues. ${ }^{313}$

Yet another different approach to State regulation is to identify areas of skill - and responsibility - that are important to workers, but which fall outside the responsibilities of traditional labour administration. One example is the work done by the ILO in the Philippines and Tanzania to improve workers' health and safety. These programmes focused on developing the capacity of City Council Health Services, together with other organizations that may have a role to play, including self-help associations and cooperatives. These programmes developed and delivered training, helped in the establishment of private first-aid clinics, and worked to link those in the informal economy to the established national health care systems. ${ }^{314}$ This approach is an example of pursuing the substantive end of the policy goal of improved occupational health and safety outcomes, but doing so in a way that takes a broad view of which actors - both State and private may be able to play a positive regulatory role.

\footnotetext{
312 ILO/SEED survey, as cited in Reinecke, 2005, p. 5.

313 See 'Labour Law in Indonesia':

<http://www.sweatshops-retail.org/NRF\%20website/Indonesia.htm> on 15 July 2005; Quinn, 2003, pp. 4-5.

314 Aryee, 1996, pp. 48-49.
} 
Another approach is to draw on trade unions. This of course can be difficult where trade union membership within small enterprises is limited. One way of responding to this is to create a system of regional trade union representatives, who can then play a key role in monitoring the implementation of minimum labour standards in this sector. In Sweden, the regional health and safety representative scheme is a valuable example of an initiative designed to overcome the limitations that would flow from relying on enterprise-based health and safety representatives.

\section{Regional occupational health and safety inspectors in Sweden}

Like many other countries, Swedish workplace health and safety legislation exempts enterprises with a number of workers below a certain threshold from formal workplace representation. In lieu of this, trade unions are given the right to appoint safety representatives from outside the enterprise workforce. This statutory entitlement forms the basis of the regional safety representative (RSR) scheme.

An RSR may be appointed to an enterprise whose workforce includes at least one member of the trade union. The main tasks of the RSR are:

- to act as an itinerant safety representative who inspects and investigates OH\&S conditions in small enterprises and requests necessary changes;

- to promote employee participation in $\mathrm{OH} \& \mathrm{~S}$, including the recruitment, training and support of inhouse health and safety representatives; and

- to activate local health and safety work, within the overall framework of 'internal control' in MSEs. ${ }^{315}$

Evaluations of the scheme suggest that it has been successful. ${ }^{316}$ The scheme now covers the majority of MSEs in Sweden and the RSRs generally enjoy good relations with the labour inspectorate and with employers. RSRs may not visit an MSE more than once every two years, but this compares very favourably with an average of one visit every 8 to 10 years by a labour inspector. The RSRs also play an important educative function for MSE employers and workers. The cost of the scheme is relatively low. Finally, sources suggest that the scheme makes a major contribution to improving the work environment and, consequently, to reducing the incidence of occupational injuries and diseases in MSEs. ${ }^{317}$

Identified weaknesses of the Regional Safety Representative Scheme include the difficulties faced by RSRs in transferring the responsibility for inspection from RSRs to internal health and safety systems; the lack of employee participation in the scheme; disputes between employers and employees over funding for the scheme; and a lack of adequate training and support for RSRs. Finally, the success of the scheme must be evaluated in the context of the unique institutional environment in Sweden, including a comparatively high trade union density in the MSE sector, a tradition of social dialogue, and acceptance of trade union representation and activity.

Participation is plainly an important element of the operation and success of the Swedish RSR scheme. Participation is also a key element of the ILO's WISE programme, which is designed to bring about improved health and safety outcomes in MSEs. This is of course a critical element of job quality, and so of Decent Work. It is also a key consideration in maintaining and developing skills - that is, human capabilities - which in turn are essential for continuing and improved productivity.

\footnotetext{
315 Frick and Walters, 1998, pp. 367, 370.

316 Lamm and Walters, 2004, p. 108.

317 Frick and Walters, 1998, pp. 372-376.
} 


\title{
The ILO'S WISE programme
}

The WISE (Work Improvements in Small Enterprises) programme seeks to improve working conditions in MSEs by educating MSE owners and managers on the link between improved working conditions and higher productivity. The programme is predicated on the recognition that one of the major problems with occupational health and safety in MSEs is that most workers and employers lack an understanding of the consequences and importance of improving health and safety at work.

WISE focuses on simple, low-cost solutions to improving job quality. It involves the participation of State agencies, the ILO, bilateral donors, employers, NGOs and trade unions.

Evaluations of the programme to date suggest that it has had a beneficial impact on working conditions and productivity in MSEs. In South America, a WISE programme which reached 136 enterprises identified a total of 1,042 different possible improvements. More than half of these were quickly implemented by the enterprises involved. ${ }^{318}$ In the Philippines, an ILO report has identified a number of improvements in working conditions and productivity in MSEs that participated in the WISE programme. ${ }^{319}$

The WISE programme is currently limited to enterprises in the formal economy, as the absence of participation and partners limits its capacity to be implemented in the informal economy. While a strength of the WISE programme may be that it does rely upon enforcement by regulatory authorities, this may also be a weakness: it relies largely upon the voluntary participation of employers and their willingness to implement higher working standards.

In some States regulatory strategies have been developed to assist workers in highly casualized forms of work, which can often be typical of MSE work. From the point of view of innovation in regulation, these examples are significant because not all of them have been developed by the State itself. They may, however, offer models that could be adopted in other circumstances, including with State support and/or encouragement.

\section{Solutions for highly casualized labour}

Workers' cooperatives

Several countries have seen the emergence of workers' cooperatives as a means of supplying labour. In Colombia, for example, workers join workers' cooperatives to produce goods or perform work or services. Work is carried out by workers who are not 'dependent workers' and therefore fall outside the scope of labour legislation. 320

Tripartite labour registration system

In India there are many head load workers or mathadi/hamal workers (who lift parcels/goods in the markets across India). Laws have been passed to regulate the employment relationship for this group of casual workers in the informal economy. ${ }^{321}$ The law requires all existing workers and potential workers to register with an autonomous tripartite regulating board or authority; subsequently, all employment has to be routed through this regulating authority. Records are maintained of short-term, sporadic employment and, where social security benefits are to be provided, the employer's contribution can easily be tracked. The regulation of employment involves a tripartite arrangement instead of the bilateral employer-employee relationship.

One negative consequence has been that a further underground/shadow market has been created in the informal economy, although it is considerably smaller than the previously unregulated labour market for mathadi/hamal workers.

\begin{abstract}
318 Scott, 1998, p. 20.
319 Rinehart, 2004, p. 31.

320 There have been reports that this system has given rise to fraudulent employment relationships, which have attracted penalties. In Colombia, news reports referred to an investigation involving 200 workers cooperatives, which found that 'some temporary work agencies were operating under the guise of cooperatives in order to evade tax and social security contributions': El Pais (Cali), 20 April 2004, cited in ILOb, 2005, p. 44.
\end{abstract}

321 Shankaran, 2005. 
What these approaches have in common is that they are different means of bringing workers together, so that they might develop some measure of collective strength in order to pursue and to protect their interests. Of course the most traditional institution for achieving that goal is the trade union. Knowledge about trade unions and the benefits of membership is however extremely low among MSE workers. This may suggest that they can have limited capacity to assist as elements of a regulatory strategy - leaving aside the particular circumstances of the Swedish RSRs.

In some African States, however, innovative approaches to organizing workers are proving to be an important way of promoting Decent Work. States might consider these examples when designing or reviewing the legal regulation of the registration and structure of trade unions; they might also consider education and information campaigns to advice workers of the functions of trade unions, and of the benefits of membership.

\section{Organizing in the informal sector: the experience of the Bakery, Confectionary, Manufacturing and Allied} Workers' Union in Kenya ${ }^{322}$

The Bakery, Confectionary, Manufacturing and Allied Workers' Union (BCMAU) was registered in 1977 to represent the collective interests of workers employed in enterprises that produced bakeries, pastries, biscuits, cakes, confectionary, sweets and other types of food. The union is organized on a national basis with headquarters in Nairobi and branches in all major urban areas. The BCMAU traditionally targeted the formal sector. More recent efforts, however, have been focused on extending representation and protection to MSE workers in the informal economy.

The BCMAU has sought to extend protection to MSE workers through:

- lobbying the government to review all labour laws in Kenya, in order to enhance the rights and protection afforded to MSE workers, particularly women;

- lobbying the government for more effective enforcement of labour laws in the informal economy;

- educating MSE workers on their rights at work through various education and awareness programmes, covering such areas as HIVIAIDS and the workplace, child labour and sexual harassment; and

- $\quad$ building strategic alliances with NGOs.

The BCMAU continues to face a range of challenges, including employer hostility to unionization, the 'invisibility' of informal sector enterprises, a restrictive legal framework which inhibits the ability of unions to organize within MSEs, poor access to justice for MSE workers and severe resource constraints. 


\section{Organizing workers in MSEs: the experience of the Southern African Clothing and Textile Workers'}

Union ${ }^{323}$

The Southern African Clothing and Textile Workers' Union (SACTWU) has taken a multifaceted approach to organizing workers in formal MSEs in the clothing industry. Historically, most workers in formal MSEs were protected through the extension of collective agreements that had been negotiated between SACTWU and employers through centralized bargaining institutions (Bargaining Councils or 'BCs'). Since the mid-1990s, however, the integration of the South African economy into global markets and the subsequent restructuring of the domestic clothing industry have posed enormous challenges to SACTWU's strategies. In particular, the restructuring resulted in a proliferation of small enterprises and of atypical forms of employment in the clothing industry. Significant numbers of MSE employers removed themselves from BC jurisdiction through rejecting it outright or by subcontracting work to informal undertakings or independent subcontractors. In the face of these challenges, SACTWU has implemented a strategy based on an awareness that union strength is best developed through a multi-faceted approach, involving recruitment activities and legal and institutional reform.

SACTWU has sought to reform and strengthen Bargaining Councils. This approach is predicated on SACTWU's recognition that without effective BCs, the high number of MSEs would mean SACTWU would have to dramatically increase the number of staff it employs. In the last few years, SACTWU's activities have included:

- developing proposals for a single BC for the clothing industry, to be called the Council on Fashion. This Council would have five chambers, assigned with the following tasks:

1. bargaining and dispute resolution;

2. the provision and coordination of social services;

3. the provision of a range of industrial services to enterprises in order to improve the performance of companies;

4. addressing the needs of homeworkers and small business services; and

5. the provision of a range of industry education and training services.

SACTWU hoped that such a BC system would increase the attractiveness of the system for enterprises through offering a range of productivity enhancing services. This proposal, however, was not met favourably by employer groups and has since been reappraised by SACTWU.

- the successful establishment of a single national BC for the clothing industry in 2002. This centralized structure ensures that SACTWU does not have to negotiate numerous agreements, which would require more resources;

- the employment of a range of legal strategies to ensure the effective application of $B C$ agreements in all factories within the scope of the Council. This has involved ensuring workers who have been made independent contractors are recognized as employees; and

- the development of a programme to facilitate organizing workers in the informal economy, and the review of union policies and strategies to better meet the challenges posed by organizing workers in the informal economy.

SACTWU continues to face a raft of serious challenges. In particular, it still hopes to increase the appeal of centralized collective bargaining agreements for employers by providing business services. It also recognizes the need to develop an effective and uniform policy for employers who wish to remain outside the Bargaining Councils.

323 This case study is based on Bennett, 2002. See also Goldman, 2003. 


\section{Formalization as a prerequisite for access to specific benefits or policies targeting MSEs}

Some States have made concerted attempts to develop and formalize MSEs; in some cases these policies target the application of labour law in particular, while in others they are more general. These attempts frequently involve the adoption of specific policies designed to facilitate and assist the development of MSEs. In some cases, governments have established disincentives for MSEs that do not formalize. One way of doing this is to refuse access to beneficial credit or other regimes that are features of policies to assist MSEs that have not formalized their activities. An example is the case of Chile, where draft legislation currently under discussion would require compliance with labour law for all enterprises that operate as suppliers under government contracts. ${ }^{324}$

On the other hand, many States offer positive incentives to MSEs to formalize. Some of these, listed below, are simple examples of innovative regulation by the use of economic policy instruments.

- In Uruguay, micro entrepreneurs who register with authorities are classified as empresas unipersonales and are entitled to free health insurance coverage.

- In Viet Nam, new companies to register under the Enterprise Law are eligible for considerable tax holidays. However, this incentive appears to have negative effects as many existing companies are registering new legal entities and transferring assets, or are registering new or parallel businesses rather than expanding established operations to take advantage of the tax holidays. ${ }^{325}$

- In Hungary, the government has sought to boost employment by offering corporate tax allowances for small enterprises that employ an additional 30 workers or more, or an additional 15 workers in disadvantaged areas. ${ }^{326}$

In a number of instances, Governments at various levels have developed special arrangements designed to facilitate the formation of MSEs and thereby to promote employment growth. In Shanghai, the Municipal Government has adopted a policy of facilitating and providing benefits to so-called 'informal labour organizations.' In Peru and Viet Nam (as in a number of other countries) authorities have simplified the procedures for registering an enterprise.

\footnotetext{
324 Reinecke, 2005, p. 4. Reinecke notes that it is unclear what impact this would have on MSEs as most would find it difficult to obtain government contracts anyway.

325 Freeman, 2004, p. 236.

326 Fazekas, 2004, p. 2.
} 


\section{Creating Employment through Informal Labour Organizations in Shanghai ${ }^{327}$}

In 1996, the Shanghai Municipal Government introduced a policy and regulatory regime to facilitate the development of the informal economy as a means of providing employment for unemployed workers. The policy encourages individuals to establish individual ventures or small firms in certain types of activities. ${ }^{328}$ The enterprises established under the policy are called 'informal labour organizations'. These enterprises are registered and regulated by state policies but are not registered with the Industrial and Commercial Bureau and do not have status as legal entities. The Shanghai Labour Bureau encourages these 'informal labour organizations' to develop to a point where they can register with authorities and transfer to the formal economy.

Informal labour organizations are promoted and assisted through special administrative organs, known as employment services organs. These organs, established at the city, district, county, street committee and town levels, assist informal organizations by providing a variety of administrative and technical assistance.

Some of the preferential policies enjoyed by 'informal labour organizations' include:

- $\quad$ social insurance (employers and employees pay a lower base rate and lower contributions);

- $\quad$ free training opportunities;

- an exemption from local taxes for a period of 3 years. This exemption continues to apply to enterprise that have converted during the 3 year period into registered individual households or small enterprises;

- $\quad$ support for credit;

- the subsidy and employment of informal labour organizations that provide public works;

- $\quad$ risk insurance; and

- voluntary provision of advice and assistance by experts.

By September 2001, there were over 10,000 approved 'informal labour organizations', employing more than 150,000 people. At the same time, a survey by the Shanghai Bureau of Labour and Social Security of 500 'informal labour organizations' found that 25 per cent of them had entered the formal economy.

There has been little systematic assessment of the impact of these policies on job quality or on the extent to which they facilitate entry into the formal economy. Identified weaknesses include:

- $\quad$ some 'informal labour organizations' are not competitive. Extending client networks appears to depend upon the ability to draw upon social connections;

- in 2001, only between 40 and 50 per cent of organizations could afford to purchase social insurance, even at the preferential rates. This means that many workers are still at risk of poverty in old age or in the case of illness or unemployment;

- many informal labour organizations still struggle to access credit;

- there is no system of employee representation in these organizations;

- $\quad$ existing research suggests males are benefiting considerably more from the scheme than women; and

- there is no direct focus by the state or any other organization on labour standards within these informal organizations.

327 Howell, 2002.

328 The policy encourages the development of enterprises in 15 types of activities, including, for example, repairing and maintaining household equipment, sewing, washing clothes and public works labour. 
The Shanghai example illustrates the complexity inherent in designing an innovative approach to labour regulation for MSEs. On the one hand, the fact that 25 per cent of informal labour organizations had moved into the formal economy suggests a positive outcome from the point of view of encouraging MSE growth and formalization. At the same time, however, there are evidently significant weaknesses with the system in practice, including major deficiencies in creating sustainable, quality jobs. Taken together, these findings illustrate at the very least that the development of a policy that promotes both the creation of Decent Work and the growth of MSEs requires more than an approach based on whether or not labour laws apply. In particular, it suggests the need for a strong State role in the facilitation of market access and growth. MSEs:

Peru and Viet Nam have also adopted special regimes for the regulation of

\section{Simplification of registration requirements in Peru and Viet Nam}

In Peru, the Small Enterprise Law (Legislative Decree 705) 1991 simplified access to legal formality through the introduction of the Unified Registration System. This system embodied the principle of a 'one-stop-shop' for registration of a new enterprise. The Unified Registration System was eliminated in 1999 as its functions were subsumed under the general Tax-Payers' Registry. The current system of registration for new enterprises involves registration in the Tax-Payers' Registry, obtaining a Municipal Business Licence; the maintenance of a Payroll Record Book and, within 10 days of opening the Payroll Record Book, registration with the Social Health System.

These reforms have significantly reduced the hurdles faced by individuals seeking to register their businesses. In 1984, establishing a small industrial workshop in Lima required 11 steps, took an average of 289 days and cost around US $\$ 1,321$. In the late 1990s, the same process required 5 steps, took an average of 30 days and cost US $\$ 200.329$

Whether these reforms have lowered the level of informality and thus improved job quality in MSEs is unclear. There has been no impact study on these regulations and some authors suggest that there have been no significant changes observed in the level of informality in Peru. ${ }^{330}$

In Viet Nam, the introduction of the Enterprise Law in 2000 reduced the number of steps required to register an enterprise, the average time needed to register a business and the average monetary cost. The simplification of procedures and costs associated with business appears to have had a positive effect: during the first year of its enactment, 14,444 enterprises were newly registered, about two and a half times the number of registrations in 1999 under earlier legislation. ${ }^{331}$

\section{Conclusion}

State regulation of labour standards is essential to the promotion of job quality, higher productivity, and also to formalization of MSEs. While States must continue to develop basic rules, and establish sanctions for failure to comply, this need not be the only approach they take. Indeed, they can and should develop innovative, responsive regulatory approaches. In developing their policies, States can draw on the insights of comparative law and regulation theory, and pursue key development goals, including the propagation of economically nutritious activities, and the growth of human capabilities. States can and must move beyond simplistic arguments about regulation or

\footnotetext{
329 Figures cited in Chacaltana, 2003, p. 25.

330 Ibid., p. 28.

331 Mallon, 2002, p. 9.
} 
'deregulation': the market requires certain measures of State regulation, and there are many examples of innovative regulatory practices which are inclusive of MSEs, trade unions and NGOS that might guide States in the development of their own approaches. Many of these practices are likely to be useful in the particular context of developing States, which may have limited capacity to develop and pursue traditional approaches to labour regulation. 


\section{CHAPTER 5}

\section{RECOMMENDATIONS FOR IMPROVED DESIGN AND APPLICATION OF LABOUR LAWS FOR MSES}

\section{Chapter summary}

1. States should not simply exclude MSEs from the application of labour laws. Rather, States can and should adopt innovative regulatory techniques to address the two problems of poor job quality in MSEs and the reluctance of MSEs to formalize.

2. This report suggests that States can develop labour regulation policies for MSEs according to the following principles:

3. Labour regulation should pursue three inter-related and mutually reinforcing objectives: promoting human capabilities; improving job quality; and encouraging the formalization of MSEs.

4. Labour regulation should be underpinned by the basic values of the Decent Work agenda.

5. Labour regulation should be innovative and responsive.

\section{Introduction}

The major focus of this report has been on the need for States to develop and to implement labour regulation that promotes Decent Work while being responsive to the needs of MSEs. Promoting job quality in a way that is responsive to the needs of MSEs is consistent with key development goals, including developing human capacity, and improving enterprise efficiency.

The findings of this study suggest that States can and should use innovative regulatory techniques to deal with two related and pressing problems: low job quality in MSEs, and the reluctance of MSEs to formalize. The study has suggested that these techniques may better achieve the desired policy goals than the simplistic approach of excluding MSEs from the scope and coverage of labour law. Although suitable data are difficult to obtain, there appears to be little evidence that excluding MSEs from the scope of labour law has significant positive effects on the growth or the formalization of MSEs. Moreover, there is a strong correlation between poor job quality in MSEs and their exclusion from the scope and coverage of labour laws.

This chapter outlines some basic principles for improved design and application of labour laws for MSEs. These principles facilitate the development of innovative labour regulation, which can be a key element of an enabling regulatory environment for achieving Decent Work, while also encouraging MSEs to formalize. ${ }^{332}$

332 ILO Recommendation 169, article 6(3): States should 'include specific measures and incentives aimed at assisting and upgrading the informal sector to become part of the organized sector.' 


\section{The objectives of labour regulation for MSES}

This report has suggested that States can draw on development and regulation theory, together with the insights of comparative law to form a coherent theoretical basis from which to develop specific labour regulation policies that will be responsive to MSEs. Drawing on that approach suggests that States should have three primary objectives in designing labour regulation for MSEs, outlined as follows:

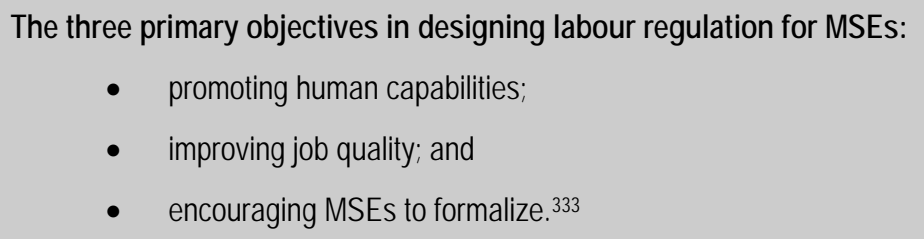

These three objectives are interlinked, and mutually reinforcing. Promoting the capabilities which provide individuals with opportunities to make selfdefined choices is a key development objective. Pursuing a 'Decent Work agenda' is in turn a way of promoting opportunities for women and men to obtain decent and productive work in conditions of freedom, equity, security and human dignity. It is therefore a means to the greater enjoyment of democratic freedoms (including in particular the freedom of association), and to the development of the skills and knowledge of individuals. The promotion of human capabilities in work is also a key factor in organizational learning, which is essential to improving productivity. Increased access to capital and finance, for example, is essential for MSE growth and sustainability, but it is futile without the skills, knowledge and capacity to utilize it. Further, because of the extent to which the job quality experienced by an individual determines their broader quality of life (their income, their health, and so on), the promotion of human capabilities in the workplace, as well as improved job quality, are central development goals.

It is virtually impossible to achieve these vital objectives if enterprises remain unregulated, unorganized and/or informal. So from a development point of view, regulation is essential: both to assure basic labour standards for workers, and also to control the harmful effects of competition based on low wages rather than on other means of increasing efficiency, and therefore value. The institutional and regulatory environment can make a significant difference to the way in which actors respond, and entrepreneurs develop their businesses: 'wellfunctioning markets do not come about spontaneously but rather depend on various institutional arrangements and policy interventions. ${ }^{334}$ Regulation should however be responsive, and innovative; this will facilitate the development of labour laws that move beyond the simplistic terms of regulation versus 'deregulation.'

\footnotetext{
333 The first two objectives, at least, might also be pursued for labour regulation policy more broadly, but the focus here is on how to pursue these in a way that is responsive to the needs of MSEs and MSE workers in particular.
}

334 Reinecke and White, 2004, p. 18; Polanyi, 1957; and Burk, 1988. 


\section{Values}

The primary value driving the design and implementation of labour regulation for MSEs must be the pursuit of Decent Work: that is, the recognition that 'all those who work have rights at work'. In 2002 the ILO Conference discussed a report entitled Decent Work in the Informal Economy, where it was emphasized that:

The goal is to promote decent work along the entire continuum from the informal to the formal end of the economy, and in development-oriented, poverty reductionfocused and gender-equitable ways. ${ }^{335}$

Decent Work has four interlocking components: employment, rights at work, social protection and social dialogue. Thus, an examination of how to achieve Decent Work in MSE employment necessitates a rights-based approach. A rights-based conception of a Decent Work approach to labour regulation is incompatible with mere 'deregulation' of the labour market, in the hope that this will unleash entrepreneurial spirit and lead to formalization. It is also incompatible with the pursuit of the key development objective of improving human capability. Thus, acknowledging that a rights-based approach is essential has important implications for both the scope and the normative content of labour regulation, as well as for the regulatory approach to the enforcement and application of labour law.

\section{Responsive regulation}

\section{Responsive regulation is based on three essential principles:}

1. Design of labour related laws for MSEs must take account of both the question of normative content, and the issues that arise with enforcement and compliance;

2. Design and implementation of labour regulation must be participatory; and

3. Both the design and implementation of labour regulation should be specifically targeted at MSEs. That is, it should take into account the particular needs and problems of MSEs - this may or may not require that States adopt specific laws that apply only to MSEs.

\section{Designing for enforcement and compliance}

States must address the challenges confronting monitoring and enforcement of labour rights and standards in the development of labour law and regulation itself. Most labour law regimes in general depend on a 'command and control' model of regulation. In other words, they establish mandatory labour rights and standards, empower a regulatory agency to oversee the monitoring and enforcement of those standards, and provide for sanctions in the event of failure to comply.

The findings of this study, however, show that - for various reasons - many States fail to monitor and to enforce labour laws in relation to MSEs. There are problems of inconsistency - State authorities often selectively enforce some laws whilst ignoring breaches of others - and there are problems of corruption. There

335 ILO, 2002b, p. 4. 
are also many practical obstacles to effective monitoring and enforcement, such as inadequate resourcing of regulatory agencies. In some cases, labour administrations may make strategic choices about their approach to enforcement, perhaps as part of a broader enforcement policy, which might lead to lower levels of sanctioning failure to comply with regulatory requirements. ${ }^{336}$ Regardless of how it comes about, however, lack of enforcement can lead to workers being left with little or no protection. It fails to assure their rights at work, to promote Decent Work, and in turn to contribute to essential development objectives.

The ability of labour law to achieve these objectives is therefore often seen as a function of the application or enforcement of labour laws to MSEs. But dealing with ineffectiveness requires something more than simply establishing a regulatory system based on rules and sanctions, leaving the issues of effective monitoring and enforcement of the system for separate and subsequent consideration. A more holistic and responsive approach to the design of labour law is needed: one that incorporates innovative approaches to monitoring and enforcement of labour law at the stage of regulatory design. This is likely to be a more successful strategy for confronting the challenges facing the application of labour law to MSEs.

The concept of a 'labour regulation pyramid' is a tool that can be used in the design of responsive labour regulation for MSEs. ${ }^{337}$ A key aspect of the 'labour regulation pyramid' is that it assumes that regulation is likely to be more effective when regulators have a number of different options available to them in enforcing labour laws. The existence of legal rules and norms enshrining labour rights and standards as non-negotiable behavioural minimums, with noncompliance subject to non-discretionary punishment, are at the apex of the pyramid. These enshrine recognition of the development objectives of labour regulation, and the value of a rights-based approach as key elements of the regulatory approach. They serve as goal, guide, and ultimately as a source of sanction. However, frequently the most effective way for governments to achieve behavioural change in recognition of labour law is if MSEs themselves choose to comply with relevant rights and standards, without the application of sanctions. The pyramid therefore contemplates other regulatory strategies that the State might use, often in collaboration with other regulatory actors, to achieve the desired change in a manner that is responsive to the circumstances of MSEs.

A particular advantage of the labour regulation pyramid is that it is flexible: the pyramid will not necessarily be the same for every country. Thus, it is not a concept of optimal labour regulation that might be applied in any social, economic, cultural or political context. Rather, it is a way to conceptualize - and to depict graphically - a range of interlinked regulatory approaches that States might adopt, all of which reflect and promote key development objectives by working both toward and from a rights-based approach. Thus, an essential feature of each pyramid would be the 'apex' of substantive labour rights and standards, with sanctions for non-compliance. This is because in the absence of the apex, regulators will have far less capacity to apply any leverage against

\footnotetext{
336 Ayres and Braithwaite, 1992, pp. 38-41.

337 This concept is based on the idea of an 'enforcement pyramid', developed by Ayres and Braithwaite, op.cit. The discussion in this section of the report draws extensively on their work.
} 
MSEs unwilling to comply with labour law. The rest of the pyramid, however, would be designed in different ways according to different circumstances.

\section{Figure 5: Pyramid of labour regulation strategies for MSEs $^{338}$}

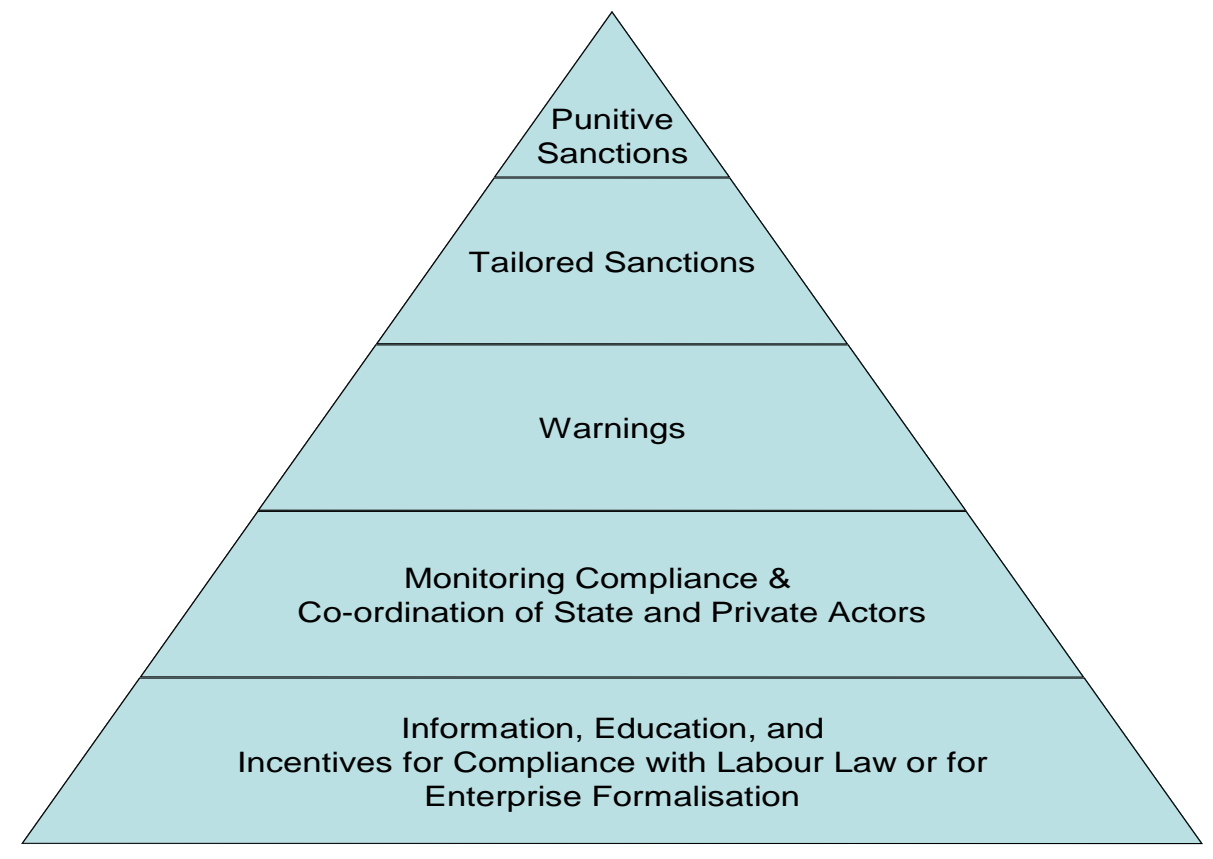

This diagram shows the layers of regulatory strategies that could be applied to MSEs and the informal economy. We discuss each of the layers of the labour regulation pyramid in further detail below.

Before doing so it is important to emphasize that the pyramid is a way of depicting two key things: the differences between levels of sanction in regulatory response, and the frequency with which different regulatory responses might be deployed. In other words, formal sanctions appear at the top of the pyramid because they are a more stringent response to failure to comply than is providing information and education. For the most part, it might be anticipated that the labour administration in its regulatory activity would emphasize the use of measures at lower levels of the pyramid. ${ }^{339}$ However the pyramid is not intended to suggest a 'linear' approach to labour regulation: that is, States need not approach any particular situation starting from the bottom of the pyramid and working their way to the top. On the contrary: responsive regulation would be best designed in a way that utilized different elements of the pyramid in interlinked ways depending upon a range of particular circumstances.

338 In some regulatory scholarship, two ‘enforcement pyramids' have been developed: in the area of environmental regulation, for example, Bridget Hutter used one pyramid for enforcement strategies, and another for sanctions: Hutter, 1997, pp. 229-230.

339 Ayres and Braithwaite, 1992, Hutter, 1997. 


\section{Information, education and incentives for formalization}

This strategy recognizes two key facts. Firstly, a low level of legal literacy is a key obstacle to the application of labour law: for many MSEs and their workers, non-compliance with labour laws is a result of ignorance of the regulatory requirements. Secondly, entrepreneurs make strategic choices about compliance with labour laws, and they may wrongly perceive labour regulation to be a constraint on enterprise growth, when in fact promotion of higher job quality (and human capability) is entirely consistent with economic development. In these cases, regulatory strategies such as providing advice or education to MSEs about labour rights and standards, together with incentives for MSEs to formalize and recognize their obligations under labour law, can form the first stage in an overall enforcement strategy, or the base of the pyramid. These strategies promote voluntary formalization together with recognition of labour rights and standards by MSEs, thus avoiding the simplistic and ineffective approach of simply excluding MSEs from the application of labour law. The ILO's WISE Programme is an example of this regulatory approach. It shows that raising MSE employers' awareness of the link between improved job quality and higher productivity provides them with a clear incentive to improve working conditions. States may also provide incentives for MSEs to formalize through offering a variety of services and opportunities that are only accessible to registered organizations (such as the training, insurance and credit opportunities provided by the Shanghai Municipal Government to 'informal labour organizations') or by providing tax allowances to MSEs for a certain period after registration (such as those offered in Viet Nam and Hungary).

\section{Monitoring compliance and coordination between state and private actors}

This strategy recognizes that it will be necessary for regulatory agencies to monitor the extent to which MSEs comply with labour laws. The inspection system developed by Chile, which is adapted to the realities of MSEs, is an example of such a strategy. This level of the enforcement pyramid could also incorporate cooperation between State labour administrations and representative organizations such as trade unions in monitoring and inspection. An excellent example of such cooperation is the Regional Safety Representative Scheme in Sweden, under which trade unions play a prominent role in monitoring, and promoting compliance with, occupational health and safety standards in small businesses. States can also play a role in coordinating monitoring and enforcement between the State labour administrations and representative organizations, especially where businesses are subject to (or participate in) private voluntary initiatives such as corporate codes of conduct that include minimum labour standards.

\section{Warnings}

Another stage in moving toward the imposition of formal sanctions for noncompliance might be State labour administrations notifying MSEs of their noncompliance with labour laws. The notice would be accompanied by a warning which would make it clear that further non-compliance would lead to the imposition of targeted and/or punitive sanctions. Such an approach is adopted by the Philippines in relation to small enterprises. This strategy would be used in 
situations where education and monitoring had failed to bring about behavioural change with respect to labour law.

\section{Tailored sanctions}

This strategy allows State labour administrations to impose sanctions on MSEs for non-compliance with labour law, but to do so in a manner that is accommodative to their context. An example is the Chilean programme under which an enterprise with fewer than 10 workers may participate in a compulsory training course on labour law as an alternative to paying fines for noncompliance. This programme attempts to address lack of awareness as a common cause of MSE non-compliance.

\section{Punitive sanctions}

The final strategy would be a sanctioning approach. This would most likely involve legal action taken by a State labour administration invoking and seeking the application of sanctions available under labour laws to a non-complying MSE. Where possible, action might be initiated by a trade union, or another representative organization. Alternatively, private actors might be able to apply for sanctions, which would be enforced by a judicial or semi-judicial body. Trade unions, for example, could be given specific standing rights to pursue sanctions. This approach would only be utilized where persuasion, warnings, and tailored sanctions were unsuccessful. Although punitive sanctions form the peak of the enforcement pyramid, the fact that they are available to regulators contributes to the effectiveness of other strategies in the pyramid.

\section{Design and implementation must be participatory}

The second major principle is that both regulatory design and implementation should be participatory. There are three elements to this principle. Firstly, that those who will be most affected by regulation, or their representatives, should be involved in its design. Secondly, that representative organizations, especially trade unions, should be involved in monitoring and compliance. Thirdly, that representative organizations should be involved in periodic assessment of the regulatory programme.

1. The people who will be affected by the regulation, or their representatives, should be involved in the design of the regulation

Those who will be affected by regulation or who will be involved in its enforcement should be consulted about its design. This includes both the development of rules and standards which businesses are expected to meet, as well as the regulatory structure for application and enforcement of those rules. Servais accurately observes that the challenge for States is 'to reinvent new institutions offering all those concerned the chance to take part, no matter at what 
level, in defining and implementing policies and programmes that provide them with decent work ${ }^{340}$

Optimal structuring of responsive regulation which takes account of local conditions is more likely to result from negotiations between governments, MSEs, and other interested organizations. Workers in MSEs suffer a representation gap, particularly through trade unions and tripartite institutions. (MSE employers may also suffer a representation gap in this respect). Thus, it may be appropriate and necessary to involve other organizations than those typically envisaged by the usual scope of tripartite negotiation. Innovative ways of involving MSE employers and workers in representative organizations include the Self-Employed Women's Association (SEWA) in India, and the efforts by trade unions in Kenya and South Africa. (It should be noted that SEWA is a consultative body rather than a process.) Those consulted might include local councils, community organizations, cooperatives, unions and employer organizations. At the beginning of the design and implementation process, the representational deficit may initially result in a lack of capacity by representative bodies. ${ }^{341}$ However, studies of consultative processes suggest that the iterative process of repeated consultation, combined with education concerning the process, can assist in building the capacity of representative organizations which has positive flow on effects for monitoring and compliance. ${ }^{342}$

Consultation during design is also an important factor in generating demand for regulatory programmes. Rinehart's study, for example, found that local demand for change was essential to the success and sustainability of the programmes. He emphasized that policy-makers need to assess problems and solutions in an interactive way at the local level in order to allow project participants to develop a sense of ownership, awareness and respect of the programmes. $^{343}$ This is likely to foster cooperation with monitoring and enforcement of labour laws. Importantly, a transparent and well-designed consultative process can also assist in avoiding capture by dominant players or groups opposed to enforcement. It may also minimize the chances of labour regulation being rendered ineffective by corruption (or the perception of corruption).

2. Representative organizations, especially trade unions, must be involved in monitoring and compliance

Ensuring that representative organizations are involved in the compliance process is no simple task. Workers in MSEs are under-represented, and labour regimes often fail to ensure that workers in MSEs can exercise their rights to

\footnotetext{
340 Servais, 2001, p. 361.

341 For an assessment of tripartite consultation in Latin America during the transition from corporatism, see Bronstein, 1997, p. 1. For a similar discussion of transition economies, see Ost, 2000, p. 503. For comments on the effectiveness and outcomes of labour law reform through consultative processes with under-developed union structures see Fenwick, 2005.

342 Baiocchi, 2001, p. 43.

343 Rinehart, 2004, p. 11.
} 
organize, and to bargain collectively. ${ }^{344}$ It follows that labour laws should be changed to better facilitate freedom of association in MSEs, and labour organizations must be strengthened through education and training programmes.

Research for this report has shown that attempts to improve the application of labour laws to MSEs will have greater success if worker - and often employer - organizations are in a position to represent the interests of their members in social dialogue processes. Policy-makers have recognized that 'an existing level of organization among workers is a prerequisite to effectively addressing the working condition issues of informal sector operators'. More specifically, it has been noted that long-term representation and support provided by workers' organizations are needed to ensure the success and durability of improvements to the conditions of workers in MSEs. ${ }^{345}$

The role of workers' or self-employed workers' organizations is also particularly important in the face of inadequate inspection by governmental bodies. A study on informal food sector workers in South East Asia, for example, reported that a number of occupational health and safety issues in this sector would be more adequately addressed if vendors were organized and therefore 'in a more spatially and economically secure position’. ${ }^{346}$

\section{Representative organizations should be involved \\ in the assessment of the regulatory programme}

Another way that design of labour law can incorporate responsive regulation is by providing for periodic assessment of the regulatory framework that has been established, with specific reference to MSEs. The effectiveness of the regulation and its enforcement should be assessed after an initial period of implementation, in order to provide those affected an opportunity to comment and to propose ways in which the regulation could be more effectively enforced. The observations of representative organizations can be fed back into the design process to ensure that the regulatory programme applicable to MSEs is dynamic rather than static. This will help to prevent situations where labour laws remain 'on the books' for long periods, but are not enforced in practice. It will help to facilitate the sharing of institutional learning amongst State and non-State actors. Further, this strategy is particularly helpful where a staged implementation of regulatory techniques is envisaged (that is, where authorities plan to use regulatory strategies from different layers of the pyramid in turn). This might happen, for example, where a period of voluntary compliance is to be followed by mandatory enforcement in the event that voluntary compliance has not occurred.

\footnotetext{
344 ILO, 2002d, Resolution concerning Decent Work and the Informal Economy, ILC, $90^{\text {th }}$ session.

345 Save the Children, Occupational Safety and Health for the Urban Informal Sector: The Save the Children Experience (1996), as cited in Rinehart, 2004, p. 60.

346 Yasmessn, 'Workers in the Urban "Informal” Food Sector: Innovative Organising Strategies', as cited in ibid., p. 94.
} 


\section{The design and implementation of the regulation should be specifically targeted at improving job quality in MSES}

This study has shown that there is a critical inter-linkage between the goals of job quality for MSE workers, and formalization of MSEs. It is not sufficient for regulation to be aimed broadly at formalization of MSEs without targeting job quality issues. Nor can it be broadly aimed at improving job quality, without targeting MSEs specifically.

Country-specific research undertaken for this report suggests that even policies ostensibly directed toward 'microenterprises' can be rendered largely ineffectual by unrealistic definitions of what constitutes an MSE. In Indonesia, for example, post-Suharto governments have introduced six Action Plans directly focused on MSEs. ${ }^{347}$ These initiatives, however, have shown little potential to improve conditions or opportunities for workers in micro-enterprises. This is in part attributable to the fact that the Action Plans are preoccupied with enhancing enterprise competitiveness, without a correlated concern for job quality. A second problem has arisen because the Government's definition of an MSE is an enterprise with assets of more than 20 million rupiah (excluding land and building). In 2002, enterprises with assets of less than 20 million rupiah constituted 99.8 per cent of all enterprises in Indonesia. ${ }^{348}$ Anecdotal evidence suggests that those at the poorer end of this bracket are not accessing assistance and the bracket needs to be further disaggregated in order to target the varied problems experienced by enterprises that might be labelled 'small'. Moreover, labour standards for MSE employment have not changed over the past ten years, despite new regulations and initiatives. This suggests that programmes require redesign in order to address various job quality and human capability issues.

A similar conclusion can be drawn concerning Chile's attempt to widen the availability of training programmes through reform of its National Service of Training and Employment, and its provision of tax breaks for business expenditures on training. Training-focused policies like this have great potential to provide mutual benefits to both workers and enterprises through improved conditions and increased productivity. However, although Chile's approach does

\footnotetext{
347 These are: Action Plan for creating a business-conducive environment (the government takes part in formulating regulations required by SMEs); Action Plan for market access (the government works to facilitate market access and opportunity); Action Plan for financial access (the role of the government is divided into two areas, the government can provide a special scheme for SMEs, setting up procedures and standard requirement, and it can cooperate with financial institutions to provide financial resources for SMEs); Action Plan for information access (this program is a part of marketing access plan, a current weak point in SME marketing, it is about business networking through information technology); and Action Plan for technology and technology sharing (the government can assist SMEs through increasing awareness of how to apply proper technology, with the aim of enhancing competitiveness).

348 See 'Indonesia: SME Profile' <http://www.actetsme.org/indo/indo2000.htm> on 25 September 2005.
} 
include some specific efforts directed toward MSEs, ${ }^{349}$ the programmes generally cover enterprises of all sizes, and fail to deal adequately with the particular vulnerabilities of MSEs relative to larger enterprises. As a result, medium and large enterprises have been the main beneficiaries of the policy, and MSEs are failing to access the potential benefits for themselves and their workers. Flores cites a range factors that are either specific to, or more acute in, MSEs, which generic policies are unable to address. These include lack of time to participate; lack of interest on the part of workers; workers' lack of financial resources; and lack of information about where and how to access training. ${ }^{350}$

These are just two examples of the way in which the best-intentioned policy developments can under-perform if they are not carefully and precisely targeted at smaller enterprises and their specific needs. Despite their shortcomings in terms of improving job quality for employees of MSEs, these regulatory experiments have been successful in some respects. As a result, they demonstrate that carefully designed and targeted regulation can bring about positive change.

\section{v. Conclusion}

States face significant obstacles and challenges when seeking to design labour regulation for MSEs. While MSEs continue to offer great promise for job creation, job quality in MSEs is too low: MSE workers generally do not have Decent Work. States must also balance - and in some cases, it seems, choose between - two policy goals. One is promoting workers' rights and interests through the design and application of labour laws. The other is providing an environment for MSEs that is encouraging and facilitative, and which promotes formalization.

States must make these policy choices in a challenging environment. They face the pressure of the forces of 'globalization', which pushes them towards exploitation of the competitive advantage of low wages as trade flows increase internationally. They face the policies that are promoted by the Bretton Woods institutions and (increasingly) through bilateral aid funding. States must also make their policy choices within the context of a debate about the nature and function of State regulation that grossly distorts and over-simplifies its nature and purpose. There is no such thing as 'de-regulation': the choice is not between regulating or not regulating. Indeed States should not simply 'deregulate' in the area of labour law, excluding MSEs from some (or all) of the labour law framework, in the hope that this may facilitate MSE development. This approach has the significant downside of creating a potential 'growth trap', and promoting a general lowering of working conditions. It has the potential to create unfair competition between enterprises within particular sectors and industries. It also ignores the fact that all those who work have rights at work - it is not an approach that is consistent with a Decent Work agenda. Neither does it seem to be an effective approach. The findings of this study show that while the majority

\footnotetext{
349 Flores, 2003, p. 26, referring to the credit programme aimed at alleviating the cashflow problems that are more acute in MSEs; and the provision of a direct subsidy specifically for MSEs of approximately US\$1,000 per year (which equates to 160 hours of training) in order to train both employers and workers and which requires enterprises to have an annual turnover of less than US\$500,000, be at least 18 months old, have no tax or labour infractions, and show that trainees have a signed contract.

350

Ibid., p. 40, Table 4.1.
} 
of States exclude MSEs from some parts of their labour law framework, there has been little positive impact. Job quality in MSEs remains low; there is no discernible increase in formal sector employment; and MSEs continue to make strategic decisions about regulatory compliance.

States must therefore face the choice of how to regulate. This report shows that States can and should regulate in ways that are innovative, and can be responsive to the needs of both workers and MSEs. States can devise labour regulation that promotes job quality - Decent Work - as well as economic growth and formalization of MSEs which, in turn, will lead to further consolidation and improvement of job quality.

Theories of development and regulation, and the insights of comparative law, suggest that States may pursue a range of inter-related goals and policies in devising innovative labour regulation. Moreover, there are many examples of innovative practices from which States might seek inspiration. Together, theory and practice suggest the following principles to guide States in the development of labour regulation for MSEs:

1. Labour regulation should pursue three inter-related and mutually reinforcing objectives: promoting human capabilities, improving job quality, and encouraging formalization of MSEs.

2. Labour regulation should be underpinned by the basic values of the Decent Work agenda: it should recognize that all those who work have rights at work.

3. Labour regulation should be responsive. Firstly, it should be designed so as to take into account issues in enforcement and application, by drawing on the options presented in the 'labour regulation pyramid'. Secondly, it should be designed through participatory processes, which should extend to participation in enforcement and to periodic review. Thirdly, design and implementation should be targeted specifically at MSEs.

A key point however is that State flexibility in regulatory approach does not require that States abandon the objectives of their regulation; responsive regulatory design does not require the abdication of the values of a Decent Work agenda and the rights of all those who work. On the contrary, these must serve as the touchstones for any regulatory framework, and must always be protected in labour laws.

The challenge for States is to identify, to encourage and to develop innovative methods of labour regulation. To do so, they must draw on their own resources, their existing institutions, and their citizens (especially through their representative organizations) to establish locally designed regulatory strategies to pursue the twin goals of job quality, and formalization of MSEs. In this way, labour regulation can play a vital part in the achievement of Decent Work, and in turn in enterprise development and formalization. 


\section{APPENDIX 1: FORMAL SCOPE AND COVERAGE OF LABOUR LAW TO MSES}

\section{A. Brazil, Chile, China, Denmark, Hungary, Indonesia and Kenya}

× Obligations vary according to size of enterprise

— Information not available

\begin{tabular}{|c|c|c|c|c|c|c|c|}
\hline & Brazil & Chile & China & Denmark & Hungary & Indonesia & Kenya \\
\hline Minimum wage & $\checkmark$ & $\checkmark$ & $\checkmark$ & $x$ & $\checkmark$ & $\checkmark$ & $\checkmark$ \\
\hline Overtime/working limits & $\checkmark$ & $\checkmark$ & $\checkmark$ & $x$ & $\checkmark$ & $\checkmark$ & $\checkmark$ \\
\hline Paid time off & $\checkmark$ & $\checkmark$ & $\checkmark$ & $\checkmark$ & $\checkmark$ & $\checkmark$ & $\checkmark$ \\
\hline Unemployment insurance & $\checkmark$ & $\checkmark$ & $\checkmark$ & $\checkmark$ & $\checkmark$ & $\begin{array}{l}\text { Only mandatory } \\
\text { for enterprises } \\
\text { employing more } \\
\text { than } 10 \text { workers }\end{array}$ & $\checkmark$ \\
\hline Workers' compensation & - & $\checkmark$ & $\checkmark$ & $\checkmark$ & $\checkmark$ & - & - \\
\hline $\begin{array}{l}\text { Collective bargaining \& freedom } \\
\text { of association }\end{array}$ & $\checkmark$ & $\checkmark$ & $\checkmark$ & $\checkmark$ & $\checkmark$ & $\checkmark$ & $\checkmark$ \\
\hline Unjust dismissal & $\checkmark$ & $\checkmark$ & $\checkmark$ & $\begin{array}{c}\text { For certain types } \\
\text { of employees }\end{array}$ & $\checkmark$ & $\checkmark$ & - \\
\hline Occupational health \& safety & $\checkmark$ & $\begin{array}{l}\text { Obligations vary } \\
\text { according to } \\
\text { enterprise size }\end{array}$ & $\checkmark$ & $\checkmark$ & $\checkmark$ & $\checkmark$ & $\checkmark$ \\
\hline $\begin{array}{l}\text { Anti-discrimination/ Equal } \\
\text { employment opportunity }\end{array}$ & $\checkmark$ & $\checkmark$ & $\checkmark$ & $\checkmark$ & $\checkmark$ & $\checkmark$ & - \\
\hline Prohibition on forced labour & $x$ & $x$ & $x$ & $x$ & $x$ & $x$ & - \\
\hline
\end{tabular}




\begin{tabular}{|c|c|c|c|c|c|c|c|}
\hline & Brazil & Chile & China & Denmark & Hungary & Indonesia & Kenya \\
\hline Prohibition on child labour & $\checkmark$ & $\checkmark$ & $\checkmark$ & $x$ & $\checkmark$ & $\checkmark$ & - \\
\hline $\begin{array}{l}\text { Advance notice and consultation } \\
\text { (large-scale layoffs) }\end{array}$ & $\checkmark$ & $\checkmark$ & $\checkmark$ & $\checkmark$ & $x$ & $\checkmark$ & - \\
\hline Parental/ family leave & $\checkmark$ & $\checkmark$ & $\checkmark$ & $\checkmark$ & $\checkmark$ & $\checkmark$ & $\checkmark$ \\
\hline Employee consultation & $x$ & $x$ & $\checkmark$ & $x$ & $\begin{array}{l}\text { Only mandatory } \\
\text { for enterprises } \\
\text { employing more } \\
\text { than } 15 \text { workers }\end{array}$ & $\begin{array}{l}\text { Only mandatory } \\
\text { for enterprises } \\
\text { employing } 50 \text { or } \\
\text { more workers }\end{array}$ & - \\
\hline Transfer of undertaking & $x$ & $x$ & $x$ & $\checkmark$ & $\checkmark$ & $\checkmark$ & - \\
\hline
\end{tabular}

x Obligations vary according to size of enterprise

— Information not available 


\section{B. Namibia, Nepal, Peru, Philippines, South Africa, Thailand and Viet Nam}

× Obligations vary according to size of enterprise

— Information not available

\begin{tabular}{|c|c|c|c|c|c|c|c|}
\hline & Namibia & Nepal & Peru & Philippines & South Africa & Thailand & Viet Nam \\
\hline Minimum wage & $x$ & $\checkmark$ & $\checkmark$ & $\begin{array}{c}\text { Microenterprises } \\
\text { are exempt from } \\
\text { minimum wage } \\
\text { providing they } \\
\text { conform with } \\
\text { other labour } \\
\text { standards. }\end{array}$ & $x$ & $\checkmark$ & $\checkmark$ \\
\hline Overtime/working limits & $\checkmark$ & $\checkmark$ & $\checkmark$ & $\checkmark$ & $\checkmark$ & $\checkmark$ & $\checkmark$ \\
\hline Paid time off & $\checkmark$ & $\begin{array}{l}\text { Enterprises with } \\
\text { fewer than10 } \\
\text { employees not } \\
\text { required to pay } \\
\text { annual and sick } \\
\text { leave }\end{array}$ & $\checkmark$ & $\begin{array}{l}\text { Not applicable to } \\
\text { retail and service } \\
\text { establishments } \\
\text { employing fewer } \\
\text { than } 10 \text { workers. }\end{array}$ & $\checkmark$ & $\checkmark$ & $\checkmark$ \\
\hline Unemployment insurance & $\checkmark$ & $x$ & $x$ & - & $\checkmark$ & $\checkmark$ & $\begin{array}{l}\text { Compulsory } \\
\text { social security } \\
\text { scheme only } \\
\text { applies to } \\
\text { enterprises } \\
\text { employing } 10 \text { or } \\
\text { more employees }\end{array}$ \\
\hline
\end{tabular}




\begin{tabular}{|c|c|c|c|c|c|c|c|}
\hline & Namibia & Nepal & Peru & Philippines & South Africa & Thailand & Viet Nam \\
\hline Workers' compensation & $\checkmark$ & $\checkmark$ & $\checkmark$ & $\checkmark$ & $\begin{array}{c}\text { Only enterprises } \\
\text { with } 10 \text { or more } \\
\text { workers must } \\
\text { contribute to } \\
\text { workers' } \\
\text { compensation } \\
\text { insurance scheme }\end{array}$ & $\checkmark$ & $\checkmark$ \\
\hline $\begin{array}{l}\text { Collective bargaining \& } \\
\text { freedom of association }\end{array}$ & $\checkmark$ & $\checkmark$ & $\checkmark$ & $\checkmark$ & $\checkmark$ & $\checkmark$ & $\begin{array}{c}\checkmark \\
\text { Trade unions and } \\
\text { the signing of a } \\
\text { collective labour } \\
\text { agreement are } \\
\text { mandatory in all } \\
\text { enterprises with } \\
10 \text { or more } \\
\text { employees }\end{array}$ \\
\hline Unjust dismissal & $\checkmark$ & $\begin{array}{l}\text { Not applicable to } \\
\text { enterprises } \\
\text { employing fewer } \\
\text { than } 10 \\
\text { employees. } \\
\text { Applies to } \\
\text { enterprises of all } \\
\text { sizes in industrial } \\
\text { areas }\end{array}$ & $\checkmark$ & $\checkmark$ & $\checkmark$ & $\checkmark$ & $\checkmark$ \\
\hline
\end{tabular}




\begin{tabular}{|c|c|c|c|c|c|c|c|}
\hline & Namibia & Nepal & Peru & Philippines & South Africa & Thailand & Viet Nam \\
\hline Occupational health \& safety & $\begin{array}{c}\checkmark \\
\text { Obligations vary } \\
\text { according to } \\
\text { enterprise size }\end{array}$ & $\checkmark$ & $\checkmark$ & $\begin{array}{c}\checkmark \\
\text { Obligations vary } \\
\text { according to } \\
\text { enterprise size }\end{array}$ & $\begin{array}{c}\checkmark \\
\text { Obligations vary } \\
\text { according to } \\
\text { enterprise size }\end{array}$ & $\checkmark$ & $\begin{array}{c}\checkmark \\
\text { Obligations vary } \\
\text { according to } \\
\text { enterprise size }\end{array}$ \\
\hline $\begin{array}{l}\text { Anti-discrimination/ Equal } \\
\text { employment opportunity }\end{array}$ & $\checkmark$ & $x$ & $\checkmark$ & $\checkmark$ & $\checkmark$ & $\checkmark$ & $\checkmark$ \\
\hline Prohibition on forced labour & $x$ & $\checkmark$ & $x$ & $x$ & $x$ & $\checkmark$ & $\checkmark$ \\
\hline Prohibition on child labour & $\checkmark$ & $\checkmark$ & $\checkmark$ & $\checkmark$ & $\checkmark$ & $\checkmark$ & $\checkmark$ \\
\hline $\begin{array}{l}\text { Advance notice and } \\
\text { consultation (large-scale } \\
\text { layoffs) }\end{array}$ & & $x$ & $x$ & $\checkmark$ & $x$ & $\checkmark$ & $\checkmark$ \\
\hline Parental/family leave & $\checkmark$ & $\begin{array}{l}\quad>10 \\
\text { Applies to } \\
\text { enterprises of all } \\
\text { sizes in industrial } \\
\text { areas }\end{array}$ & $\checkmark$ & $\checkmark$ & $\checkmark$ & $\checkmark$ & $\checkmark$ \\
\hline Employee consultation & $x$ & $\begin{array}{c}>10 \\
\text { Applies to } \\
\text { enterprises of all } \\
\text { sizes in industrial } \\
\text { areas }\end{array}$ & $x$ & $\checkmark$ & $\begin{array}{l}\text { Only mandatory } \\
\text { in enterprises } \\
\text { employing more } \\
\text { than } 100 \text { workers }\end{array}$ & $x$ & $\checkmark$ \\
\hline Transfer of undertaking & $x$ & $x$ & $x$ & $x$ & $\checkmark$ & $\checkmark$ & $\checkmark$ \\
\hline
\end{tabular}

x Obligations vary according to size of enterprise;

— Information not available 


\section{BIBLIOGRAPHY}

\section{Journal articles}

Arat, Z. 'Analyzing Child Labour as a Human Rights Issue; Its Causes, Aggravating Policies, and Alternative Proposals’ (2002) Vol. 24, Human Rights Quarterly.

Bardhan, P. 'The New Institutional Economics and Development Theory: A Brief Critical Assessment’ (1989) Vol. 17, World Development.

Beattie, R. 'Social Protection for All: But How?’ (2000) Vol. 139, International Labour Review.

Biagi, M. 'Labour Law in Small and Medium-Sized Enterprises: Flexibility or Adjustment?' (1995) Vol. 16, Comparative Labour Law Journal.

Black, J. 'Proceduralizing Regulation: Part I' (2000) Vol. 20, Oxford Journal of Legal Studies.

Black, J. 'Critical Reflections on Regulation' (2002) Vol. 27, Australian Journal of Legal Philosophy.

Block, R. and Roberts, K. 'A Comparison of Labour Standards in the United States and Canada' (2000) Vol. 55, Relations Industrielles.

Braithwaite, J. 'Rewards and Regulation’ (2002) Vol. 29, Journal of Law and Society.

Bronstein, A. 'Labour Law Reform in Latin America: Between State Protection and Flexibility' (1997) Vol. 136, International Labour Review.

Bronstein, A. 'Societal Change and Industrial Relations in Latin America: Trends and Prospects (1995) Vol. 134, International Labour Review.

Coker, T. 'Globalization and Corporatism: The Growth and Decay of Organized Labor in Venezuela: 1990-1998’ (2001) Vol. 60, International Labor and Working-Class History.

Cooke, F. 'Employment Relations in Small Commercial Businesses in China' (2005) Vol. 36, Industrial Relations Journal.

Cooney (a), S. ‘A Broader Role for the Commonwealth in Eradicating Foreign Sweatshops?' (2004) Vol. 28, Melbourne University Law Review.

Cooney (b), S. 'Towards More Effective Implementation of Labour Standards in China' (2004) Vol. 2 International Law Review of Wuhan University.

Cotterrell, R. 'Law as Culture' (2004) Vol. 17, Ratio Juris.

Darian-Smith, E, 'Structural Inequalities in the Global Legal System' (2000) Vol. 34, Law and Society Review.

Dickens, L. 'Problems of Fit: Changing Employment and Labour Regulation' (2004) Vol. 42, British Journal of Industrial Relations.

Frankenburg, G. 'Stranger Than Paradise: Identity and Politics in Comparative Law' (1997) Vol. 2 Utah Law Review.

Fredman, S. 'Women at Work: the Broken Promise of Flexicurity' (2004) Vol. 33, Industrial Relations Journal. 
Frenkel, S. and Kuruvilla, S. 'Logics of Action, Globalization and Changing Employment Relations in China, India, Malaysia and Philippines' (2002) Vol. 55, Industrial and Labor Relations Review.

Frick, K. and Walters, D. 'Worker Representation on Health and Safety in Small Enterprises: Lessons from a Swedish Approach’ (1998) Vol. 137, International Labour Review.

Galli, R. and Kucera, D. 'Labor Standards and Informal Employment in Latin America' (2004) Vol. 20, World Development.

Gereffi, G. 'International Trade and Industrial Upgrading in the Apparel Commodity Chain'(1999) Vol. 48, Journal of International Economics.

Grabosky, P. 'Regulation by Reward: On the Use of Incentives as Regulatory Instruments' (1995) Vol. 17, Law and Policy.

Hepple, B. 'Can Collective Labour Law Transplants Work? The South African Example' (1999) Vol. 20, Industrial Law Journal (South Africa).

Howe, J. 'The Job Creation Function of the State: a New Subject for Labour Law?' (2001) Vol. 14, Australian Journal of Labour Law.

Howse, R. 'Retrenchment, Reform or Revolution? The Shift to Incentives and the Future of the Regulatory State' (1993) Vol. 31, Alberta Law Review.

Kahn-Freund, O. 'On Uses and Misuses of Comparative Law’ (1974) Vol.37, Modern Law Review.

Legrand, P. 'The Impossibility of Legal Transplants' (1997) Vol. 4, Maastricht Journal of European and Comparative Law.

Liubicic, R. 'Corporate Codes of Conduct and Product Labeling Schemes: The Limits and Possibilities of Promoting International Labor Rights through Private Initiatives' (1998) Vol. 30, Law and Policy in International Business.

Maldonado, C. ‘The Informal Sector: Legalization or Laissez-Faire?’ (1995) Vol. 134, International Labour Review.

Marshall, S. 'An Exploration of 'Control' in the Context of Vertical Disintegration and its Implications for Regulation'.

Mayntz, R. 'The Conditions of Effective Public Policy: A New Challenge for Policy Analysis' (1983) Vol. 11, Policy and Politics.

Nguyen, T. and Bryant, S. 'A Study of the Formality of Human Resource Management Practices in Small and Medium-Size Enterprises in Vietnam' (2004) Vol. 22, International Small Business Journal.

Nossar, I. Johnstone, R. and Quinlan, M. 'Regulating Supply-Chains To Address the Occupational Health and Safety Problems Associated with Precarious Employment: The Case of HomeBased Clothing Workers in Australia’ (2004) Vol. 17, Australian Journal of Labour Law.

Ogus, A. 'Corrective Taxes and Financial Impositions as Regulatory Instruments' (1998) Vol. 61, Modern Law Review.

Orford, A. and Beard, J. 'Making the State Safe for the Market: The World Bank's World Development Report 1997’ (1998) Vol. 22, Melbourne University Law Review.

Pahuja, S. 'Technologies of Empire: IMF Conditionality and the Reinscription of the North/South Divide’ (2000) Vol. 13, Leiden Journal of International Law. 
Revenga, A. 'Employment and Wage Effects of Trade Liberalization: The Case of Mexican Manufacturing' (1997) Vol. 15, Journal of Labour Economics.

Saavedra, J. and Chong, A. 'Structural Reform, Institutions and Earnings: Evidence from the Formal and Informal Sectors in Urban Peru' (1999) Vol. 35, Journal of Development Studies.

Scott, A. 'Occupational Health and Safety in SMEs' (1998) Small Enterprise Development.

Servais, J-M. 'The Informal Sector: Any Future for Labour Law?'(1992) Vol. 8, International Journal of Comparative Labour Relations.

Stewart, M. 'Global Trajectories of Tax Reform' (2003) Vol. 44, Harvard International Law Journal.

Teubner, G. 'Legal Irritants: Good Faith in British Law or How Unifying Law Ends Up in New Divergences’ (1998) Vol. 61, Modern Law Review.

Tipples, R. 'The Human Capability Framework - An Important and Useful Framework for Understanding the Labour Market' (2004) Vol. 29, New Zealand Journal of Employment Relations.

Von Potobsky, G. 'Small and Medium-Sized Enterprises and Labour Law' (1992) Vol. 131, International Labour Review.

Wade, R. H. 'On the Causes of Increasing World Poverty and Inequality, or Why the Matthew Effect Prevails' (2004) Vol. 9, New Political Economy.

Warner, M. and Ng, S. H. 'Industrial Relations versus Human Resource Management in the PRC: Collective Bargaining "with Chinese Characteristics" in M. Warner (ed.) Changing Workplace Relations in the Chinese Economy (Basingstoke: MacMillan, 2000).

Warner, M. and Ng, S. H. 'Collective Contracts in Chinese Enterprises: A New Brand of Collective Bargaining under “Market Socialism”?’ (1999) Vol. 37, British Journal of Industrial Relations.

Watson, A. ‘Legal Transplants and Law Reform’ (1996) Vol. 92, The Law Quarterly Review.

Watson, A. 'Aspects of the Reception of Law' (1996) Vol. 44, The American Journal of Comparative Law.

Ziskind, D. 'Forced Labour in the Law of Nations’ (1980) Vol. 3, Comparative Labor Law .

\section{Books}

Ayres, I. and Braithwaite, J. Responsive Regulation: Transcending the Deregulation Debate (New York: Oxford University Press, 1992).

Baldwin, R. and Cave, M. Understanding Regulation Theory, Strategy and Practice (Oxford: Oxford University Press, 1999).

Burk, J. Values in the Market Place (Berlin; New York: W de Gruyter, 1988).

Chanock, M. The Making of South African Legal Culture (Cambridge: Cambridge University Press, 2001).

Chanock, M. Law, Custom and Social Order: The colonial experience in Malawi and Zambia (Cambridge: Cambridge University Press, 1985).

Chossudovsky, M. The Globalization of Poverty: Impacts of IMF and World Bank Reforms (London: Zed Books, 1997). 
Collins, H. Davies, P. and Rideout, R. (eds.) Legal Regulation of the Employment Relation (London: Kluwer Law International, 2001).

Cooke, F. HRM, Work and Employment in China (London; New York: Routledge, 2005).

Cooney, S. et al. (eds.) Law and Labour Market Regulation in East Asia (London; New York: Routledge, 2002).

Cornia, G. (ed.) Inequality, Growth and Poverty in the Era of Liberalization and Globalization (Oxford: Oxford University Press, 2004).

Deakin, S. and Wilkinson, F. The Law of the Labour Market: Industrialization, Employment and Legal Evolution (New York: Oxford University Press, 2005).

Deery, S. and Mitchell, R. (eds.) Employment Relations: Individualisation and Union Exclusion: an International Study (Leichardt, NSW: Federation Press, 1999).

Deraniyagala, S. 'Technical Change and Efficiency in Sri Lanka’s Manufacturing Industry’ (PhD Dissertation, University of Oxford, 1995).

De Soto, H. El Otro Sendero: La Revolución Informal (Lima: El Barranco, 1986).

De Soto, H. The Other Path: The Invisible Revolution in the Third World (New York: Harper \& Row, 1989).

Du Toit, D. et al., Labour Relations Law: A Comprehensive Guide (4th ed.) (Durban: LexisNexis Butterworths, 2003).

Escobar, A. Encountering Development: The Making and Unmaking of the Third World (Princeton, NJ: Princeton University Press, 1995).

Gunningham, N. and Grabosky, P. with Sinclair, D. Smart Regulation: Designing Environmental Policy (Oxford: Clarendon Press, 1998).

Held, D. et al. Global Transformations: Politics, Economics and Culture (Oxford: Polity, 1999).

Hoogvelt, A. Globalization and the Post-Colonial World: The New Political Economy of Development (2nd ed.) (Basingstoke, Hampshire: Palgrave, 2001).

Hutter, B. Compliance: Regulation and Environment (Oxford: Clarendon Press, 1997).

Legrand, P. Fragments on Law-as-Culture (Deventer: Willink, 2001).

Lindsey, T. (ed.) Law Reform in Developing and Transitional States (Routledge, 2007).

Nabli, M. and Nugent, J. The New Institutional Economics and Development: Theory and Application to Tunisia (Amsterdam; New York: North-Holland, 1989).

North, D. Institutions, Institutional Change and Economic Performance (Cambridge; New York: Cambridge University Press, 1990).

North, D. Structure and Change in Economic History (New York: Norton, 1981).

Nussbaum, M. and Sen, A. (eds.) The Quality of Life (Oxford: Clarendon Press, 1993).

OECD, Employment Outlook in 1999: Giving Youth a Better Start (Paris; OECD, 1999).

Parker, C. et al. (eds.) Regulating Law (Oxford: Oxford University Press, 2004).

Parkinson, J. Corporate Power and Responsibility: Issues in the Theory of Company Law (Oxford: Clarendon Press, 1993). 
Phong, D. and Beresford, M. Authority Relations and Economic Decision-Making in Vietnam: An Historical Perspective (Copenhagen: NIAS, 1999).

Pistor, K. and Wellons, P. The Role of Law and Legal Institutions in Asian Economic Development 1960-1995 (New York: Oxford University Press, 1999).

Polanyi, K. The Great Transformation (Boston: Beacon Press, 1957).

Sen, A. Inequality Re-examined (New York: Russell Sage Foundation, 1992).

Sen, A. Development as Freedom (Oxford: Oxford University Press, 1999).

Stone, K. From Widgets to Digits: Employment Regulation for the Changing Workplace (Cambridge, UK; New York: Cambridge University Press, 2004).

Sunstein, C. After the Rights Revolution: Reconceiving the Regulatory State (Cambridge: Harvard University Press, 1990).

Watson, A. Legal Transplants: An Approach to Comparative Law (Athens: University of Georgia Press, 1993).

World Bank, Doing Business in 2006: Creating Jobs (Washington DC: World Bank, 2006).

World Bank, Doing Business in 2005: Removing Obstacles to Growth (Washington DC: World Bank, 2005).

World Bank, Doing Business in 2004: Understanding Regulation (Washington DC: World Bank, 2004).

World Bank, Labor and Economic Reforms in Latin America and the Caribbean (Washington DC: World Bank, 1995).

World Bank, World Development Report 1995: Workers in an Integrating World (Washington DC: World Bank, 1995).

\section{Chapters in edited books}

Arup, C. et al. 'Employment Protection and Employment Promotion: The Contested Terrain of Australian Labour Law', in M. Biagi (ed.) Job Creation and Labour Law: From Protection Towards Pro-action (Dordrecht; London; Boston: Kluwer International, 2000).

Bacungan, F. and Ofreneo, R. 'The Development of Labour Law and Labour Market Policy in the Philippines' in S. Cooney et al. (eds.) Law and Labour Market Regulation in East Asia (London; New York: Routledge, 2002).

Baldwin, R. 'After Command and Control', in K. Hawkins (ed.) The Human Face of Law: Essays in Honour of Donald Harris (Oxford: Clarendon Press, 1997).

Bardhan, P. 'Institutional Impediments to Development' in M. Olson and S. Kähkönen (eds.) A Not-So-Dismal Science: A Broader View of Economies and Societies (Oxford: Oxford University Press, 2000).

Candiland, C. and Sil, R. 'The Politics of Labour in Late-industrializing and Post-socialist Economies: New Challenges in a Global Age' in C. Candiland and R. Sil (eds.) The Politics of Labour in a Global Age (Oxford: Oxford University Press, 2001).

Cooney, S. et al. 'Labour Law and Labour Market Regulation in East Asian States: Problems and Issues for Comparative Inquiry', in S. Cooney et al., Law and Labour Market Regulation in East Asia (London; New York: Routledge, 2002). 
Cooney, S. and Mitchell, R. 'What is Labour Law Doing in East Asia?' in S. Cooney et al. (eds.) Law and Labour Market Regulation in East Asia (London; New York: Routledge, 2002).

Daintith, T. 'Law as a Policy Instrument: A Comparative Perspective’ in T Daintith (ed.) Law as an Instrument of Economic Policy: Comparative and Critical Approaches (Berlin; New York: W. de Gruyter, 1988).

Daintith, T. 'Techniques of Government', in J. Jowell and D. Oliver (eds.), The Changing Constitution (3rd ed.) (Oxford: Clarendon Press, 1994).

Freeman, N. J. 'Developing Entrepreneurship and SMEs in Southeast Asia's Transitional Economies' in D Hew and L. Nee (eds.) Entrepreneurship and SMEs in Southeast Asia (Singapore: Institute of Southeast Asian Studies, 2004).

Greenfield, G. 'The Development in Capitalism in Vietnam' in R. Miliband and L. Panitch (eds.) Between Globalism and Nationalism (London: Merlin Press, 1994).

Huei-Ling, W. and Cooney, S. 'Taiwan’s Labour Law: the End of State Corporatism?’ in S. Cooney et al. (eds.) Law and Labour Market Regulation in East Asia (London; New York: Routledge, 2002).

Jiminez, R. T. 'The Philippines' in S. Deery and R. Mitchell, Labour Law and Industrial Relations in Asia: Eight Country Studies (Melbourne: Longman Cheshire, 1993).

Kalula, E. 'Beyond Borrowing and Bending: Labour Market Regulation and Labour Law in Southern Africa' in C. Barnard, S. Deakin and G. Morris (eds.), The Future of Labour Law: Liber Amicorum Sir Bob Hepple QC (Oxford: Hart Publishing, 2004).

Klein, E. and Tokman, V. 'A Comparative View of Regulations and Informality' in V. Tokman and E. Klein (eds.) Regulation and the Informal Economy - Microenterprises in Chile, Ecuador, and Jamaica (Boulder: L. Reinner Publishers, 1996).

Kongshøj Madsen, P. 'The Danish Model of Flexicurity: a Paradise - with Some Snakes' in H. Sarfati and G. Bonoli (eds.) Labour Market and Social Protection Reforms in International Perspective: Parallel or Converging Tracks? (Aldershot: Ashgate, 2002).

Lall, S. 'Imperfect Markets and Fallible Governments: The Role of the State in Industrial Development' in D. Nayyar (ed.) Trade \& Industrialisation (Delhi: Oxford University Press, 1997).

Lamm, F. and Walters, D. 'Regulating Occupational Health and Safety in Small Business' in E. Bluff, N. Gunningham and R. Johnstone (eds.) OHS Regulation for a Changing World of Work (Annandale, NSW: Federation Press, 2004).

Langille, B. 'Seeking Post-Seattle Clarity - And Inspiration' in J. Conaghan, R. Michael and K. Klare (eds.) Labour Law in an Era of Globalization: Transformative Practices and Possibilities (Oxford: Oxford University Press, 2002).

Legrand, P. 'What “Legal Transplants”?’ in D Nelken and J Feest (eds.), Adapting Legal Cultures (Oxford: Hart Publishing, 1999).

Lindsey, T. 'Labour Law in Indonesia After Soeharto' in S. Cooney et al. (eds.) Law and Labour Market Regulation in East Asia (London; New York: Routledge, 2002).

Manusphaibool, S. 'Thailand' in S. Deery and R. Mitchell (eds.) Labour Law and Industrial Relations in Asia: Eight Country Studies (Melbourne: Longman Cheshire, 1993).

Meyanathan, S. and Munter, R. 'Industrial Structures and the Development of Small and Medium Enterprise Structures: An Overview' in S. Meyanathan (ed.) Industrial Structures and the Development of Small and Medium Enterprise Linkages: Examples from East Asia (Washington DC: World Bank, 1994). 
Ng, S. H. and Warner, M. 'Industrial Relations versus Human Resource Management in the PRC: Collective Bargaining "with Chinese Characteristics”' in M. Warner (ed.) Changing Workplace Relations in the Chinese Economy (Basingstoke: Macmillan, 2000).

Nicholson, P. 'Vietnam's Labour Market: Transition and the Role of Law' in S. Cooney et al. (eds.) Law and Labour Market Regulation in East Asia (London; New York: Routledge, 2002).

Noerlund, I. 'The Labour Market in Vietnam: Between State Incorporation and Autonomy' in J. Dragsbaek Schmidt, J. Hersch and N. Fold (eds.) Social Change in Southeast Asia (Harlow, Essex: Longman, 1998).

North, D. C. 'The New Institutional Economics and Third World Development' in J Harriss, J. Hunter and C. Lewis (eds.) New Institutional Economics and Third World Development (London; New York: Routledge, 1995).

Offe, C. 'The Theory of the Capitalist State and the Problem of Policy Formation' in L. Lindberg (ed.) Stress and Contradiction in Modern Capitalism: Public Policy and the Theory of the State (Lexington, Mass: Lexington Books, 1975).

Ogus, A. 'New Techniques for Social Regulation: Decentralisation and Diversity', in H. Collins, P. Davies and R. Rideout (eds.) Legal Regulation of the Employment Relation (London: Kluwer Law International, 2001).

Parker, C. 'Introduction' in C Parker et al. (eds.) Regulating Law (Oxford: Oxford University Press, 2004).

Portes, A. 'When More Can Be Less: Labor Standards, Development, and the Informal Economy' in C. Rokowski (ed.) Conrapunto - The Informal Sector Debate in Latin America (Albany: State University Press of New York, 1994).

Rawling, M. 'Altering Labour Markets in Hierarchically Organized Industry Through Supply Chain Regulation: A Generic Model of Regulating Outsourced Work’, 2006).

Sen, A. 'Capability and well-being' in M Nussbaum and A Sen (eds.) The Quality of Life (Oxford: Clarendon Press, 1993).

Servais, J. M. 'Working Conditions and Globalization' in R Blanpain and C. Engels (eds.) Comparative Labour Law and Industrial Relations in Industrialized Market Economies (7th ed.) (The Hague; London: Kluwer Law International, 2001).

Shearing, C. 'A Constitutive Conception of Regulation' in P. Grabosky and J. Braithwaite, Business Regulation and Australia’s Future (Canberra: Australian Institute of Criminology, 1993).

Tokman, V. 'The Informal Sector in Latin America: From Underground to Legality' in V. Tokman (ed.) Beyond Regulation - The Informal Economy in Latin America (Boulder: Lynne Reinner, 1992).

Wade, R. 'The US role in the Long Asian Crisis of 1990 - 2000' in F. Revera and A. Lukauskas (eds.) The East Asian Crisis and its Aftermath: Tigers in Distress (Cheltenham: Edward Elgar, 2001).

Wormald, G. and Rozas, J. 'Microenterprises and the Informal Sector in the Santiago Metropolitan Area' in V. Tokman and E. Klein (eds.) Regulation and the Informal Economy: Microenterprises in Chile, Ecuador and Jamaica (Boulder: Lynne Reinner, 1996).

Zhu, Y. 'Economic Reform and Labour Market Regulation in China' in S. Cooney et al. (eds.) Law and Labour Market Regulation in East Asia (London; New York: Routledge, 2002). 


\section{Working papers/conference papers/ reports}

Bartley, A. et al. "'We Might Call Them Once" - Mediating Supply and Demand in Regional Labour Markets?' (Working Paper No. 2, Labour Market Dynamics Research Programme, Massey University, Auckland, 2001).

Bazan, L. and Navas-Alemán L. 'Comparing Chain Governance and Upgrading Patterns in the Sinos Valley, Brazil' (Paper presented at the Local Upgrading in Global Chains Workshop, Sussex, $14-17$ February 2001).

Benjamin, P. 'Beyond the Boundaries: Prospects for Extending Labour Market Regulation in South Africa' (Paper presented at Conference on the Scope of Labour Law: Re-Drawing the Boundaries of Protection, Bellagio, 23-27 May 2005).

Blaikie, H. 'Corporate Social Responsibility and Codes of Conduct: The Privatization of International Labour Law' (Paper presented at the Canadian Council on International Law Conference, 15 October 2004).

Brown, A. Thonachaisetavut, B. and Hewison, K. 'Labour Relations and Regulation in Thailand: Theory and Practice’ (Working Paper Series No. 27, Southeast Asian Research Centre, Hong Kong, 2002).

Chandra, N. and Parashar, V. 'Labour Law Reforms and MSEs Growth Trap' (Institute for Human Development, New Delhi, mimeo, undated).

Davies, P. and Freedland, M. 'The Disintegration of the Employing Enterprise and its significance for the Personal Scope of Employment Law' (Paper presented at the Conference on the Scope of Employment Law: Re-drawing the Boundaries of Protection, Bellagio, 23-27 May 2005).

Davis, K. 'What Can the Rule of Law Variable Tell Us About Rule of Law Reforms?' (Working Paper No. 04-026, New York University Law and Economics Research Paper Series, 2004).

Fazekas, K. 'Monthly Labour Market Update: Hungary' (Institute of Economics, Budapest, November 2004).

Fenwick, C. 'Labour Law in Namibia: Towards an "Indigenous Solution”?' (Working Paper No. 35, Centre for Employment and Labour Relations Law, Faculty of Law, University of Melbourne, 2005).

Ferguson, C. 'A Review of UK Company Codes of Conduct' (Social Development Division, Department for International Development, UK, 1998).

Godfrey, S. and Theron, J. 'Labour Standards versus Job Creation? An Investigation of the Likely Impact of the New Basic Conditions of Employment Act on Small Businesses' (Development and Labour Monographs 1/99, Institute of Development and Labour Law, University of Cape Town, 1999).

Gonzaga, G. 'Labor Turnover and Labor Legislation in Brazil' (Texto Para Discussao No. 475, Departmento de Economia, 2003).

Hansohm, D. et al. 'Economic Reform Programmes, Labour Market Institutions, Employment and the Role of the Social Partners in Namibia' (Nambian Economic Policy Research Unit, July 1999).

Harriss, J. 'Institutions, Politics and Culture: A Case for 'Old' Institutionalism in the Study of Historical Change’ (Working Paper 02-34, Development Studies Institute, London, 2002).

Howe, J. '“Deregulation” of Labour Relations in Australia: Towards Command and Control' (Working Paper No. 34, Centre for Employment and Labour Relations Law, University of Melbourne, 2005). 
Jenkins, R. 'Corporate Codes of Conduct: Self Regulation in a Global Economy' (Technology, Business and Society Programme Paper No. 2, United Nations Research Institute for Social Development, 2001).

Jørgensen, C. 'Thematic Feature: Works Councils and Other Workplace Employee Representation and Participation Structures: Denmark’ (European Industrial Relations Observatory On-line, European Foundation for the Improvement of Living and Working Conditions, 2003) <www.eiro.eurofound.eu.int/2003/09/tfeature/dk0309102.html> on 12 July 2005.

Kannan, K. 'The Welfare Fund Model of Social Security for Informal Sector Workers: the Kerala Experience' (Working Paper 332, Centre for Development Studies, Kerala, 2002).

Mallon, R. 'Country Report: Viet Nam' (Approaches to Support the Development of an Enabling Environment for Small Enterprises, German Agency for Technical Cooperation, 2002).

Mkandawire, T. and Rodriguez, V. 'Globalization and Social Development after Copenhagen (Occasional Paper 10, United Nations Research Institute for Social Development, 2000).

Morrison, C. 'What Institutional Framework for the Informal Sector?' (Policy Brief No. 10, OECD Development Centre, 1995).

OECD. 'Promoting Entrepreneurship and Innovative SMEs in a Global Economy: Towards a More Responsible and Inclusive Globalisation' (Report of the Second OECD Conference of Ministers Responsible for Small and Medium-Sized Enterprises (SMEs) Istanbul, 3-5 June 2005).

Olomi, D. 'Enhancing SMEs: Contribution to Employment and Poverty Reduction: Policy, Legal and Regulatory Barriers to SMEs' Access to Markets in Tanzania' (Final Report, Tanzania Association of Employers, 2005).

Pedersini, R. “"Economically Dependent Workers” Employment Law and Industrial Relations' (European Industrial Relations Observatory On-line, European Foundation for the Improvement of Living and Working Conditions, 2003).

QUIT. (Grup d'Estudies Sociologics Sobre la Vida Quotidiana I el Treball) and IRES (Institut de Recherches Economique et Sociales), Industrial Relations in SMES, (1999).

Ranis, G. 'Human Development and Economic Growth' (Centre Discussion Paper No. 887, Economic Growth Centre, Yale University, 2004).

Raynard P. and Forstater M. 'Corporate Social Responsibility: Implications for Small and Medium Enterprises in Developing Countries’ (United Nations Industrial Development Organization, 2002).

Schrage, E. J. 'Promoting International Worker Rights through Private Voluntary Initiatives: Public Relations or Public Policy?' (Report presented to the U.S. Department of State by the University of Iowa Centre for Human Rights, 2004).

Shankaran, K. 'Protecting the Worker in the Informal Economy: The Role of Labour Law' (Paper presented at the Conference on the Scope of Employment Law: Re-drawing the Boundaries of Protection, Bellagio, 23-27 May 2005).

Sunstein, C. 'A New Progressivism' (John M. Olin Law and Economics Working Paper No. 245, Law School, University of Chicago, 2005). 
Supiot, A. et al. 'Transformation of the Labour and Future of Labour Law in Europe - Final Report' (Directorate General for Employment and Social Affairs, European Commission, 1998) $<$ http://europa.eu.int/comm/employment_social/labour_law/publications_en.htm> on 25 August 2005.

Sutcliffe, B. '100 Ways of Seeing an Unequal World' (2002) < http://www.geocities.com/bobsutcl> on 15 August 2005.

United States General Accounting Office. 'Contingent Workers: Incomes and benefits Lag behind those of Rest of Workforce' (GAO/HEH-00-76, June 2000) <http://www.gao.gov/new.items/he00076.pdf> on 29 August 2005.

United Nations Development Programme. 'Unleashing Entrepreneurship: Making Business Work for the Poor (Report to the Secretary-General of the United Nations, New York, 2004).

United Nations Industrial Development Organization. 'Corporate Social Responsibility: Implications for Small and Medium Enterprises in Developing Countries’ (Vienna: UNIDO, 2002).

Theron, J. and Godfrey, S. 'The CCMA and Small Business: the Impact of the Labour Dispute Resolution System' (Development and Labour Monographs 2/ 2001, Institute of Development and Labour Law, University of Cape Town, 2001).

Theron, J. and Godfrey, S. 'Protecting Workers on the Periphery' (Development and Labour Monographs 1/ 2000, Institute of Development and Labour Law, University of Cape Town, 2000).

Wade, R. 'Out of the Box: Rethinking the Governance of International Financial Markets' (Working Paper Series No. 02-24, Development Studies Institute, 2002).

\section{ILO publications}

Allal, M. 'ILO General Survey 2003 on Employment Related Conventions and Recommendations: Analysis of Member States’ Responses to Recommendation 189 (Job Creation in Small and Medium-Sized Enterprises), Chapter XI' (Draft SEED Working paper, October 2003, unpublished).

Alter Chen, M. Jhabvala, R. and Lund, F. 'Supporting Workers in the Informal Economy: A Policy Framework’ (Working Paper on the Informal Economy 2, ILO, Geneva, 2002).

Aryee, G. Promoting Productivity and Social Protection in the Urban Informal Sector (ILO, Geneva, 1996).

Bekko, G. and Muchai, G. 'Protecting Workers in Micro and Small Enterprises: Can Trade Unions Make a Difference? A Case Study of the Bakery and Confectionery Sub-sector in Kenya' (IFP/SEED Working Paper No. 34, Series on Representation and Organization Building, ILO, Geneva, 2002).

Bennett, M. 'Organizing Workers in Small Enterprises: The Experience of the Southern African Clothing and Textile Workers' Union' (IFP/SEED Working Paper No. 33, Series on Representation and Organization Building, ILO, Geneva, 2002).

Chacaltana, J. 'Public Policy and Employment in Micro and Small Enterprises in Peru' (IFP/SEED Working Paper No. 56, ILO, Geneva, 2003).

Chapagain, D. P. 'Role of Trade Unions in Micro and Small Enterprises in Nepal: A Case Study of Small Restaurants' (IFP/SEED, ILO, Geneva, 2001).

Cortes Neri, M. 'Decent Work in the Informal Sector in Brazil' <http://www.ilo.org/public/english/bureau/integration/decent/publicat.htm> on 25 July 2005. 
Daza, J. ‘Informal Economy, Undeclared Work and Labour Administration’ (Dialogue Paper No. 9, ILO, Geneva, June 2005).

De Gobbi, M. S. 'Labour market flexibility and employment and income security in Ethiopia: Alternative considerations' (Employment Policy Unit, Employment Strategy Paper 2006/1, ILO, Geneva, 2006).

Drying Christensen, J. and Goedhuys, M. 'Impact of National Policy and Legal Environments on Employment Growth and Investment in Micro and Small Enterprises' (IFP/SEED Working Paper No. 63, ILO, Geneva, 2004).

Egger, P. and Sengenberger, W. (eds.). Decent Work in Denmark: Employment, Social Efficiency and Economic Security (ILO, Geneva, 2003).

Flores, C. 'Creating a Conducive Policy Environment for Employment Creation in MSEs in Chile' (IFP/SEED Working Paper No. 61, ILO, Geneva, 2003).

Goldman, T. 'Organizing in South Africa’s Informal Economy: An Overview of Four Sectoral Case Studies' (IFP/SEED Working Paper No. 60, Series on Representation and Organization Building, ILO, Geneva, 2003).

Hayter, S., Reinecke, G. and Torres, R. South Africa (Studies on the Social Dimensions of Globalization, ILO, Geneva, 2001).

Howell, J. 'Good Practice Study in Shanghai on Employment Services for the Informal Sector' (Employment Paper 6, ILO, Geneva, 2002).

Hussmans, Ralf and du Jeu, Brigitte. 'ILO Compendium of Official Statistics on Employment in the Informal Sector (ILO, Geneva, 2001).

ILO. (2005a) A Global Alliance Against Forced Labour: Global Report under the Follow-Up to the ILO Declaration on Fundamental Principles and Rights at Work 2005, Report I(B), ILC, 93rd session.

_. (2005b) The Employment Relationship, Report V (1), ILC, 95th session.

(2004a) Organizing for Social Justice: Global Report under the Follow-up to the ILO Declaration on Fundamental Principles and Rights at Work (Geneva).

. (2004b) 'Decent Employment through Small Enterprises: A Progress Report on SEED activities' (IFP/SEED, ILO, Geneva).

. (2004c) 'Technical Note on the Extension of Social Security to the Informal Sector in Thailand' (Sub-regional Office for East Asia, ILO, Bangkok).

_ . (2003a) The Employment Relationship, Report V, ILC, 91st session.

_ (2003b) 'Defining Strategies for Improving Working and Employment Conditions in Micro and Small Enterprises and the Informal Economy: Overview of the ILO Leaning and Research Agenda' (Draft version, Conditions of Work and Employment Programme, ILO, Geneva).

. (2002a) A Future Without Child Labour: Global Report under the Follow-Up to the ILO Declaration on Fundamental Principles and Rights at Work 2002, Report I(B), ILC, 90th session.

. (2002b) Decent Work and the Informal Economy, Report VI, ILC, 90th session.

. (2002c) Panorama Laboral 2002 [Labour Overview 2002] (ILO Regional Office, Lima).

. (2002d) Resolution concerning Decent Work and the Informal Economy, ILC, 90th session. 
(2001a) Stopping Forced Labour: Global Report under the Follow-Up to the ILO Declaration on Fundamental Principles and Rights at Work 2001, Report I(B), ILC, 89th session.

. (2001b) Modernization in Vocational Education and Training in the Latin American and the Caribbean Region (Geneva).

— . (2001c) Reducing the Decent Work Deficit: A Global Challenge, Report of the DirectorGeneral, ILC, 89th session.

. (2001d) 'Good Practices in Action against Child Labour: A Synthesis Report of Seven Country Studies, 1997-8 by Independent Researchers’ (ILO/IPEC, Geneva).

. (2001e) Global Agenda for Employment: Summary (Global Employment Forum, Geneva, 1-3 November).

_ _ (2001f) 'Women Organizing for Social Protection: the Self-Employed Women's Association Integrated Insurance Scheme, India' (STEP Programme, Geneva).

. (2000a) Employment and Social Protection in the Informal Sector, ILO GB 277/ESP/1/2, 277th session.

. (2000b) Termination of Employment Digest (ILO, Geneva).

. (2000c) Your Voice at Work: Global Report under the Follow-Up to the ILO Declaration on Fundamental Principles and Rights at Work, Report I (B), ILC, 88th session.

_. (1999a) Decent Work, Report of the Director-General, ILC, 87th session.

_. (1999b) 'Job Quality and Small Enterprise Development' (IFP/SEED Working Paper No. 4, ILO, Geneva).

. (1991) Report of the Director-General, ILC, 78th session.

_ _ (1986) The Promotion of Small and Medium-Sized Enterprises, 72nd session, ILC.

Joshi, G. 'Urban Informal Sector in Metro Manila: A Problem or Solution?' (Southeast Asia and the Pacific Multi-disciplinary Advisory Team, Philippines, ILO, 1997).

Kani, F. Structural Adjustment and Economic Reform Programmes, Labour Market Institutions, Employment and the Role of the Social Partners: The Zambian Experience, (ILO, Harare, 2000).

Kantor, P. 'Promoting Women's Entrepreneurship Development based on Good Practice Programmes: Some Experiences from the North to the South' (IFP/SEED Working Paper No. 9, Geneva, 2001).

Kongshøj Madsen, P. 'Denmark: Flexibility, Security and Labour Market Success' (Employment and Training Papers 53, Employment and Training Department, ILO, Geneva, 1999).

Maldonado, C. et al. Le Secteur Informel en Afrique Face aux Contraintes Légales et Institutionelles (ILO, Geneva, 1999).

Mamic, I. Business and Code of Conduct Implementation: How Firms Use Management Systems for Social Performance (ILO, Geneva, 2003).

Marcucci, P. 'Jobs, Gender and Small Enterprises in Africa and Asia: Lessons Drawn from Bangladesh, the Philippines, Tunisia and Zimbabwe' (IFP/SEED Working Paper No. 18, Series on Women’s Entrepreneurship Development and Gender in Enterprise, ILO, Geneva, 2001).

Mayoux, L. 'Jobs, Gender and Small Enterprises: Getting the Policy Environment Right' (IFP/Seed Working Paper No. 15, ILO, Geneva, 2001). 
Mogalakwe, M. and Siphambe, H. Economic Reform Programmes, Labour Market Institutions, Employment and the Role of the Social Partners in Botswana, (ILO, Harare, 2000).

Morton, P. 'Job Quality in Micro and Small Enterprises in Ghana: Field Research Results' (IFP/SEED Series on Job Quality in Micro and Small Enterprise Development, ILO, Geneva, 2004).

Mthinidi, G. Structural Adjustment and Economic Reform Programmes, Labour Institutions, Employment and the Role of the Social Partners in Malawi, (ILO, Harare, 2000).

Navas-Aleman, L. and Bazan, L. 'Local Implementation of Quality, Labour and Environmental Standards: Opportunities for Upgrading in the Footwear Industry' (IFP/SEED Working Paper No. 45, ILO, Geneva, 2003).

Ofreneo, R. 'Philippines Informal Sector: Labour Laws and Industrial Relations' (Assessment Report Series No. 6, Interdepartmental Project on the Urban Informal Sector, ILO/ SEAPOT, Manila, 1994).

Overy-Miehlbradt, A. 'Assessment of Regional Programme on Micro and Small Enterprises Development and Workers' Protection (in the Asia Pacific Region)' (ILO Regional Office for Asia and the Pacific, Bangkok, 1998).

Pham, H. 'Creating a Conducive Policy Environment for Employment Creation in Small Enterprises in Vietnam' (IFP/SEED Working Paper No. 31, Series on Conducive Policy Environment for Small Enterprise Employment, ILO, Geneva, 2002).

Quinn, P. 'Freedom of Association and Collective Bargaining: A Study of the Indonesia Experience 1998 - 2003’ (Working Paper No. 15, ILO, Geneva, 2003).

Reinecke, G. 'Labour and Labour Related Laws in Micro and Small Enterprises: Cases from Latin America’ (Version 1, ILO SRO Santiago, 2005).

- 'Small Enterprises, Big Challenges: A Literature Review on the Impact of the Policy Environment on the Creation and Improvement of Jobs within Small Enterprises' (IFP/SEED Working Paper No. 23, ILO, Geneva, 2002).

Reinecke, G. and White, S. Policies for Small Enterprises: Creating the Right Environment for Good Jobs (IFP/SEED, ILO, Geneva, 2004).

Rinehart, R. 'Designing Programmes to Improve Working and Employment Conditions in the Informal Economy: A Literature Review’ (Conditions of Work and Employment Series No. 10, ILO, Geneva, 2004).

Sachikonye, L. Structural Adjustment, Labour Market Institutions, Employment and the Role of the Social Partners: The Case of Zimbabwe (ILO, Harare, 2000).

Schlyter, Charlotta. 'International Labour Standards and the Informal Sector: Developments and Dilemmas' (Working Paper on the Informal Economy, Employment Sector, ILO, Geneva, 2002).

Shakya, P. 'Labour Law Reforms and Growth Trap among Micro and Small Enterprises (MSES) in Nepal' (ILO, mimeo, 2004).

Singh, A. K. et al. 'Report on Survey of Micro and Small Enterprises in Uttar Pradesh, India' (Report prepared for ILO South Asia Office, Giri Institute of Development Studies, mimeo, 2004).

Trebilcock, A. 'Using Development Approaches to Address the Challenge of the Informal Economy for Labour Law', in G. Davidov and B. Langille, The Scope of Labour Law: Redefining the Boundaries of Protection (Hart Publishing, 2006). 
Urminsky, M. (ed.) 'Self-Regulation in the Workplace: Codes of Conduct, Social Labeling and Socially Responsible Investment' (MCC Working Paper No. 1, Series on Management Systems and Corporate Citizenship, ILO, Geneva, 2001).

Van Der Geest, W. and Wignara, G. (eds.) Adjustment, Employment and Labour Market Institutions in Sub-Saharan Africa in the 1990s: A Survey (ILO, Geneva, 1996).

Vietnam Chamber of Commerce and Industry. 'Survey on Micro and Small Enterprises in Viet Nam’ (Survey Report, IFP/SEED unpublished background paper, 2001).

White, S. 'Assessing the Influence of the Business Environment on Small Enterprise Employment: An Assessment Guide’ (IFP/SEED Working Paper No. 71E, ILO, Geneva, 2005).

. 'Creating an Enabling Environment for Micro and Small Enterprise (MSE) Development in Thailand’ (Working Paper 3, ILO/UNDP, Geneva, 1999).

Zheng, X., Lu, L. and Idris, S. 'Working Time in Transition: The Dual Task of Standardization and Flexibilization in China' (Conditions of Work and Employment Series No. 11, School of Labour and Human Resources, Renmin University of China, ILO, Geneva, 2005).

Zuin, V. 'Business Strategies of Informal Micro-Entrepreneurs in Lima, Peru' (Decent Work Research Program, International Institute for Labour Studies, Geneva, 2004).

\section{Conventions and recommendations}

Convention Concerning Forced or Compulsory Labour, 1930 (No. 29).

Convention Concerning Labour Inspection, 1947 (No. 81).

Convention Concerning Freedom of Association and Protection of the Right to Organize, 1948 (No. 87).

Convention Concerning the Application of the Principles of the Right to Organize and to Bargain Collectively, 1949 (No. 98).

Convention Concerning Equal Remuneration for Men and Women Workers for Work of Equal Value, 1951 (No. 100).

Convention Concerning Minimum Standards of Social Security, 1952 (No. 102).

Convention Concerning the Abolition of Forced Labour, 1957 (No. 105).

Convention Concerning Conditions of Employment of Plantation Workers, 1958 (No. 110).

Protocol to the Convention Concerning Conditions of Employment of Plantation Workers, 1982 (No. 110).

Convention Concerning Discrimination in Respect of Employment and Occupation, 1958 (No. 111).

Social Policy Convention, 1962 (No. 117).

Convention Concerning Employment Policy, 1964 (No. 122).

Convention Concerning Protection and Facilities to be Afforded to Workers' Representatives in the Undertaking, 1971 (No. 135).

Convention Concerning Minimum Age for Admission to Employment, 1973 (No. 138).

Convention Concerning Paid Education Leave, 1974 (No. 140). 
Convention Concerning Organizations of Rural Workers and their Role in Economic and Social Development, 1975 (No. 141).

Convention Concerning Labour Administration: Role, Functions and Organization, 1978 (No. 150).

Convention Concerning Termination of Employment at the Initiative of the Employer, 1982 (No. 158).

Convention Concerning Employment Promotion and Protection against Unemployment, 1988 (No. 168).

Convention Concerning Indigenous and Tribal Peoples in Independent Countries, 1989 (No. 169).

Convention Concerning Home Work, 1966 (No. 177).

Convention Concerning the Prohibition and Immediate Action for the Elimination of the Worst Forms of Child Labour, 1999 (No. 182).

Recommendation Concerning Consultation and Co-operation between Employers and Workers at the Level of the Undertaking, 1952 (No. 94).

Recommendation Concerning Occupational Health Services in Places of Employment, 1959 (No. 112).

Recommendation Concerning the Role of Co-operatives in the Economic and Social Development of Developing Countries, 1966 (No. 127).

Recommendation Concerning Occupational Heatlh and Safety and the Working Environment, 1981 (No. 164).

Recommendation Concerning General Conditions to Stimulate Job Creation in Small and MediumSized Enterprises, 1998 (No. 189).

Recommendation Concerning Employment Policy, 1984 (No. 169).

Universal Declaration of Human Rights, 1948.

International Covenant on Civil and Political Rights, 1966.

Convention on the Rights of the Child, 1989.

\section{National legislation}

\section{Argentina}

Employment Contracts Act 1998.

\section{Australia}

Industrial Relations and Other Acts Amendment Act 2005 (Queensland).

Industrial Relations (Fair Work) Act 2005 (South Australia).

Industrial Relations (Ethical Clothing Trades) Act 2001 (NSW).

Outworkers (Improved Protection) Act 2003 (Victoria).

\section{Bangladesh}

Employment of Labour (Standing Orders) Act 1965. 


\section{Botswana}

Employment Act 1982.

\section{Brazil}

By Laws of Micro Enterprises and Small Companies (Law 9841), 1999.

Codification of Labour Legislation, Legislative Decree No. 5452, 1943.

Constitution of the Federative Republic of Brazil 1988.

\section{China}

Labour Code 1995.

\section{Hungary}

Labour Code Act No. 22 of 1992.

\section{India}

Industrial Employment (Standing Orders) Act 1946.

Maternity Benefit Act 1961.

Bonded Labour System (Abolition) Act 1976.

Labour Laws (Exemption from Furnishing Returns and Maintaining Register by Certain Establishments) Act 1988.

\section{Indonesia}

President of Republic of Indonesia Act No. 13 Concerning Manpower 2003.

\section{Jordan}

Social Security Law No. 19, 2000.

\section{Kuwait}

Law No. 38 of 1964 concerning Labour in the Private Sector.

\section{Lesotho}

Labour Code Order, 1992 (Order No. 24 of 1992).

\section{Namibia}

Labour Act 1992.

Labour Act 2004.

Nepal

Legal provisions Applicable to Industries as well as Enterprises Related to Transport Services Employing Less than Ten Workers or Employees 17/12/2049.

\section{Nigeria}

Labour Act (No. 21) 1974. 
Peru

General Law on Small and Micro Enterprises 2000.

Productivity and Labour Competitiveness Law 1997.

\section{Philippines}

Barangay Micro Business Enterprise Act (Republic Act No. 9178) 2002.

Labor Code of the Philippines (Presidential Decree No. 442) 1974.

Omnibus Rules Implementing the Labour Code 1989.

Wage Order No. RB05-10 Providing for New Minimum Wage Rates in Region-V, 2004.

\section{South Africa}

Compensation for Occupational Injuries and Diseases Act 1993.

Labour Relations Act 1995.

Basic Conditions of Employment Act 1997.

Basic Conditions of Employment Amendment Act, 2002.

\section{Thailand}

Labour Relations Act 1975.

Labour Protection Act 1998.

Social Security Act 1990.

Social Security Act 1994.

Social Security Act 1999.

Workmen’s Compensation Act B.E. 25371997.

\section{Viet Nam}

Labour Code 1995.

Enterprise Law 2000. 


\section{SEED WORKING PAPERS}

1. "Home Work in Selected Latin American Countries: A Comparative Overview” (Series on Homeworkers in the Global Economy), Manuela Tomei, 2000

2. "Homeworkers in Paraguay" (Series on Homeworkers in the Global Economy), María Victoria Heikel, 2000

3. "Homeworkers in Peru” (Series on Homeworkers in the Global Economy), Francisco Verdera, 2000

4. “Job Quality and Small Enterprise Development” (Series on Job Quality in Micro and Small Enterprise Development), 1999

5. "The Hidden MSE Service Sector: Research into Commercial BDS Provision to Micro and Small Enterprises in Viet Nam and Thailand" (Series on Innovation and Sustainability in Business Support Services (FIT)), Gavin Anderson, 2000

6. “Home Work in Argentina” (Series on Homeworkers in the Global Economy), Elizabeth Jelin, §Matilde Mercado, Gabriela Wyczykier, 2000

7. "Home Work in Brazil: New Contractual Arrangements" (Series on Homeworkers in the Global Economy), Lena Lavinas, Bila Sorj, Leila Linhares, Angela Jorge, 2000

8. "Home Work in Chile: Past and Present Results of a National Survey" (Series on Homeworkers in the Global Economy), Helia Henríquez, Verónica Riquelme, Thelma Gálvez, Teresita Selamé, 2000

9. "Promoting Women's Entrepreneurship Development based on Good Practice Programmes: Some Experiences from the North to the South” (Series on Women's Entrepreneurship Development and Gender in Enterprises - WEDGE), Paula Kantor, 2000

10. “Case Study of Area Responses to Globalization: Foreign Direct Investment, Local Suppliers and Employment in Györ, Hungary" (Series on Globalization, Area-based Enterprise Development and Employment), Maarten Keune, András Toth, 2001

11. "Local Adjustment to Globalzation: A Comparative Study of Foreign Investment in Two Regions of Brazil, Greater ABC and Greater Porto Alegre” (Series on Globalization, Areabased Enterprise Development and Employment), Glauco Arbix, Mauro Zilbovicius, 2001

12. “Local Response to Globalization: MESTA Region, Bulgaria” (Series on Globalization, Areabased Enterprise Development and Employment), Hanna Ruszczyk, Ingrid Schubert, Antonina Stoyanovska, 2001

13. "Ethnic Minorities — Emerging Entrepreneurs in Rural Viet Nam: A Study on the Impact of Business Training on Ethnic Minorities”, Jens Dyring Christensen, David Lamotte, 2001

14. “Jobs, Gender and Small Enterprises in Bangladesh: Factors Affecting Women Entrepreneurs in Small and Cottage Industries in Bangladesh” (Series on Women's Entrepreneurship Development and Gender in Enterprises - WEDGE), Nilufer Ahmed Karim, 2001

15. “Jobs, Gender and Small Enterprises: Getting the Policy Environment Right” (Series on Women's Entrepreneurship Development and Gender in Enterprises - WEDGE), Linda Mayoux, 2001

16. “Regions, Regional Institutions and Regional Development” (Series on Globalization, Areabased Enterprise Development and Employment), Maarten Keune, 2001

17. “ICTs and Enterprises in Developing Countries: Hype or Opportunity?” (Series on Innovation and Sustainability in Business Support Services (FIT)), Jim Tanburn and Alwyn Didar Singh, 2001 
18. “Jobs, Gender and Small Enterprises in Africa and Asia: Lessons drawn from Bangladesh, the Philippines, Tunisia and Zimbabwe” (Series on Women's Entrepreneurship Development and Gender in Enterprises - WEDGE), Pamela Nichols Marcucci, 2001

19. “Jobs, Gender and Small Enterprises in the Caribbean: Lessons from Barbados, Suriname and Trinidad and Tobago" (Series on Women's Entrepreneurship Development and Gender in Enterprises - WEDGE), Carol Ferdinand (ed.), 2001

20. “Jobs, Gender and Small Enterprises in Bulgaria” (Series on Women's Entrepreneurship Development and Gender in Enterprises - WEDGE), Antonina Stoyanovska, 2001

21. “Women Entrepreneurs in Albania” (Series on Women's Entrepreneurship Development and Gender in Enterprises - WEDGE), Mimoza Bezhani, 2001

22. “Ajuste Local à Globalização: um estudo comparativo do investimento estrangeiro direto no ABC e na Grande Porto Alegre” (Série sobre Globalização, Desenvolvimento de Empresas ao Nível Local e Emprego), Glauco Arbix, Mauro Zilbovicius, 2002

23. "Small Enterprises, Big Challenges: A Literature Review on the Impact of the Policy Environment on the Creation and Improvement of Jobs within Small Enterprises”, (Series on Conducive Policy Environment for Small Enterprise Employment), Gerhard Reinecke, 2002

24. “Méthodes et Instruments d'Appui au Secteur Informel en Afrique Francophone”, Carlos Maldonado, Anne-Lise Miélot, Cheikh Badiane, 2004

25. “Artisanat et Emploi dans les Provinces de Settat et El Jadida”, Gérard Barthélemy, 2002

26. “Employment Creation and Employment Quality in African Manufacturing Firms”, Micheline Goedhuys, 2002

27E. “An Information Revolution for Small Enterprise in Africa: Experience in Interactive Radio Formats in Africa” (Series on Innovation and Sustainability in Business Support Services (FIT)), Mary McVay, 2002

27F. "Une révolution de l'information pour les petites entreprises en Afrique : L’expérience en matière de formats radio interactifs en Afrique” (Série Innovation et viabilité des services d'appui aux entreprises), Mary McVay, 2002

28. “Assessing Markets for Business Development Services: What have we learned so far?” (Series on Innovation and Sustainability in Business Support Services (FIT)), Alexandra Overy Miehlbradt, 2002

29. "Creating a Conducive Policy Environment for Micro, Small and Medium-Sized Enterprises in Pakistan” (Series on Conducive Policy Environment for Small Enterprise Employment), Small and Medium Enterprise Development Authority of Pakistan (SMEDA), 2002

30. "Creating Market Opportunities for Small Enterprises: Experiences of the Fair Trade Movement”, Andy Redfern and Paul Snedker, 2002

31. “Creating a Conducive Policy Environment for Employment Creation in Small Enterprises in Viet Nam" (Series on Conducive Policy Environment for Small Enterprise Employment), Pham Thi Thu Hang, 2002

32. "Business Training Markets for Small Enterprises in Developing Countries: What do we know so far about the potential?” (Series on Innovation and Sustainability in Business Support Services (FIT)), Akiko Suzuki, 2002

33. "Organizing Workers in Small Enterprises: The Experience of the Southern African Clothing and Textile Workers' Union” (Series on Representation and Organization Building), Mark Bennett, 2002

34. "Protecting Workers in Micro and Small Enterprises: Can Trade Unions Make a Difference? A Case Study of the Bakery and Confectionery Sub-sector in Kenya" (Series on Representation and Organization Building), Gregg J. Bekko and George M. Muchai, 2002 
35. "Creating a Conducive Policy Environment for Employment Creation in SMMEs in South Africa” (Series on Conducive Policy Environment for Small Enterprise Employment), Jennifer Mollentz, 2002

36. "Organizing in the Informal Economy: A Case Study of Street Trading in South Africa" (Series on Representation and Organization Building) Shirin Motala, 2002

37. "Organizing in the Informal Economy: A Case Study of the Clothing Industry in South Africa” (Series on Representation and Organization Building), Mark Bennett, 2003

38. "Organizing in the Informal Economy: A Case Study of the Building Industry in South Africa” (Series on Representation and Organization Building), Tanya Goldman, 2003

39. "Organizing in the Informal Economy: A Case Study of the Minibus Taxi Industry in South Africa” (Series on Representation and Organization Building), Jane Barrett, 2003

40. "Rags or Riches? Phasing-Out the Multi-Fibre Arrangement”, Auret van Heerden, Maria Prieto Berhouet, Cathrine Caspari, 2003

41. “Flexibilizing Employment: An Overview”, Kim Van Eyck, 2003

42. "Role of the Informal Sector in Coping with Economic Crisis in Thailand and Zambia”, Gerry Finnegan and Andrea Singh (eds.), 2004

43. “Opportunities for SMEs in Developing Countries to Upgrade in a Global Economy” (Series on Upgrading in Small Enterprise Clusters and Global Value Chains), John Humphrey, 2003

44. "Participation in Global Value Chains as a Vehicle for SME Upgrading: A Literature Review" (Series on Upgrading in Small Enterprise Clusters and Global Value Chains), Cathrine Caspari, 2003

45. “Local Implementation of Quality, Labour and Environmental Standards: Opportunities for Upgrading in the Footwear Industry” (Series on Upgrading in Small Enterprise Clusters and Global Value Chains), Lizbeth Navas-Alemán and Luiza Bazan, 2003

46. "Industrial Renewal and Inter-firm Relations in the Supply Chain of the Brazilian Automotive Industry” (Series on Upgrading in Small Enterprise Clusters and Global Value Chains), Anne Caroline Posthuma, 2004

47. "The Challenges of Growing Small Businesses: Insights from Women Entrepreneurs in Africa” (Series on Women's Entrepreneurship Development and Gender Equality WEDGE), Pat Richardson, Rhona Howarth and Gerry Finnegan, 2004

48. "Facilitating Labour Market Entry for Youth through Enterprise-based Schemes in Vocational Education and Training and Skills Development” (Series on Youth and Entrepreneurship), Michael Axmann, 2004

49. "Promoting the Culture Sector through Job Creation and Small Enterprise Development in SADC Countries: The Music Industry" (Series on Upgrading in Small Enterprise Clusters and Global Value Chains), Cecile Ambert, 2003

50. "Promoting the Culture Sector through Job Creation and Small Enterprise Development in SADC Countries: The Ethno-tourism Industry" (Series on Upgrading in Small Enterprise Clusters and Global Value Chains), Steven Bolnick, 2003

51. "Promoting the Culture Sector through Job Creation and Small Enterprise Development in SADC Countries: Crafts and Visual Arts" (Series on Upgrading in Small Enterprise Clusters and Global Value Chains), The Trinity Session, 2003

52. "Promoting the Culture Sector through Job Creation and Small Enterprise Development in SADC Countries: The Performing Arts and Dance" (Series on Upgrading in Small Enterprise Clusters and Global Value Chains), Annabell Lebethe, 2003 
53. "Promoting the Culture Sector through Job Creation and Small Enterprise Development in SADC Countries: The Film and Television Industry" (Series on Upgrading in Small Enterprise Clusters and Global Value Chains), Avril Joffe and Natalie Jacklin, 2003

54. "Promouvoir un environnement de développement des micro et petites entreprises guinéennes favorable à la création d'emplois décents” (Série Cadre stratégique favorable à l'emploi dans les petites entreprises), Moussa Kourouma, 2003

55. “Creating a Conducive Policy Environment for Employment Creation in Micro and Small Enterprises in Tanzania” (Series on Conducive Policy Environment for Small Enterprise Employment) Paul Tibandebage, Samuel Wangwe, Moses Msuya, Darlene Mutalemwa, 2003

56. "Public Policy and Employment in Micro and Small Enterprises in Peru" (Series on Conducive Policy Environment for Small Enterprise Employment), Juan Chacaltana, 2003

57. "Business Centres for Small Enterprise Development: Experiences and Lessons from Eastern Europe”, Merten Sievers, Klaus Haftendorn, Astrid Bessler, 2003

58. "Promoting Female Entrepreneurship in Mauritius: Strategies in Training and Development”, (Series on Women's Entrepreneurship Development and Gender Equality - WEDGE), Patricia Day-Hookoomsing and Vedna Essoo, 2003

59. "Facilitating Youth Entrepreneurship, Part I: An analysis of awareness and promotion programmes in formal and non-formal education” (Series on Youth and Entrepreneurship), Klaus Haftendorn and Carmela Salzano, 2004

59. "Facilitating Youth Entrepreneurship, Part II: A directory of awareness and promotion programmes in formal and non-formal education” (Series on Youth and Entrepreneurship), Klaus Haftendorn and Carmela Salzano, 2004

60. "Organizing in South Africa's Informal Economy: An Overview of Four Sectoral Case Studies” (Series on Representation and Organization Building), Tanya Goldman, 2003

61. “Creating a Conducive Policy Environment for Employment Creation in MSEs in Chile" (Series on Conducive Policy Environment for Small Enterprise Employment), Carolina Flores, 2003

62. “Quels facteurs influencent la croissance et l'emploi décent dans les petites enterprises en Guinée?” (Série Cadre stratégique favorable à l'emploi dans les petites entreprises), Moussa Kourouma, 2004

63. “Impact of National Policy and Legal Environments on Employment Growth and Investment in Micro and Small Enterprises” (Series on Conducive Policy Environment for Small Enterprise Employment), Jens Dyring Christensen and Micheline Goedhuys, 2004

64. "Synergies through Linkages: Who Benefits from Linking Finance and Business Development Services?”, Merten Sievers and Paul Vandenberg, 2004

65. "Social Marketing for Better Job Quality in Micro and Small Enterprises in Ghana”, Chris Seeley, 2004

66. “Organizing in the Informal Economy: A Case Study of the Municipal Waste Management Industry in South Africa” (Series on Representation and Organization Building), Melanie Samson, 2004

67. "Productivity, decent employment and poverty: Conceptual and practical issues related to small enterprises”, Paul Vandenberg, 2004

68. “Job Quality in Micro and Small Enterprises in Ghana: Field research results” (Series on Job Quality in Micro and Small Enterprise Development), Peter Morton, 2004

69. “Nepal and Pakistan. Micro-finance and microenterprise development: Their contribution to the economic empowerment of women”, Maria Sabrina De Gobbi with contributions from Nara Hari Dhakal and Syed Tahir Hijazi, 2004 
70. "Introduction aux théories et à quelques pratiques du développement local et territorial au Maroc" (Série Cadre stratégique favorable à l'emploi dans les petites enterprises), PierreNoël Denieuil, 2005

71E. "Assessing the influence of the business environment on small enterprise employment: An assessment guide" (Series on Conducive Policy Environment for Small Enterprise Employment), Simon White, 2005

71S. "Valoración de la influencia del entorno de negocios en el empleo de las pequeñas empresas: Una guía de valoración (Serie sobre entorno de políticas favorable para el empleo en la pequeña empresa), Simon White, 2005

72. 'Being 'Real' about Youth Entrepreneurship in Eastern and Southern Africa: Implications for Adults, Institutions and Sector Structures" (Series on Youth and Entrepreneurship), Francis Chigunta, David James-Wilson and Jamie Schnurr, 2005

73. "Pautas metodológicas para el análisis de experiencias de turismo comunitario" (Red de turismo sostenible comunitario para América Latina (REDTURS), Carlos Maldonado, 2005

74. "Growing out of poverty: How employment promotion improves the lives of the urban poor" (Series on Youth and Entrepreneurship), Marja Kuiper and Kees van der Ree, 2005

75. "Poverty reduction through small enterprises: Emerging consensus, unresolved issues and ILO activities", Paul Vandenberg, 2006

76. "Stimulating Youth Entrepreneurship: Barriers and incentives to enterprise start-ups by young people” (Series on Youth and Entrepreneurship), Ulrich Schoof, 2006

77. “Memoria. IV Encuentro Latinoamericano. Códigos de conducta y uso de marcas” (Red de turismo sostenible comunitario para América Latina (REDTURS), 2006

78. "El uso de marcas como herramienta para apoyar estrategias competitivas en turismo comunitario" (Red de turismo sostenible comunitario para América Latina (REDTURS), Luis Alonso García Muñoz, 2006

79. “Turismo y comunidades indigenas impactos, pautas para auto evaluación y códigos de conducta" (Red de turismo sostenible comunitario para América Latina (REDTURS), Carlos Maldonado, 2006

80. "Restaurando la esperanza con comunidades indígenas de Guatemala" (Red de turismo sostenible comunitario para América Latina (REDTURS), Francisco Enríquez and Carlos Maldonado, 2007

81. "Labour and Labour-Related Laws in Micro and Small Enterprises: Innovative Regulatory Approaches”, prepared by Colin Fenwick, John Howe, Shelley Marshall and Ingrid Landau for Centre for Employment \& Labour Relations Law, The University of Melbourne, Australia, 2007. 